UNIVERSIDAD AUTÓNOMA METROPOLITANA UNIDAD IZTAPALAPA

DIVISIÓN DE CIENCIAS BIOLÓGICAS Y DE LA SALUD

POSGRADO EN BIOLOGÍA EXPERIMENTAL

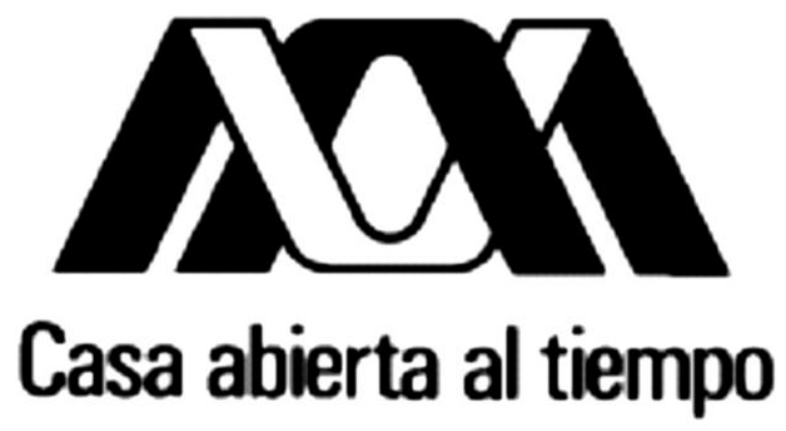

PARTICIPACIÓN DE ENZIMAS GENERADORAS DE ERO EN LA ALTERACIÓN DE LA ESTRUCTURA DE LA CAPA FIBROSA EN EMBRIONES DE MAÍZ.

TESIS

QUE PARA OBTENER EL GRADO DE DOCTOR EN BIOLOGÍA EXPERIMENTAL PRESENTA

BIOL. EXP. JOSÉ ISAAC CORONA CARRILLO

DIRECTOR:

DR. DAVID MANUEL DÍAZ PONTONES

ASESORES:

DRA. MARINA GAVILANES RUÍZ

DRA. MARÍA DEL ROCÍO CRUZ ORTEGA

México, D.F., 12 de febrero de 2015 
El programa de Doctorado en Biología Experimental de la Universidad Autónoma Metropolitana pertenece al Padrón de Posgrados de Calidad (PNPC) del CONACyT, registro 001482, en el Nivel Consolidado, y cuenta con apoyo del mismo Consejo, clave DAFCYT-2003IDPTNNN0020.

El presente trabajo fue realizado gracias a la beca CONACYT otorgada al alumno José Isaac Corona Carrillo con número de registro CVU/Becario: 229139/212820.

El presente trabajo fue realizado en el Laboratorio de Bioquímica Tisular del Departamento de Ciencias de la Salud de la Universidad Autónoma Metropolitana Iztapalapa. 
El jurado designado por la Comisión Académica del Posgrado en Biología Experimental de la División de Ciencias Biológicas y de la Salud de la Universidad Autónoma Metropolitana aprobó la Tesis titulada: “PARTICIPACIÓN DE ENZIMAS GENERADORAS DE ERO EN LA ALTERACIÓN DE LA ESTRUCTURA DE LA CAPA FIBROSA EN EMBRIONES DE MAÍZ", que presentó José Isaac Corona Carrillo el día 12 de febrero del año 2015.

Dr. Fernando Díaz de León Sánchez

Presidente

Departamento de Ciencias de la Salud Universidad Autónoma Metropolitana Unidad Iztapalapa

Dra. Marina Gavilanes Ruíz

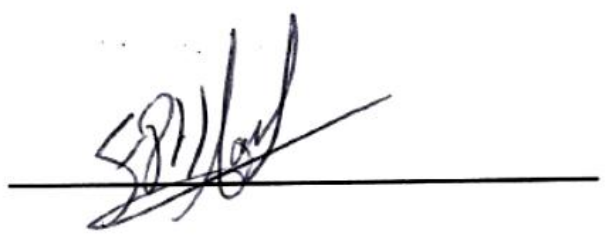

Secretaria

Departamento de Bioquímica

Facultad de Química.

Universidad Nacional Autónoma de México

\section{Dra. María del Rocío Cruz Ortega}

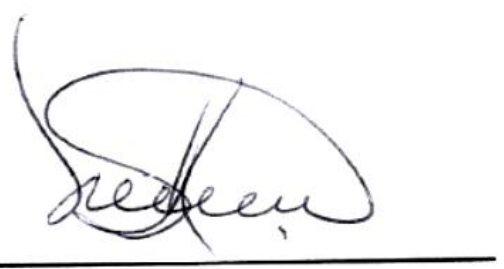

Vocal

Departamento de Ecología Funcional Universidad Nacional Autónoma de México

\section{Dra. Sara Lucía Camargo Ricalde}

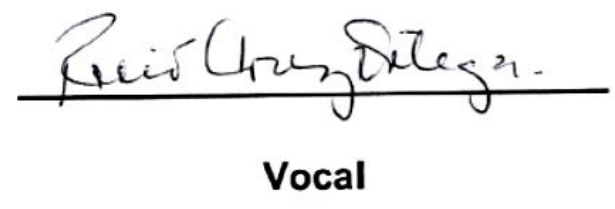

Departamento de Biología Universidad Autónoma Metropolitana Unidad Iztapalapa

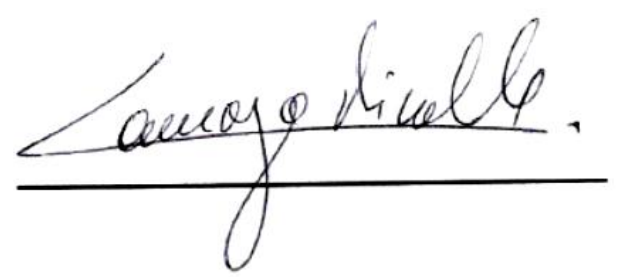


COMITÉ TUTORAL

DIRECTOR DE TESIS:

DR. DAVID MANUEL DÍAZ PONTONES

Departamento de Ciencias de la Salud

División de Ciencias Biológicas y de la Salud

Universidad Autónoma Metropolitana-Iztapalapa

ASESORES:

DRA. MARINA GAVILANES RUÍZ

Departamento de Bioquímica de la Facultad de Química.

Universidad Nacional Autónoma de México

DRA. MARÍA DEL ROCíO CRUZ ORTEGA

Departamento de Ecología Funcional

Universidad Nacional Autónoma de México 
Al que vendrá después, y cómo puede llegar a través del tiempo y de las esferas...

(H.P. Lovecraft)

A los que están entre nosotros, pero no los vemos.

To all these nameless feelings I can't deal with in my life, to all these greedy people trying to feed on what is mine (J. Davis) 


\section{Agradecimientos}

A mis padres, José Corona y Lydia Carrillo, quienes siempre han estado conmigo, me han apoyado y me han enseñado lo más importante, vivir con honestidad, sencillez y en búsqueda de la superación. A ustedes les debo todo, mis más grandes éxitos son suyos y son para ustedes.

A mi hermana Ana, que desde siempre ha sido mi amiga, confidente y consejera. Gracias por estar conmigo en los momentos más importantes, gracias también por mostrarme que la felicidad viene en forma de sobrinos; a Dana y Ferchito que quiero tanto.

A mi esposa Ofelia, que es una fuente inagotable de amor, comprensión y apoyo. Gracias por estos años que has compartido conmigo, que este momento sirva como prueba de que busco lo mejor para nosotros. ¡Te amo! 
Al Dr. David Díaz.

Doc, a usted tengo que agradecerle por tantas y tantas cosas... por darme la oportunidad de trabajar en su laboratorio, por toda la paciencia que me tuvo cuando las cosas no marchaban bien, por toda la confianza que me ha brindado y que ahora comienza a materializarse, por todo el cariño y el apoyo que me ha brindado durante todos estos años, por enseñarme que la ciencia más que números o papeles es pasión e integridad. También muchas gracias por su amistad.

A las Dras. Rocío Cruz y Marina Gavilanes. Gracias por todas las observaciones, consejos y correcciones, que a lo largo de todos estos años me han permitido mejorar y crecer como profesionista.

Al Dr. Fernando Díaz de León y a la Dra. Sara Camargo por sus valiosos aportes para mejorar este escrito. Muchas gracias.

A esa parte del espejo, que no refleja pero mira. 


\section{RESUMEN}

El maíz es el principal cereal consumido en México y el tercero más importante a nivel mundial; sus granos están compuestos por el embrión, el escutelo y el endospermo, rodeados por el pericarpio. En diversas publicaciones se ha reportado la presencia de una estructura fibrosa ubicada entre el escutelo y el endospermo, y se ha determinado que está constituida por remanentes de paredes celulares colapsadas provenientes del endospermo almidonoso. Pese a que la presencia de esta estructura, denominada capa fibrosa, ha sido reportada para el maíz y otros cereales, hasta ahora no hay ningún reporte que profundice en su composición estructural y su función durante la germinación.

Los objetivos de la presente investigación incluyeron 1) previo al inicio de la germinación, la caracterización histoquímica de los componentes estructurales de la capa fibrosa y la determinación de su permeabilidad mediante pruebas de difusión de colorantes. 2) Durante la germinación, la evaluación de cambios morfológicos de la capa fibrosa, asociando este proceso con la actividad de las enzimas peroxidasa de clase III (POD) y superóxido dismutasa (SOD). 3) La determinación de los cambios en la actividad de las enzimas POD y SOD durante el almacenamiento de granos de maíz en condiciones de humedad relativa y temperatura controladas, y cómo estas condiciones de almacenamiento alteran la estructura de la capa fibrosa. 
Se encontró que la capa fibrosa está compuesta por remanentes de paredes celulares que contienen lípidos, fenoles y glucanos $\beta-1,3$ tipo calosa. Debido a su composición, la capa fibrosa previene la difusión de componentes entre el escutelo y el endospermo al inicio de la germinación. Sin embargo, 24 horas después del inicio de la imbibición, la epidermis del escutelo presenta una serie de modificaciones que incluyen el crecimiento de las células, la perforación de algunas de sus paredes y la liberación de superóxido, peróxido de hidrógeno, fenoles y otros compuestos. Estas modificaciones, junto con la actividad de la enzima POD favorecen la transformación de la capa fibrosa, haciendo posible la comunicación entre el escutelo y el endospermo.

Se estableció que la actividad de las enzimas SOD y POD, presentes en el escutelo, está relacionada con el mantenimiento del vigor y de la capacidad germinativa de granos de maíz almacenados bajo diferentes condiciones de humedad relativa y temperatura. Se confirmó que el almacenamiento con altos niveles de humedad genera un deterioro rápido o lento en función de la temperatura, y que el almacenamiento en baja humedad y temperatura favorece la conservación de los granos por periodos prolongados.

Se concluye que la capa fibrosa representa una barrera física que impide el libre flujo entre el escutelo y el endospermo. Durante el inicio de la germinación esta compartimentación resulta benéfica para el embrión al impedir que los recursos presentes difundan hacia el endospermo, sin embargo, cuando los requerimientos nutricionales aumentan al tiempo que la raíz embrionaria empieza su alargamiento, 
se requiere la eliminación parcial de la capa fibrosa, para que este evento se realice, la epidermis del escutelo se modifica y correlaciona con cambios en la actividad de POD y generación o liberación de compuestos reductores como fenoles, $\mathrm{O}_{2} \cdot{ }^{-}$y $\mathrm{H}_{2} \mathrm{O}_{2}$.

La POD podría participar en el proceso de eliminación de la capa fibrosa en zonas puntuales o microambientes mediante la generación de ERO cuando es necesaria la comunicación del escutelo hacia el endospermo, o bien en una forma más amplia funcionando como una enzima antioxidante, que junto con la actividad de SOD, controlen las pozas de ERO para evitar daños y mantener la integridad y funcionalidad del escutelo durante procesos que generan estrés como el almacenamiento. 


\section{ABSTRACT}

Maize is the main cereal consumed in Mexico and the third most important globally; maize grains are composed by the embryo, the endosperm and the scutellum, surrounded by the pericarp. It has been reported the presence of a fibrous structure located between the endosperm and scutellum and was determined that consists of remnants of collapsed cell wall from the starchy endosperm. Although the presence of this structure, called fibrous layer, has been reported for maize and other cereals, to our knowledge no other report explains its structural composition and function during germination.

The aims of this research included: 1) previous to germination, histochemical characterization of the fibrous layer components and the determination of its capacity for dye diffusion. 2) During germination, the evaluation of the fibrous layer morphological changes, in relation with peroxidase (POD) and superoxide dismutase (SOD) activities. 3) Determination of changes in POD and SOD activities during maize grain storage in controlled relative humidity and temperature, and how these storage conditions affects the structure of the fibrous layer.

It was determined that the fibrous layer is composed of collapsed cellular layers that contain lipids, phenols and 1,3- $\beta$-glucan of the callose type. Due to its composition, the fibrous layer prevents free diffusion of components between embryo and endosperm at the onset of germination. Twenty-four hours after imbibition, the scutellum epidermis initiated a series of modifications, including cell growth, the perforation of cell walls and release of superoxide, hydrogen peroxide, phenols, and other components which along with peroxidase activity allows the transformation of the fibrous layer; thus ensuring communication between scutellum and endosperm. 
It was established that activities of superoxide dismutase and peroxidase present in the scutellum are related to the maintenance of vigor and germination of maize grains stored under different conditions of relative humidity and temperature. It was confirmed that storage at high humidity levels produces a rapid or slow deterioration depending on the temperature, and that storage at low humidity and temperature favors the preservation of the grains for prolonged periods.

We conclude that the fibrous layer is a physical barrier that prevents free diffusion between scutellum and endosperm. At the onset of germination, compartmentalization is beneficial for the embryo due to nutriments cannot diffuse to endosperm. When the nutritional requirements rise as the embryonic root grows, the partial removal of the fibrous layer is required, for this, scutellum epidermis is modified and this correlates with changes in POD activity and generation and liberation of reducing components as phenols, $\mathrm{O}_{2}-\mathrm{y}_{2} \mathrm{O}_{2}$.

POD could participate in regional or microenvironmental fibrous layer elimination through ROS generation when communication between scutellum to endosperm is necessary, or in a broader way, acting as antioxidant enzyme, that together with SOD activity could regulate ROS levels to avoid cellular damages and keep the integrity and functionality of the scutellum during events that generate stress such as storage. 


\section{ÍNDICE GENERAL}

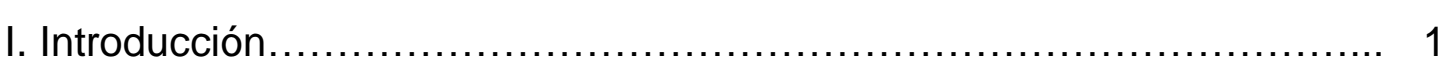

II. Antecedentes.......................................................... 4

A) Origen e importancia del maíz.................................. 4

B) Estructura del grano........................................... 6

a) El embrión................................................ 7

b) El escutelo.................................................. 8

c) El endospermo......................................... 9

c.1) Aleurona....................................... 10

c.2) Endospermo central almidonoso.................... 11

c.3) Células de transferencia.......................... 12

c.4) Región que rodea al embrión........................ 12

C) Interfase entre el embrión y el endospermo........................ 13

D) Importancia de las peroxidasas en plantas....................... 16

E) Propiedades y funciones de las ERO durante la germinación.................................................. 18

F) Principales mecanismos antioxidantes en plantas................. 20

III. Justificación............................................................... 22

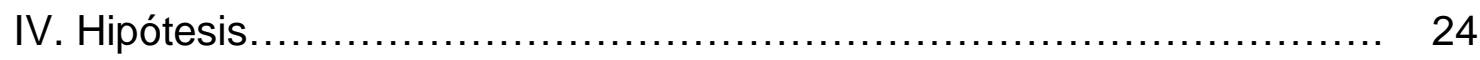

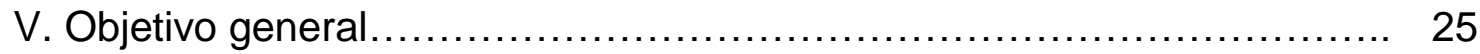

VI. Objetivos particulares.................................................. 26

VII. Materiales y métodos................................................ 27

1. Material biológico.................................................. 27

2. Detección histoquímica de los componentes de la capa fibrosa....... 28 2.1 Fijación, infiltración y corte ...................................... 28

2.2 Detección de lípidos.............................................. 28

2.3 Detección de compuestos fenólicos.............................. 29

2.4 Detección de glucanos $\beta-1,3$ tipo calosa......................... 29 
3. Ensayos de difusión y permeabilidad.......

3.1 Perforación de los granos y capacidad de difusión de colorantes a través de la capa fibrosa

3.2 Extracción de los componentes de la capa fibrosa y su efecto en la permeabilidad.

4. Modificaciones estructurales de la capa fibrosa y determinación in situ de la actividad de la peroxidasa

5. Inmunolocalización de la peroxidasa y superóxido dismutasa en los escutelos.

5.1 Obtención de secciones histológicas............................. 32

5.2 Inmunolocalización.............................................. 32

6. Cuantificación de la actividad de la peroxidasa en escutelos.......... 34

7. Cuantificación de la actividad de la superóxido dismutasa en escutelos.

8. Cuantificación de compuestos oxidorreductores extruidos desde la superficie del escutelo.

8.1 Cuantificación del poder reductor extruido: Reducción de XTT por equivalentes de $\mathrm{O}_{2}$ 36

8.2 Cuantificación de $\mathrm{H}_{2} \mathrm{O}_{2}$ por permanganometría.

8.3 Liberación de fenoles cuantificada por la reducción de ferricianuro 39

8.4 Solutos con capacidad de reducir al XTT

9. Efecto del almacenamiento en la actividad de la peroxidasa, vigor y emisión de compuestos endógenos

9.1 Condiciones de almacenamiento controlado

9.2 Cuantificación de actividad de la peroxidasa en escutelos de granos almacenados en condiciones controladas

9.3 Ensayos de vigor en granos almacenados en condiciones controladas 
9.4 Cambio en la autofluorescencia de compuestos endógenos de escutelos de granos almacenados en condiciones controladas....... 42

10. Análisis estadístico................................................... 43

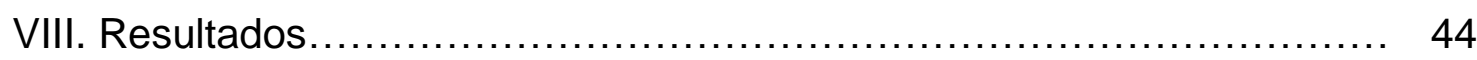

1. Composición química de la capa fibrosa........................... 44

2. Permeabilidad de la capa fibrosa .................................. 46

3. Transformaciones morfológicas de la epidermis del escutelo y pérdida de la integridad de la capa fibrosa......................... 49

4. Inmunolocalización de la peroxidasa y superóxido dismutasa...... 53

5. Cuantificación de la actividad de la peroxidasa y superóxido dismutasa en escutelos.......................................... 55

6. Cuantificación de compuestos oxidorreductores extruidos desde la superficie del escutelo......................................... 59

6.1 Cuantificación del poder reductor extruido: Reducción de XTT

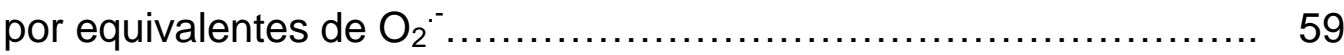

6.2 Cuantificación de $\mathrm{H}_{2} \mathrm{O}_{2}$ por permanganometría.................... 62

6.3 Liberación de fenoles desde la superficie del escutelo, cuantificados por la reducción de ferricianuro......................... 64

6.4 Otros solutos con capacidad de reducir al XTT in vitro............ 66

7. Efecto del almacenamiento en condiciones controladas sobre la actividad de la peroxidasa del escutelo y el vigor de los granos..... 67

8. Efecto del almacenamiento en la fluorescencia de los componentes tisulares del escutelo................................ 72

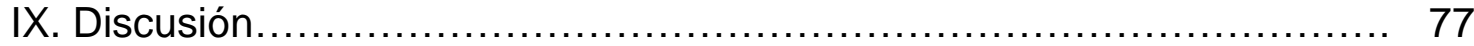

1. Composición de la capa fibrosa y sus funciones durante la germinación.

2. Modificaciones de la epidermis del escutelo y eliminación regional de la capa fibrosa por métodos pro-oxidantes.

3. Mecanismos antioxidantes del escutelo y su importancia durante el almacenamiento controlado. 


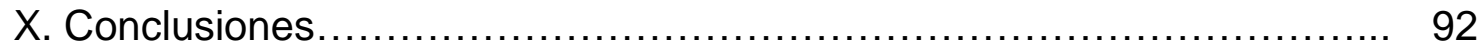

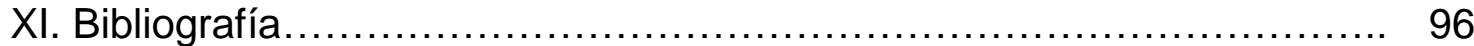

Anexo 1. Artículo publicado:

Peroxidase activity in scutella of maize in association with anatomical

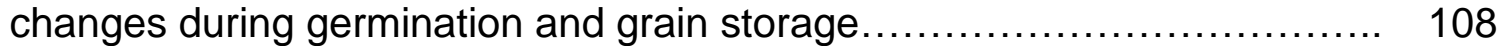




\section{INTRODUCCIÓN}

El maíz es uno de los principales cereales consumidos en el mundo junto con el trigo y el arroz. Se emplea para la alimentación humana, ganadera y para la obtención de productos industriales (González, 1995, Singh et al., 2014). En su madurez, el grano de maíz está constituido por tres principales elementos: 1) El pericarpio, que es la parte estructural más externa del grano y se encarga primordialmente de la protección de las estructuras internas. 2) El endospermo, que es un tejido de alta importancia, ya que es ahí donde se acumulan los almidones de reserva, y 3) El embrión, a partir del cual se desarrollará la parte vegetativa de la plántula, y que para su estudio puede subdividirse en un eje embrionario y el escutelo (Young y Gallie, 2000; Scanlon y Takacs, 2009).

El escutelo es un tejido que presenta funciones de reserva, secreción y absorción, por esto es clave durante los procesos de germinación y postgerminación (Szcziparev, 2006). Durante las primeras etapas de la germinación provee de nutrientes a la radícula en expansión, mientras que durante la postgerminación, su función secretora se encarga de la liberación de hidrolasas que degradan los elementos de reserva del endospermo y en etapas posteriores se encargan de la liberación de señales hormonales que inducen en la aleurona la síntesis de enzimas amilolíticas (Szcziparev, 2006; Taiz y Zeiger, 2010). En la postgerminación la función de absorción del escutelo también es destacada, ya que se encarga de la asimilación de los elementos derivados de la acción de enzimas amilolíticas (Szcziparev, 2006). Debido a que la epidermis del escutelo desarrolla las funciones de reserva, secreción y absorción, es considerado como un epitelio (Szcziparev, 2006). 
Durante la postgerminación temprana el escutelo y el endospermo deben interactuar adecuadamente, por ello debe existir una comunicación ideal entre ambos tejidos para que ocurra un libre flujo de señales y metabolitos, sin embargo se ha reportado que tanto en maíz como en granos de cebada, arroz y trigo existe una estructura compuesta por paredes colapsadas derivadas del endospermo almidonoso y ubicada entre el escutelo y el endospermo (Brown y Morris, 1890; Horning y Petrie, 1927). Múltiples nombres se han asignado a esta estructura; sin embargo, ninguno de los autores que ha reportado su presencia ha profundizado acerca de su composición o funciones durante la germinación.

En escutelos de maíz, la presencia de esta estructura fibrosa, que se ha denominado capa fibrosa en función de su apariencia (Enríquez-Arredondo et al., 2005), correlaciona con importantes niveles de actividad de la enzima peroxidasa de clase III. La actividad de esta enzima se ha vinculado con diferentes procesos que incluyen mecanismos de protección antioxidante y otros como el entrecruzamiento de compuestos fenólicos a proteínas y polisacáridos, el depósito de polifenoles y la suberización (Passardi et al., 2005; Cosio y Dunand, 2009); no obstante, también se conoce que la peroxidasa es una enzima multifuncional que bajo ciertas condiciones presenta un papel pro-oxidante (Liszkay et al., 2003; Passardi et al., 2005) durante el cual se generan especies reactivas de oxígeno (ERO).

Las ERO se producen continuamente en las células durante el metabolismo ordinario del desarrollo, germinación y almacenamiento de las semillas (Sharma et al., 2012). Dependiendo de su concentración, pueden funcionar como mensajeros en vías de señalización o como productos tóxicos que pueden oxidar y dañar todo tipo de componentes celulares (Møller et al., 2007). Por estas funciones duales, la producción 
de ERO debe estar finamente controlada de modo que en la célula vegetal existen metabolitos y enzimas encargadas de la eliminación del exceso de ERO.

Entre las enzimas más importantes se encuentran la superóxido dismutasa (SOD), encargada de la eliminación del anión superóxido $\left(\mathrm{O}_{2}{ }^{-}\right)$, y las peroxidasas de clase III (POD) que emplean compuestos fenólicos como donadores de electrones y se encargan de la transformación del peróxido de hidrógeno $\left(\mathrm{H}_{2} \mathrm{O}_{2}\right)$ en agua (Passardi et al., 2005; Sharma et al., 2012). La pérdida de vigor de las semillas como consecuencia de una alta generación de ERO durante el almacenamiento es uno de los principales problemas que enfrentan los agricultores pues redunda en una baja cosecha, lo cual implica pérdidas económicas (Goel y Sheoran, 2003).

Considerando que la capa fibrosa está ubicada entre el escutelo y el endospermo, y que la comunicación entre estas estructuras es fundamental para la adecuada transición de germinación a postgerminación, los objetivos de este trabajo incluyen el análisis de la composición química de la capa fibrosa y su correlación con la actividad de peroxidasa localizada sobre la parte basal del escutelo, además de la determinación de las alteraciones a nivel del escutelo y la capa fibrosa que ocurren durante el almacenamiento y deterioro del grano.

Los resultados derivados de esta investigación contribuirán a generar recomendaciones para minimizar las pérdidas de cosecha derivadas de malas condiciones de almacenamiento, y los resultados también podrían ser contemplados en planes de fitomejoramiento durante los cuales pueda alterarse la composición de la capa fibrosa. 


\section{ANTECEDENTES.}

A) Origen e importancia del Maíz.

El maíz (Zea mays L.) pertenece a la tribu Andropogoneae de la familia de las gramíneas (Poaceae); los parientes silvestres del maíz domesticado son los teosintes, plantas anuales perennes del género Zea que son endógenos de México y América Central (Strable y Scanlon, 2009). Existe un debate acerca del contexto temporal en el cual ocurrió la domesticación del maíz; pues mientras Piperno y Flannery (2001) y Benz (2001) sugieren que la domesticación ocurrió hace 5,500 años aproximadamente, Rong-Lin et al. (1999) y Yamasaki et al. (2005) sugieren un intervalo más amplio que va desde 5,000 a 10,000 años.

Estudios genéticos indican que el ancestro del maíz moderno es el teosinte $Z$. mays ssp. parviglumis y se ha determinado que su domesticación ocurrió en la región del Río Balsas en el suroeste de México (Rong-Lin et al,. 1999; Strable y Scanlon, 2009), posteriormente ocurrió un proceso de dispersión natural, hasta que durante el siglo XX algunos agricultores comenzaron a seleccionar líneas y a realizar híbridos para su producción (Yamasaki et al., 2005). De manera que la planta tal y como la concebimos ahora es el resultado de un proceso de selección natural en el que se ven involucrados factores de selección climática como sequías y procesos migratorios; además de procesos de selección artificial realizados por los agricultores (Rong-Lin et al., 1999; Pressoir y Berthaud, 2004; Yamasaki et al., 2005). 
México es considerado como centro de origen y domesticación del maíz, por lo cual, en el territorio nacional existe una amplia variedad de razas criollas, un reporte publicado en el Diario Oficial de la Federación (DOF) en el año 2006, indica que los estados de Chiapas, Chihuahua, Durango, Estado de México, Guerrero, Hidalgo, Jalisco, Oaxaca, Michoacán, Nayarit, Puebla, San Luis Potosí, Sinaloa, Veracruz y Zacatecas presentan la mayor diversidad de las 47 razas criollas descritas (DOF, 2006). Para el año 2012 se publicó en el DOF una actualización en la cual se indica la existencia de más de 70 variedades criollas de maíz (DOF, 2012); entre las cuales está incluido el maíz Chalqueño, material biológico que fue empleado durante la presente investigación.

El maíz es el tercer grano alimenticio más importante después del trigo y el arroz (Singh et al., 2014); representa el $5.4 \%$ del total de las fuentes alimenticias de la población humana (González, 1995), y también es empleado en actividades alimentarias ganaderas (Consonni et al., 2005). Su demanda de producción está siendo incrementada por sus amplios usos industriales entre los cuales destaca la producción de biocombustibles (Singh et al., 2014). En México es el principal cereal consumido, los datos más recientes publicados en 2010 por la Secretaría de Agricultura, Ganadería, Desarrollo Rural, Pesca y Alimentación (SAGARPA), muestran que el consumo nacional aparente per cápita durante 1998 a 2007 fue de 253.2 kg/año/habitante, lo cual representa que a nivel mundial es el octavo principal consumidor (SAGARPA, 2010). En el mismo estudio también se indica que del total de 18.3 millones de toneladas disponibles para consumo nacional el $75.1 \%$ fue destinado a consumo humano, el $19.2 \%$ a consumo pecuario, el $1.3 \%$ se utilizó como semilla para siembra y $4.4 \%$ fueron mermas. En el rublo del consumo humano, los principales destinos consisten en la 
elaboración de harina de maíz, además de la elaboración de almidones, féculas y levaduras (SAGARPA, 2010).

B) Estructura del grano.

El grano de maíz es un fruto de una sola semilla y está compuesto por cuatro componentes: el pericarpio, la testa, el endospermo y el embrión (Young y Gallie, 2000; Scanlon y Takacs, 2009). El pericarpio es la capa más externa y está caracterizada por un alto contenido de hemicelulosa, celulosa y lignina (Singh et al., 2014). En el maíz, a diferencia de otros cereales, la testa se compone únicamente de una cutícula y es responsable de la relativa impermeabilidad del grano al agua; en esta estructura suelen acumularse sustancias pigmentadas que le otorgan coloración a los granos (Evers y Millar, 2002). Debido a la importancia del embrión y el endospermo para la presente investigación, estas estructuras serán descritas en las siguientes secciones y pueden ser visualizadas en la Figura 1. 


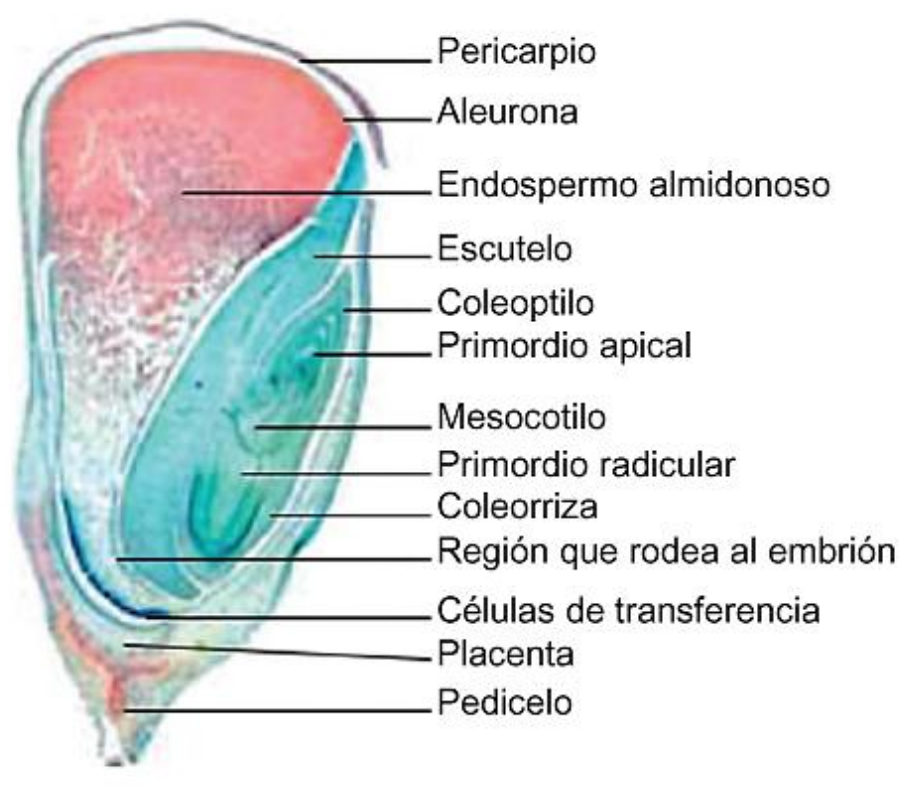

Figura 1. Componentes estructurales de un grano de maíz; (Modificado de Scanlon y Takacs, 2009).

\section{a) El embrión}

Derivado del proceso de doble fecundación característico de las angiospermas y ampliamente revisado en Lopes y Larkins (1993), Faure et al. (2003), Olsen (2004), Dumas y Rogowsky (2008), Yan et al. (2014) y Bleckmann et al. (2014); el embrión diploide se compone de un eje embrionario y un cotiledón masivo llamado escutelo. El eje embrionario comprende todos los tejidos que constituirán a la plántula y consiste de un primordio apical y uno radicular localizados en polos opuestos, además de un tallo con cinco o seis internodos que poseen una hoja en cada nodo (Consonni et al., 2005) y que en conjunto están envueltos en una estructura protectora denominada coleoptilo; la radícula también se encuentra rodeada por una estructura protectora llamada coleorriza (Fig. 1; Scanlon y Takacs, 2009). 
b) El escutelo

Regulando el progreso en el proceso germinativo se encuentra el escutelo (Fig. 1), que en cereales se considera como un tipo de hoja modificada que junto con el endospermo y la aleurona funciona como fuente de obtención de energía no fotosintética durante el desarrollo de la plántula (Thomas y Rodríguez, 1994). Se ubica rodeando al eje embrionario y está compuesto por tres tipos celulares: 1) Las células parenquimatosas que constituyen esencialmente la masa del escutelo, 2) Las células epidérmicas que se disponen como una capa externa adyacente al endospermo, y 3) Las células del sistema conductor que se distinguen por estar altamente ramificadas entre las células del parénquima (Szcziparev, 2006).

El escutelo es considerado como el equivalente funcional de los cotiledones de las dicotiledóneas (Dolfini et al., 2007), durante la germinación y la postgerminación cumple con funciones de reserva, secreción, absorción y conducción (Yan et al., 2014); de modo que éste almacena proteínas, almidón, lípidos y fitina, además de sacáridos solubles, ácidos orgánicos, vitaminas y elementos minerales (Szcziparev, 2006).

En las etapas tempranas de la germinación, el eje embrionario se nutre a expensas de las reservas del escutelo, de modo que parte de la sacarosa almacenada se utiliza para el inicio y el cumplimiento de la protrusión de la radícula, proceso en el que se ven involucrados la actividad de la $\mathrm{H}^{+}$-ATPasa y transportadores de sacarosa y hexosas (Sánchez-Linares et al., 2012). El resto de las reservas es empleado en el proceso de la respiración, proporcionando energía y metabolitos para los procesos de secreción y transporte así como para la síntesis de novo de hidrolasas, que durante la postgerminación temprana se emplean para hidrolizar a los elementos almidonosos localizados en el endospermo contiguo al escutelo. Durante la postgerminación, cuando 
las células epidérmicas del escutelo adquieren características de un epitelio, secretan hidrolasas hacia el endospermo (Asakura et al., 2007; Taiz y Zeiger, 2010) entre las cuales se han caracterizado celulasas, a y $\beta$-amilasas, fosfatasas, proteasas y nucleasas (Szcziparev, 2006; Yan et al., 2014). Los carbohidratos recién obtenidos por la acción hidrolítica sobre los almidones del endospermo son transportados hacia el escutelo donde son convertidos en sacarosa, la cual es transportada al floema y de ahí hacia el eje embrionario (Thomas y Rodríguez, 1994; Asakura et al., 2007).

Las células epiteliales del escutelo sintetizan y liberan giberelinas hacia la aleurona, en donde inducen la síntesis de $\alpha$-amilasas, proteasas y nucleasas, por esto el tejido escutelar es considerado un sitio clave para el control de la germinación de los granos de cereales (Asakura et al., 2007; Domínguez y Cejudo, 2014); sin embargo, se ha observado que el escutelo deja de funcionar 8 o 10 días después del inicio de la germinación, y en este tiempo se puede observar la degeneración y autolisis del tejido (Szcziparev, 2006). La degradación del escutelo ocurre mediante un proceso de muerte celular programada cuya progresión en el parénquima del escutelo y el epitelio parecen ser los últimos eventos en la movilización de nutrientes antes del crecimiento autónomo del embrión (Domínguez y Cejudo, 2014).

c) El endospermo

En el grano de maíz el endospermo se encuentra rodeando al escutelo; la función principal del endospermo es sustentar el desarrollo del embrión durante la postgerminación. El endospermo es un tejido triploide que se origina a partir de la fecundación de la célula central (Olsen et al. 1999; Bleckmann et al. 2014; Yan et al. 2014); su desarrollo en semillas de cereales engloba diferentes procesos como son la endoreduplicación del material genético, seguido por varias rondas de divisiones 
celulares que se caracterizan por la ausencia en la formación de la pared celular; a este endospermo se le conoce como nuclear o endospermo cenocítico (Geiser-Lee y Gallie, 2005). En un determinado momento el endospermo nuclear se celulariza, es decir ocurre la formación de paredes celulares mediante un proceso que utiliza la maquinaria básica de la citocinesis (Berger, 2003). Durante este tiempo se acumulan nutrientes y al final del desarrollo de la semilla el endospermo muere a través de un proceso de muerte celular programada (Domínguez y Cejudo, 2014; Yan et al., 2014).

El endospermo aporta el $85 \%$ de la masa del grano maduro (Scanlon y Takacs, 2009) lo cual es de gran importancia agronómica (Singh et al., 2014). Se han realizado múltiples estudios que han establecido que en cereales el endospermo está compuesto por diferentes tipos celulares; en el caso particular del maíz, Consonni et al. (2005), Scanlon y Takacs (2009) y Yan et al. (2014) han propuesto que el endospermo está compuesto por cuatro dominios: la aleurona, el endospermo central almidonoso, las células de transferencia y la región que rodea al embrión (Fig. 1).

\section{c.1) Aleurona}

La aleurona se ubica entre el pericarpio y el endospermo almidonoso (Fig. 1), y está compuesta por células cuboidales con citoplasmas densos (Geiser-Lee y Gallie, 2005) que presentan granos de almidón, vacuolas líticas y vacuolas de almacenamiento de proteínas (Olsen, 2001). En cereales y algunas dicotiledóneas con endospermo persistente, la aleurona tiene funciones importantes en la acumulación y remoción de compuestos de reserva durante el desarrollo de la semilla y la germinación (Becraft, 2007). La función de almacenamiento de las células de aleurona involucra la acumulación de altos niveles de ácido fítico, que es quelante de algunos minerales. Las células de la aleurona permanecen viables a través de todo el desarrollo del grano, y 
además de la función de almacenamiento, éstas células desempeñan otro papel importante durante la postgerminación, que es la denominada función hidrolítica, misma que se realiza mediante la secreción de hidrolasas que tienen el propósito de degradar almidón, ácidos nucleicos y proteínas almacenadas en las células del endospermo almidonoso (Becraft, 2007; Taiz y Zeiger, 2010; Domínguez y Cejudo, 2014), los metabolitos generados por la hidrólisis de estas biomoléculas son empleados para nutrir a la plántula emergente durante la postgerminación (Scanlon y Takacs, 2009).

En el maíz, la aleurona está compuesta por una sola capa de células cuboidales con citoplasmas muy densos (Olsen, 2001; Geiser-Lee y Gallie, 2005), y consiste de un estimado de 250,000 células que cubren totalmente el perímetro del endospermo excepto en la región de las células de transferencia (Olsen, 2001). A diferencia de las células del endospermo, las células de la aleurona permanecen viables al final del desarrollo de la semilla y solamente cuando han completado su función de secreción de enzimas hidrolíticas para la degradación de los elementos de reserva del endospermo, experimentan un programa de muerte celular programada, que en maíz se ha reportado que ocurre 12 días después del inicio de la imbibición (Domínguez y Cejudo, 2014).

\section{c.2) Endospermo central almidonoso}

Representa entre el 82 y $83 \%$ de la masa celular de todo el grano (Fig. 1; Singh et al., 2014) y consta de un estimado de 80 a 90 mil células en el grano de cebada y unas 60 mil en trigo (Olsen, 2001). La principal función del endospermo almidonoso es de almacenamiento, contiene alrededor de $85 \%$ de almidón, $8.5 \%$ de proteínas y $1 \%$ de lípidos. Las proteínas se localizan en los denominados cuerpos proteicos, que están compuestos casi completamente por la prolamina zeina, ésta se caracteriza por su bajo contenido de lisina. Los lípidos de endospermo, son mayoritariamente saturados en 
comparación a los encontrados en el embrión (Singh et al., 2014). Pese a que el endospermo presenta un alto nivel de actividad metabólica durante el desarrollo, es un tejido destinado a morir previo a la maduración de las semillas (Young y Gallie, 2000; Domínguez y Cejudo, 2014).

\section{c.3) Células de transferencia}

Las células de transferencia se desarrollan directamente sobre el tejido vascular materno (Fig. 1), y facilitan el transporte unidireccional de nutrientes desde el simplasto de la placenta al apoplasto del endospermo en desarrollo (Consonni et al., 2005; Scanlon y Takacs, 2009). Estas células poseen características distintivas entre las que destacan: la presencia de invaginaciones de la pared celular en un gradiente que decrece hacia el interior del endospermo (Olsen, 2004); con esto se aumenta la superficie de membranas plasmáticas aproximadamente veinte veces (Gómez et al., 2002; Becraft, 2007; Scanlon y Takacs, 2009); además, poseen citoplasmas densos con abundantes mitocondrias (Sabelli y Larkins, 2009). La principal función de las células de transferencia es permitir la rápida transferencia de nutrientes y fotosintatos como son aminoácidos, sacarosa y monosacáridos desde la planta madre hacia el endospermo (Berger, 2003; Olsen, 2004).

c.4) Región que rodea al embrión

La región que rodea al embrión fue identificada como una pequeña área de células que rodean a la cavidad que contiene al embrión (Olsen, 2001). Sus células presentan paredes celulares delgadas (Cosségal et al., 2007) con citoplasmas densos y ricos en pequeñas vacuolas (Sabelli y Larkins, 2009). Estas células están interconectadas por plasmodesmos (Cosségal et al., 2007) y contienen un extenso 
retículo endoplasmático rugoso (Becraft, 2007), al igual que un arreglo de mitocondrias muy cercanas al embrión, por lo que se cree que son células metabólicamente muy activas y que sintetizan grandes cantidades de membranas y proteínas que proveen nutrientes o señales hacia el embrión (Cosségal et al., 2007).

La función de este dominio del endospermo es desconocida, pero puede desempeñar un papel importante en la nutrición y crecimiento del embrión o en establecer una barrera física entre éste y el endospermo durante el desarrollo de la semilla (Olsen, 2001). También se ha especulado que este dominio puede tener un papel importante en la defensa del embrión y en el señalamiento apoplástico entre el embrión y el endospermo (Scanlon y Takacs, 2009), aunque se ha establecido que este dominio desaparece a los 15 días después de la polinización, durante el desarrollo del grano (Cosségal et al. 2007).

C) Interfase entre el embrión y el endospermo

Durante el proceso de formación de la semilla de maíz se generan dos compartimentos, en una región denominada cavidad embrionaria se desarrolla tanto en escutelo como el eje embrionario; en otra cavidad se desarrolla el endospermo que en el maíz es un tejido persistente. Se ha establecido que el endospermo y el embrión interactúan ampliamente durante la morfogénesis del grano (Scanlon y Takacs, 2009) al grado de que el endospermo es capaz de censar señales ambientales y posteriormente producir y secretar señales para regular el crecimiento del embrión (Yan et al., 2014); durante la germinación, la comunicación entre ambas estructuras es fundamental para garantizar la degradación de los elementos de reserva del escutelo y su posterior 
transferencia y distribución hacia el escutelo. No obstante pocos estudios han sido publicados acerca de la interfase entre estos dos compartimentos.

Además de la información reportada acerca de la región que rodea al embrión, la cual desaparece durante el desarrollo del grano (Cosségal et al., 2007), EnríquezArredondo et al. (2005) reportaron que en secciones histológicas de embriones de maíz de la variedad Montecillos $\mathrm{A} 6 \% 2$, existe una estructura de apariencia fibrosa que se localiza por encima de las células de la epidermis del escutelo; esta estructura presentó una fuerte actividad de fosfatasa y estos autores la denominaron capa fibrosa. Dado que la descripción de esta estructura no fue el objetivo de la investigación, no se discutieron ni se obtuvieron datos que profundizaran en sus funciones o composición.

La presencia de estructuras con ubicación similar a la capa fibrosa reportada por Enríquez-Arredondo et al. (2005) se han publicado desde finales del siglo XIX en maíz y otros cereales, no obstante el nombre de la estructura varía dependiendo del autor y desafortunadamente no existe ninguna investigación en la cual se postule la función o importancia de esta estructura. Según los reportes de Brown y Morris (1890) y Horning y Petrie (1927), las estructuras análogas a la capa fibrosa están compuestas de paredes celulares compactadas que provienen de los estratos periféricos del endospermo central almidonoso que están en contacto con el escutelo. En la Tabla 1 se indican los nombres asignados a dicha estructura y la referencia del estudio en el que se reportan. 
Tabla 1. Estructuras con ubicación similar a la capa fibrosa reportadas en diversos cereales

\begin{tabular}{|c|c|c|}
\hline Nombre de la estructura & Especie & Referencia \\
\hline $\begin{array}{l}\text { Células debilitadas y } \\
\text { comprimidas del endospermo }\end{array}$ & \begin{tabular}{|ll} 
Hordeum & vulgare \\
(Cebada) &
\end{tabular} & $\begin{array}{lll}\text { Brown } & y & \text { Morris } \\
(1890) . & & \end{array}$ \\
\hline Capa celular comprimida & $\begin{array}{l}\text { Hordeum vulgare } \mathrm{L} . \\
\text { (Cebada) }\end{array}$ & $\begin{array}{ll}\text { MacGregor } & \text { y } \\
\text { Dushnicky (1989). } & \end{array}$ \\
\hline $\begin{array}{l}\text { Capa debilitada del } \\
\text { endospermo }\end{array}$ & $\begin{array}{l}\text { Triticum aesitvum L. cv } \\
\text { Heron (Trigo) }\end{array}$ & Swift y O’brien (1972). \\
\hline $\begin{array}{l}\text { Zona fibrosa de células } \\
\text { comprimidas }\end{array}$ & $\begin{array}{l}\text { Oryza sativa cv Caloro } \\
\text { (Arroz) }\end{array}$ & $\begin{array}{l}\text { Bechtel y } \text { Pomeraz } \\
\text { (1978). }\end{array}$ \\
\hline Zona fibrosa & $\begin{array}{l}\text { Oryza sativa L. cv. Kimmaze } \\
\text { (Arroz) }\end{array}$ & Okamoto et al. (1982). \\
\hline $\begin{array}{l}\text { Paredes } \\
\text { comprimidas }\end{array}$ & $\begin{array}{l}\text { Zea mays L. cv Red Hogan } \\
\text { (Maíz) }\end{array}$ & $\begin{array}{l}\text { Horning y } \begin{array}{l}\text { Petrie } \\
(1927) .\end{array} \\
\end{array}$ \\
\hline Capa absorbente & $\begin{array}{l}\text { Zea mays L. } \\
\text { (Maíz) }\end{array}$ & $\begin{array}{l}\text { Kiesselbach y Walker } \\
\text { (1952). }\end{array}$ \\
\hline $\begin{array}{l}\text { Tejido entre el escutelo y el } \\
\text { endospermo }\end{array}$ & $\begin{array}{l}\text { Zea mays L. } \\
\text { (Maíz) }\end{array}$ & $\begin{array}{l}\text { Bourdu y } \text { Bousser } \\
\text { (1991). }\end{array}$ \\
\hline Capa fibrosa & $\begin{array}{l}\text { Zea mays L. hibrido } \\
\text { Montecillos A6q2 (Maíz) }\end{array}$ & $\begin{array}{l}\text { Enríquez-Arredondo } \\
\text { et al. (2005). }\end{array}$ \\
\hline $\begin{array}{l}\text { Nombre no asignado, pero la } \\
\text { estructura se visualiza } \\
\text { claramente en la Fig. } 1 \mathrm{~A}\end{array}$ & $\begin{array}{l}\text { Zea mays L. } \\
\text { (Maíz) }\end{array}$ & Tnani et al. (2011). \\
\hline
\end{tabular}

La publicación de Bergvinson y García-Lara (2004) concerniente al estudio de los elementos químicos que proporcionan resistencia a granos de maíz ante el ataque de insectos, puso de manifiesto que en el pericarpio se concentran compuestos fenólicos, encargados de reforzar las paredes celulares para proteger a los granos contra el ataque de insectos e invasión de hongos. No obstante, sus resultados de escaneos microespectrofotométricos de secciones transversales de granos de maíz también indican una abundante presencia de compuestos fenólicos sobre la periferia del embrión, sin embargo al depositarse estos compuestos en un compartimento interno y 
no sobre el pericarpio que es la estructura que evita el ingreso de insectos, no se realizó una investigación sobre las funciones de los compuestos fenólicos presentes sobre los bordes del embrión.

En un estudio posterior García-Lara et al. (2007), determinaron que la actividad de la enzima peroxidasa en granos de maíz del genotipo P84c2 es fundamental durante la resistencia de los granos al ataque de gorgojos. Mediante técnicas histoquímicas encontraron que la peroxidasa está presente principalmente en la aleurona, contribuyendo a generar dureza en el pericarpio lo cual representa un impedimento para el ataque de insectos. Además de la ubicación de la peroxidasa en la aleurona, también fue localizada en la raíz embrionaria y en el escutelo, implicando que en granos maduros la enzima peroxidasa debe de cumplir con otras funciones importantes, algunas de las cuales se describen a continuación.

D) Importancia de las peroxidasas en plantas

Las peroxidasas de plantas pertenecen a una gran familia de enzimas, que incluye tres diferentes clases (Passardi et al., 2005). La clase I o intracelular se encuentra en la mayoría de los organismos vivos, principalmente en procariontes; su función principal es la eliminación del exceso de $\mathrm{H}_{2} \mathrm{O}_{2}$ en la célula. Las peroxidasas de clase I se clasifican en tres principales grupos: las Ascorbato peroxidasas, las Citocromo c peroxidasa y las Catalasa-peroxidasa. Por su parte, las peroxidasas de clase II se encuentran exclusivamente en hongos (Cosio y Dunand, 2009).

Las peroxidasas de clase III (EC 1.11.1.7) están presentes en todas las plantas terrestres y se ubican principalmente en la pared celular y en la vacuola (Cosio y 
Dunand, 2009), sin embargo, en reportes recientes también han sido ubicadas en la membrana plasmática (Mika y Lüthje, 2003; Heyno et al., 2011) o incluso en el apoplasto (Noctor et al., 2014). La función típica de las peroxidasas de clase III (POD) es catalizar la reducción del $\mathrm{H}_{2} \mathrm{O}_{2}$ tomando electrones de varios donadores reducidos, como pueden ser diversos metabolitos secundarios que incluyen grupos fenólicos como los precursores de lignina, flavonoides y auxinas (Shirley, 1998; Hiraga et al., 2001; Passardi et al., 2004; Passardi et al., 2005; Cosio y Dunand, 2009).

A las POD se les han asignado múltiples funciones fisiológicas durante todo el ciclo de vida de las plantas, entre ellas destacan: el entrecruzamiento de compuestos fenólicos a proteínas o polisacáridos (Fry, 2004; Hollmann y Arends, 2012), el depósito de polifenoles (Lagrimini, 1991), la suberización (Bernards y Lewis, 1988), el catabolismo de auxinas, la oxidación de tóxicos reductores, la defensa contra patógenos y el ataque de insectos (Cosio y Dunand, 2009).

La función convencional de las POD para eliminar $\mathrm{H}_{2} \mathrm{O}_{2}$ a expensas de sustratos fenólicos ha sido definida como el ciclo peroxidativo, no obstante, se ha descrito que los sustratos fenólicos pueden ser reemplazados por compuestos como el NADH que puede ser oxidado al radical $\mathrm{NAD}^{\circ}$. En una reacción no enzimática, el radical $\mathrm{NAD}^{\circ}$ reduce el $\mathrm{O}_{2}$ a $\mathrm{O}_{2}-{ }^{-}$que puede ser convertido en $\mathrm{H}_{2} \mathrm{O}_{2}$ por la oxidación no enzimática de otro NADH o bien por la acción de la enzima SOD; de modo que la generación de $\mathrm{O}_{2}{ }^{-}$y $\mathrm{H}_{2} \mathrm{O}_{2}$ mediado por $\mathrm{NAD}^{\circ}$ se conoce como el ciclo oxidativo de las POD. Un tercer ciclo se ha descrito para las $\mathrm{POD}$, en el cual el $\mathrm{Fe}^{3+}$ del grupo hemo es reducido a $\mathrm{Fe}^{2+}$ por acción del $\mathrm{O}_{2}{ }^{-}$, posteriormente el $\mathrm{Fe}^{2+}$ puede reducir al $\mathrm{H}_{2} \mathrm{O}_{2}$ y producir radical hidroxilo $\left({ }^{\circ} \mathrm{OH}\right)$; la generación de ${ }^{\circ} \mathrm{OH}$ en presencia de $\mathrm{O}_{2} \cdot{ }^{-}$y $\mathrm{H}_{2} \mathrm{O}_{2}$ se ha descrito como el ciclo 
hidroxílico de las peroxidasas (Liszkay et al., 2003; Cosio y Dunand, 2009; Passardi et al., 2005).

Debido a que las POD están involucradas en el manejo de moléculas oxidantes es importante profundizar en las propiedades y funciones de estas moléculas relacionándolas con el proceso germinativo.

E) Propiedades y funciones de las ERO durante la germinación

Las ERO son moléculas producidas continuamente en las células durante el metabolismo ordinario del desarrollo, la germinación y el almacenamiento de las semillas (Gill y Tuteja, 2010). Dentro de las ERO se encuentran radicales libres como el $\mathrm{O}_{2} \cdot{ }^{--}$y el ${ }^{\circ} \mathrm{OH}$, así como moléculas que no son radicales como el $\mathrm{H}_{2} \mathrm{O}_{2}$ (Sharma et al., 2012). Para las plantas, así como para otros organismos, las ERO son dañinas en altas concentraciones, de modo que cuando su concentración excede la capacidad antioxidante de la célula, se dice que éstas se encuentran en un estado de estrés oxidante (Marino et al., 2012). Las ERO pueden dañar directamente proteínas, lípidos, ácidos nucleicos y casi cualquier biomolécula (Møller et al., 2007; Kranner et al., 2010) y su acumulación conlleva a alteraciones en el desarrollo de la semillas o en el proceso de germinación (Bailly, 2004).

Cuando las ERO se encuentran en bajas concentraciones, actúan como segundos mensajeros mediante procesos que involucran la modulación de la actividad de proteínas o la expresión génica (Marino et al., 2012). Las ERO participan en una variedad de procesos celulares que incluyen el crecimiento, el desarrollo y la muerte celular programada, así como en el cierre de los estomas y la respuesta a estrés biótico 
y abiótico (Apel y Hirt, 2004; Bailly et al., 2008). Además, las ERO contribuyen en el proceso de elongación de las células de coleoptilos y raíces de maíz, e hipocotilos de girasol (Schopfer et al., 2002; Liszkay et al., 2003; Liszkay et al., 2004); dichos procesos involucran modificaciones y ablandamiento de las paredes celulares de los tejidos en crecimiento, y son inducidos por el efecto del ${ }^{\circ} \mathrm{OH}$, el cual hidroliza los enlaces de los polisacáridos constituyentes de la pared celular (Schopfer, 2001; Schopfer et al., 2002; Liszkay et al., 2003; Liszkay et al., 2004; Møller et al., 2007).

De este modo, las ERO desempeñan un papel dual que involucra procesos benéficos o perjudiciales para las semillas y plantas; estos procesos están determinados por la concentración de las ERO. Para el caso particular de la germinación, Bailly et al. (2008) propusieron el concepto de ventana oxidativa que define los niveles de ERO que no deben ser sobrepasados, ya que de otra manera no ocurriría la germinación, por debajo de un nivel umbral de ERO la protrusión radicular tampoco ocurriría, en este sentido, sólo dentro de esa ventana oxidativa las ERO cumplirían con sus funciones de señalamiento al interactuar en vías de señalización hormonal, la modulación de la expresión génica, movimientos de calcio y el control del estado redox. Al excederse esta ventana oxidativa se genera un estrés que compromete la viabilidad de las semillas como ocurre durante el almacenamiento (Goel y Sheoran, 2003). Para evitar los daños oxidativos generados por la acumulación de $\mathrm{ERO}$, las semillas y plantas cuentan con un importante sistema antioxidante que involucra elementos enzimáticos y no enzimáticos, algunos de los cuales serán descritos en la siguiente sección. 
F) Principales mecanismos antioxidantes en plantas

Las plantas poseen un complejo sistema antioxidante que integra elementos enzimáticos y no enzimáticos. Entre los no enzimáticos se encuentran moléculas solubles en agua o lípidos como son: ascorbato, glutatión, tocoferoles, carotenoides, ubiquinonas, y compuestos fenólicos (Gill y Tuteja, 2010; Sharma et al., 2012). Las principales enzimas antioxidantes incluyen a la superóxido dismutasa (SOD), la catalasa (CAT) y las peroxidasas de Clase III (POD), además de las enzimas de ciclo ascorbato-glutatión como la ascorbato peroxidasa, monodehidroascorbato reductasa, dehidroascorbato reductasa y glutatión reductasa (Sharma et al., 2012; Sytykiewicz, 2014).

La SOD tiene un papel fundamental en la defensa contra el estrés oxidativo en todos los organismos aeróbicos, por lo cual es considerada como la primera línea de defensa antioxidante. Pertenece al grupo de las metaloenzimas y cataliza la dismutación del $\mathrm{O}_{2} \cdot-$ en $\mathrm{O}_{2}$ y $_{2} \mathrm{O}_{2}$. En plantas existen tres isoenzimas de SOD: las de cobre-zinc (Cu/Zn-SOD) presentes en el citosol, cloroplastos, peroxisomas, mitocondrias y el espacio extracelular; las de manganeso (Mn-SOD) localizadas en mitocondrias; y las de fierro (Fe-SOD) localizadas en los cloroplastos (Sharma et al., 2012; Sytykiewicz, 2014).

Adicional a lo antes descrito, las peroxidasas de clase III son enzimas que tienen un grupo hemo y que preferentemente oxidan donadores de electrones aromáticos como guayacol o pirogalol, a expensas de $\mathrm{H}_{2} \mathrm{O}_{2}$. Existen diferentes isoformas localizadas en vacuolas, pared celular, membrana plasmática y el citosol. La guayacol peroxidasa está asociada a importantes procesos biosintéticos incluyendo la lignificación de la pared celular, la degradación de auxinas, la biosíntesis de etileno y la 
defensa contra estrés biótico y abiótico (Sharma et al., 2012). Su funcionalidad es dual dependiendo de las condiciones microambientales, por lo que puede funcionar como una enzima pro-oxidante o como una enzima antioxidante (Liszkay et al., 2003; Passardi et al., 2005; Cosio y Dunand 2009). 


\section{JUSTIFICACIÓN}

México se encuentra entre los principales países productores de maíz, según el reporte de Singh et al. (2014), durante 2010 en el país se produjeron 23,301,900 toneladas métricas del cultivar, sólo por debajo de países como Estados Unidos, China y Brasil; sin embargo la producción del grano se encuentra por debajo de las cantidades necesarias de consumo, reflejando el hecho de que México es también uno de los principales países importadores del cereal (Singh et al., 2014).

El bajo rendimiento en las cosechas de maíz obedece a múltiples factores, entre los cuales se encuentran bajos niveles de germinación y de establecimiento de plántulas, ocasionados principalmente por el inadecuado almacenamiento del grano, o por la dependencia de factores ambientales para el desarrollo de las plantas; lo cual redunda en la necesidad de importar grandes cantidades de maíz que generan una importante inversión.

Debido al alto impacto económico y alimenticio de las cosechas de maíz, se requiere realizar investigación que permita obtener conocimientos y soluciones con respecto al proceso germinativo del grano, y pese a que existen muchos avances en la materia, el papel que desempeña la capa fibrosa en los granos de maíz y sus funciones durante la germinación no ha sido estudiado. Por otra parte, teniendo en cuenta que se ha generado mucha investigación sobre las funciones de las POD, no existe información que relacione su ubicación en el escutelo con su papel durante la germinación. 
De esta forma, este estudio se centra en caracterizar la composición de la capa fibrosa en granos de maíz y en determinar sus funciones durante la germinación, asociando ambos parámetros al deterioro paulatino que ocurre durante el almacenamiento de los granos, en donde la actividad de enzimas como las POD cobran importancia, ya que están involucradas en el manejo del estrés oxidante al cual se enfrentan las semillas durante este proceso.

Los resultados obtenidos contribuyen a explicar el déficit en la germinación y el establecimiento de plántulas y aportan conocimientos básicos que en un futuro permitirán diseñar estrategias adecuadas para procesos de fitomejoramiento y de un correcto almacenamiento del grano que garantice altos niveles de germinación y en consecuencia, el aumento del rendimiento de las cosechas. 


\section{HIPÓTESIS}

Dado que la capa fibrosa es una estructura compuesta por paredes celulares compactadas derivadas del endospermo central almidonoso, y que se establece entre el escutelo y el endospermo durante la formación de los granos de maíz, entonces por su composición constituiría un impedimento para la comunicación entre el escutelo y el endospermo, por lo cual durante la geminación, el embrión debe generar un mecanismo que elimine esta barrera. Toda vez que se ha reportado la existencia de actividad de peroxidasas de clase III en el escutelo y que se ha establecido que la peroxidasa puede generar ERO, la interacción de estas especies químicas con los elementos constitutivos de la capa fibrosa permitirían su degradación, mientras que otros elementos enzimáticos antioxidantes, como la superóxido dismutasa, protegerían la integridad del resto del tejido. Debido a que la actividad de la peroxidasa sería importante durante la degradación de la capa fibrosa y la germinación, los granos de maíz verían comprometido su vigor y viabilidad si son expuestos a condiciones de almacenamiento durante las cuales la actividad de la peroxidasa disminuye. 


\section{OBJETIVO GENERAL}

Determinar durante la transición de la germinación a la postgerminación de embriones de maíz Chalqueño, la composición y la función de la capa fibrosa, así como la participación de enzimas generadoras y eliminadoras de especies reactivas de oxígeno durante su alteración estructural; comparando cómo se modifican estos procesos y la viabilidad de los granos durante su almacenamiento en condiciones controladas. 


\section{OBJETIVOS PARTICULARES.}

1. Determinar la composición química de la capa fibrosa en embriones de maíz.

2. Determinar si la capa fibrosa impide la difusión de sustancias entre el embrión y el escutelo.

3. Cuantificar la actividad de las peroxidasas de clase III en escutelos de maíz durante la germinación y postgerminación temprana.

4. Cuantificar la actividad de la enzima superóxido dismutasa en escutelos de maíz durante la germinación y postgerminación temprana.

5. Determinar la localización de la peroxidasa de clase III y la superóxido dismutasa en el escutelo de embriones de maíz.

6. Determinar la producción de superóxido y peróxido de hidrógeno en la superficie del escutelo.

7. Cuantificar la actividad de peroxidasas de clase III en escutelos de embriones de maíz expuestos a condiciones de deterioro controlado.

8. Determinar el vigor y la capacidad germinativa de embriones de maíz expuestos a condiciones de deterioro controlado.

9. Determinar cambios en la emisión de fluorescencia en las células del escutelo asociados al almacenamiento de granos de maíz en condiciones de deterioro controlado. 


\section{MATERIALES Y MÉTODOS}

\section{Material Biológico}

Para este estudio se emplearon granos maduros de maíz variedad Chalqueño obtenidos de la región de Chalco, Estado de México, cosechados en el año 2005 y 2010. Para todos los ensayos se emplearon de 4 a 10 embriones y se realizaron de 3 a 12 réplicas independientes por cada ensayo.

Para los tratamientos experimentales descritos a detalle en las siguientes secciones se emplearon granos de maíz bajo las siguientes condiciones:

1) Para las pruebas de difusión de colorantes entre el embrión y el endospermo, se emplearon granos maduros completos.

2) Para las pruebas de vigor se emplearon granos completos, previamente desinfectados durante 5 minutos con una solución de $\mathrm{NaClO}$ al 3\% (Cloralex), posteriormente fueron lavados 3 veces con agua destilada estéril y colocados en cámaras germinadoras humedecidas con $10 \mathrm{ml}$ de agua destilada estéril, e incubados durante $12 \mathrm{~h}$, en oscuridad y a $25^{\circ} \mathrm{C}$.

3) Para las pruebas de composición de la capa fibrosa se emplearon embriones disectados manualmente de granos maduros y secos.

4) Para las pruebas de cuantificación de actividad e inmunolocalización de POD y SOD; liberación de fenoles, compuestos oxidorreductores y $\mathrm{H}_{2} \mathrm{O}_{2}$ desde la superficie del escutelo, los embriones se disectaron manualmente y después se desinfectaron, y lavaron como se describió anteriormente. Finalmente, los embriones fueron colocados en cámaras germinadoras humedecidas con $10 \mathrm{ml}$ 
de agua destilada estéril e incubados durante 18,24 o $36 \mathrm{~h}$ en la oscuridad a $25^{\circ} \mathrm{C}$.

5) Para la ubicación in situ de la actividad de POD se obtuvieron embriones, se desinfectaron y lavaron como se explica anteriormente, finalmente, los embriones se incubaron durante $24 \circ 36 \mathrm{~h}$ en cajas germinadoras bajo las mismas condiciones antes descritas.

6) Para la cuantificación de actividad de POD durante el almacenamiento en condiciones controladas, cada 30 días se tomaron granos de los lotes de almacenamiento, los embriones se disectaron manualmente, posteriormente fueron desinfectados, lavados e incubados durante 24 h según las condiciones previamente descritas.

2. Detección histoquímica de los componentes de la capa fibrosa

\subsection{Fijación, infiltración y corte}

Los embriones disectados se fijaron $1 \mathrm{~h}$ en una solución de paraformaldehido (Merck) al 4\% en agua ( $\mathrm{pH}$ 6.9). Posteriormente, los embriones se lavaron 3 veces y se infiltraron en sacarosa $320 \mathrm{mM}$ (Sigma) durante $24 \mathrm{~h}$ a $4^{\circ} \mathrm{C}$. Empleando un criostato (IEC CTD Harris-Cryostat) a $-22^{\circ} \mathrm{C}$ se obtuvieron secciones histológicas de $8 \mu \mathrm{m}$. Las secciones obtenidas se colectaron en portaobjetos cubiertos con gelatina (Knox) como lo describe Enríquez-Arredondo et al. (2005).

\subsection{Detección de lípidos}

Para la detección de lípidos, las secciones histológicas fueron tratadas por dos métodos: 1) Para la detección de lípidos neutros y ésteres (Pearse, 1968; Kruth, 1984), 
las secciones se sumergieron durante $10 \mathrm{~min}$ en etanol 60\% (Sigma), posteriormente se tiñeron con una solución al $\mathbf{0 . 5 \%}$ de Aceite Rojo-O (Sigma) en propanol (Sigma):agua (6:4; v:v); el excedente del colorante se eliminó con lavados de agua destilada (Krishnamurty, 1988). 2) Para la detección de compuestos lipídicos presentes en suberinas y cutina (Locquin y Langeron, 1995) las secciones histológicas se incubaron en etanol $60 \%$ (Sigma) por $10 \mathrm{~min}$, posteriormente se tiñeron durante $15 \mathrm{~min}$ con una solución 0.09\% de Sudan IV (Sigma) en etanol (Sigma):glicerol (Sigma) (1:1; v:v), el excedente de colorante se eliminó mediante lavados con agua destilada (Ruzin, 1999). Las preparaciones obtenidas por ambos métodos fueron montadas en medio acuoso y examinadas usando microscopía diferencial de contraste de interferencia Nomarski en un microscopio Axoskop Zeiss.

\subsection{Detección de compuestos fenólicos}

Para la localización in situ de compuestos fenólicos, las secciones histológicas se trataron durante 10 min con acetato de etilo (Sigma) y posteriormente fueron incubadas por el mismo tiempo en una solución al $0.5 \%$ de ácido difenilborínico (Sigma) disuelto en acetato de etilo (Sigma); esta solución incrementa la fluorescencia de los fenoles (Reich et al., 2006; Sen et al., 1994). El exceso de la solución de ácido difenilborínico se eliminó con papel absorbente y la detección de los compuestos fenólicos se realizó en un microscopio de epifluorescencia Axoskop Zeiss, usando una longitud de excitación de 365 nm y un filtro de emisión para fluoresceína.

\subsection{Detección de glucanos $\beta-1,3$ tipo calosa}

El azul de anilina es un reactivo que interactúa con residuos que contienen enlaces glucosídicos $\beta-1,3$ formando complejos fluorescentes y es usado para la 
detección de polisacáridos tipo calosa (Smith y McCully, 1978). Para la detección de estos compuestos, las secciones histológicas se hidrataron durante 10 min y después se trataron durante 15 min con una solución $0.01 \%$ de azul de anilina (Sigma) disuelta en amortiguador de fosfatos (J.T. Baker) $0.1 \mathrm{M}(\mathrm{pH}$ 9). El exceso de colorante se eliminó con papel absorbente. Los complejos fluorescentes se excitaron con una longitud de 365 nm y se registró la emisión en la región del azul (Ruzin, 1999) usando un microscopio de epifluorescencia Axoskop Zeiss.

\section{Ensayos de difusión y permeabilidad}

3.1 Perforación de los granos y capacidad de difusión de colorantes a través de la capa fibrosa

Para evaluar la difusión de colorantes a través de la capa fibrosa se implementaron tres tipos de pruebas: 1) Con una aguja de disección los granos fueron perforados 3 veces a través del embrión o del endospermo sin traspasar la capa fibrosa; 2) Los granos fueron perforados continuamente desde el embrión hasta el endospermo; 3) Los granos no se perforaron.

Para evaluar la difusión entre los tejidos se empleó: a) una solución acuosa de $\mathrm{I}_{2}-\mathrm{KI} 0.1 \mathrm{~N}$, preparada de acuerdo con Landry y Smyth (1988), la cual es usada para la detección de almidón presente en el endospermo y el escutelo (Szcziparev, 2006); b) una solución del colorante Verde Brillante (Merck 1310) al 0.5\% en etanol (Sigma) al $95 \%$ que se usa para teñir citoplasmas y paredes celulares en color verde (Ruzin, 1999). 
Los granos perforados en cualquiera de las estructuras se incubaron a $4^{\circ} \mathrm{C}$ durante $24 \mathrm{~h}$ en la solución de $\mathrm{I}_{2}-\mathrm{KI}$, ó $48 \mathrm{~h}$ en la solución de Verde Brillante. El exceso de los colorantes se eliminó lavando los granos exhaustivamente con agua para prevenir el arrastre del colorante por la navaja que fue empleada para cortar los granos longitudinalmente. Posterior al corte se evaluaron las áreas teñidas y los granos se escanearon para obtener archivos digitales (HP psc 1315).

\subsection{Extracción de los componentes de la capa fibrosa y su efecto en la permeabilidad}

Los granos perforados en el embrión o endospermo se incubaron durante 4 días en acetona (J.T. Baker), cloroformo (J.T. Baker) o una mezcla acetona:cloroformo (1:1, v:v), a temperatura ambiente. Después de la evaporación de los solventes durante 11 días, se evaluó la difusión de los colorantes siguiendo lo descrito en la sección 3.1.

4. Modificaciones estructurales de la capa fibrosa y determinación in situ de la actividad de la peroxidasa

Para evaluar los cambios estructurales de la capa fibrosa y determinar la localización in situ de la actividad de POD en escutelos, se obtuvieron embriones embibidos durante 24 o $36 \mathrm{~h}$ que se incubaron durante 30 min a $25^{\circ} \mathrm{C}$ en una solución de reacción compuesta de amortiguador de acetato de sodio (Sigma) $50 \mathrm{mM}(\mathrm{pH} 4.5)$ con $\mathrm{H}_{2} \mathrm{O}_{2}$ (Sigma) al $0.22 \%$ y 3 -amino-9-etilcarbazol (AEC) al $0.05 \%$ (Sigma) previamente disuelto en N,N-dimetilformamida (Sigma; Graham et al., 1965; Vallejos, 1983). Posteriormente, los embriones fueron fijados, infiltrados y cortados como se especifica en la sección 2.1. Como controles se emplearon secciones histológicas incubadas en la solución de reacción descrita anteriormente pero en ausencia de $\mathrm{H}_{2} \mathrm{O}_{2}$. 
Las secciones histológicas fueron montadas en medio acuoso y examinadas usando microscopía diferencial de contraste de interferencia Nomarski en un microscopio Axoskop Zeiss.

5. Inmunolocalización de peroxidasa y superóxido dismutasa en escutelos

\subsection{Obtención de secciones histológicas}

Embriones con 24 h de imbibición (sección 1) fueron fijados con etanol (Sigma) al $70 \%$ durante $24 \mathrm{~h}$ a temperatura ambiente. Posteriormente, los embriones fueron deshidratados con una serie de tres cambios graduales de etanol al $80,90,96$ y $100 \%$ (de 5 minutos cada uno). Para la infiltración con paraplast (Sigma), los embriones se trataron con xileno (J.T. Baker) por 10 min y después con las siguientes series de paraplast:xileno, 3:1, 2:2 y 1:3, durante $24 \mathrm{~h}$ cada uno. Finalmente los embriones fueron procesados para obtener secciones de $8 \mu \mathrm{m}$ por microtomía (820 Spencer Microtome, American Optical Corporation). Previo a su uso para inmunolocalización, a las secciones histológicas se les removió el paraplast tratándolas con xileno durante 10 min. Posteriormente, las secciones histológicas se incubaron con tres cambios de etanol a las siguientes concentraciones: 100, 96, 90, 80, 70, 60, 50, 40 y 30\% (durante 5 min cada uno; Ruzin, 1999).

\subsection{Inmunolocalización}

Las secciones histológicas sin paraplast fueron incubadas durante 10 min en un amortiguador de fosfatos (J.T. Baker) $10 \mathrm{mM}(\mathrm{pH}$ 7.4), después se les bloquearon los sitios de unión inespecífica para IgG durante $2 \mathrm{~h}$ a temperatura ambiente con una 
solución de leche descremada, sin grasa (Svelty, Nestlé), al 2.5\% disuelta en amortiguador de fosfatos (J.T. Baker) $10 \mathrm{mM}$ (pH 7.4) que contenía $\mathrm{NaCl}$ (Sigma) 150 $\mathrm{mM}, \mathrm{MgSO}_{4}$ (Sigma) $5 \mathrm{mM}$, Triton X-100 (Sigma) 0.01\%, EDTA (Sigma) $5 \mathrm{mM}$ y PVP (Sigma) 1\%. Las secciones histológicas se lavaron 3 veces durante 5 min con un

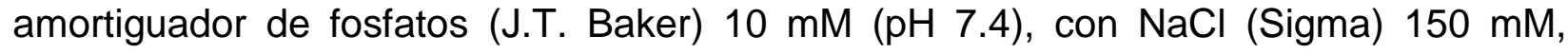
$\mathrm{MgSO}_{4}$ (Sigma) $5 \mathrm{mM}$, EDTA (Sigma) $5 \mathrm{mM}$ y PVP (Sigma) $1 \%$.

La incubación con el anticuerpo primario se realizó en un contenedor hermético con una base de papel absorbente humedecido a $7^{\circ} \mathrm{C}$ durante $24 \mathrm{~h}$, y se usaron los siguientes anticuerpos: a) Anticuerpo anti-peroxidasa de rábano producido en conejo (Sigma P7899) diluido 1:15 con amortiguador de fosfatos (J.T. Baker) $10 \mathrm{mM}(\mathrm{pH} 7.2)$, con $\mathrm{NaCl}$ (Sigma) $150 \mathrm{mM}$. b) Anticuerpo anti-superóxido dismutasa (Mn-SOD) producido en conejo (Sigma S5069) diluido 1:30 con amortiguador de fosfatos $10 \mathrm{mM}$ (pH 7.2) con $150 \mathrm{mM}$ de $\mathrm{NaCl}$ (Sigma). El anticuerpo primario no unido se eliminó mediante una serie de lavados consecutivos de 5 min cada uno con un amortiguador de fosfatos (J.T. Baker) $10 \mathrm{mM}$ (pH 7.2), con NaCl (Sigma) $150 \mathrm{mM}$.

Para la visualización de los complejos de unión específica de los anticuerpos primarios anti-peroxidasa y anti-superóxido dismutasa unidos a las enzimas peroxidasa y superóxido dismutasa respectivamente, se utilizó un segundo anticuerpo policlonal de cabra anti conejo unido al fluorocromo DyLight 555 (abcam 96896) diluido 1:50 en un amortiguador de fosfatos (J.T. Baker) $10 \mathrm{mM}$ (pH 7.2) con NaCl (Sigma) $150 \mathrm{mM}$. Las secciones histológicas se incubaron en la oscuridad durante $75 \min$ a $25^{\circ} \mathrm{C}$ con el segundo anticuerpo, posteriormente se realizaron 3 lavados de 5 min cada con un amortiguador de fosfatos (J.T. Baker) $10 \mathrm{mM}(\mathrm{pH}$ 7.2) para eliminar el segundo anticuerpo no unido. Las secciones histológicas fueron analizadas mediante un sistema 
de microscopia confocal espectral Carl Zeiss Microscopy System Model LSM 780 NLO empleando una longitud de onda de excitación a 561 nm y registrando la emisión entre $578-599 \mathrm{~nm}$.

6. Cuantificación de la actividad de peroxidasa en escutelos

Se obtuvieron embriones con 18, 24 o 36 h de imbibición como se indica en la sección 1. Para la obtención de extractos crudos para la cuantificación de actividad de POD se emplearon 4 escutelos por extracto, para lo cual sobre una cama de hielo se eliminaron los ejes embrionarios y se recuperaron los escutelos. Se descartó el uso de los ejes embrionarios, ya que se ha confirmado una alta presencia de actividad de peroxidasa (Liszkay et al., 2004).

Se registró el peso de los escutelos y posteriormente se procesaron con un homogeneizador de tejidos (Tissuemiser, Fisher Scientific) empleando $3 \mathrm{ml}$ de un amortiguador de fosfatos (J.T. Baker) $100 \mathrm{mM}(\mathrm{pH} \mathrm{6.8),} \mathrm{el} \mathrm{extracto} \mathrm{se} \mathrm{centrifugó} \mathrm{a}$ $10,000 \mathrm{~g}$ durante $30 \mathrm{~min}$ a $4^{\circ} \mathrm{C}$ (Sorvall RC-5, Dupont Instruments). El sobrenadante se recuperó y fue mantenido a $4^{\circ} \mathrm{C}$ hasta su análisis (García-Lara et al., 2007).

La actividad de POD se cuantificó en las siguientes mezclas de reacción empleando celdas de cuarzo: a) A una mezcla de reacción que contenía $440 \mu \mathrm{l}$ de un amortiguador de fosfatos (J.T. Baker) $50 \mathrm{mM}$ ( $\mathrm{pH} \mathrm{6.8),} 20 \mu \mathrm{l}$ de extracto enzimático y $440 \mu \mathrm{l}$ de solución de (+)-catequina (Sigma) $20 \mathrm{mM}$ como flavonoide modelo, se le agregaron $4 \mu \mathrm{l}$ de $\mathrm{H}_{2} \mathrm{O}_{2}$ (Sigma) al 3\% para iniciar la reacción; se registró la absorbancia cada minuto durante cinco minutos a $475 \mathrm{~nm}$; b) A $870 \mu \mathrm{l}$ de un amortiguador de fosfatos (J.T. Baker) $50 \mathrm{mM}(\mathrm{pH} \mathrm{6.8)} \mathrm{con} 10 \mu \mathrm{l}$ de extracto enzimático 
y $10 \mu \mathrm{l}$ de guayacol (Sigma) $1 \mathrm{M}$ se agregaron $9 \mu \mathrm{l}$ de $\mathrm{H}_{2} \mathrm{O}_{2}$ (Sigma) al 3\%; se registró la absorbancia cada $20 \mathrm{~s}$ durante 2 min a $475 \mathrm{~nm}$.

Para corroborar que la actividad enzimática cuantificada en el ensayo correspondía a la enzima peroxidasa, se agregaron a las mezclas de reacción $10 \mu \mathrm{l}$ de ácido salicilhidroxámico (SHAM; Sigma) 0.3 M, o $10 \mu \mathrm{l}$ de cianuro de potasio (KCN; J.T. Baker) $0.1 \mathrm{M}$ los cuales han sido reportados como inhibidores de peroxidasas (Liszkay et al., 2004). La cantidad de proteína en el extracto se cuantificó según el método de Lowry et al. (1951) usando albúmina sérica bovina (Sigma) como estándar; las determinaciones espectrofotométricas se realizaron en un equipo UV/VIS Spectrometer Lambda 2 (Perkin Elmer).

7. Cuantificación de la actividad de superóxido dismutasa en escutelos

Se obtuvieron embriones con 18, 24 o 36 h de imbibición como se indica en la sección 1. Sobre una cama de hielo se eliminaron los ejes embrionarios, posteriormente se pesaron los escutelos. Se emplearon 4 escutelos para la obtención del extracto crudo, para ello, los escutelos se homogenizaron en $3 \mathrm{ml}$ de amortiguador de fosfatos (J.T. Baker) $50 \mathrm{mM}(\mathrm{pH} 7.8)$, los extractos se centrifugaron a $15,000 \mathrm{~g}$ a $4{ }^{\circ} \mathrm{C}$ durante 40 min y recuperaron los sobrenadante que fueron mantenidos a $4^{\circ} \mathrm{C}$ hasta su uso.

La actividad de SOD se determinó mediante el método descrito por Giannopolitis y Ries (1977) que determina la eliminación de $\mathrm{O}_{2}{ }^{-}$por el extracto enzimático, y se realizó usando una mezcla de reacción con $5.8 \mathrm{mg}$ de metionina (Sigma), $2.88 \mathrm{ml}$ de amortiguador de fosfatos (J.T. Baker) $50 \mathrm{mM}(\mathrm{pH}$ 7.8), $10 \mu \mathrm{l}$ de NBT (Nitrotetrazolium Blue chloride; Sigma) $18.9 \mathrm{mM}, 10 \mu \mathrm{l}$ de riboflavina (Sigma) $0.39 \mathrm{mM}$, a la mezcla de 
reacción se le agregaron $100 \mu$ l extracto crudo para determinar la actividad en los tratamientos experimentales, o $100 \mu \mathrm{l}$ de amortiguador de fosfatos $50 \mathrm{mM} \mathrm{pH} 7.8$ para la obtención del valor de producción total de $\mathrm{O}_{2}{ }^{*}$. Las mezclas de reacción se incubaron en un refractario de vidrio (Pyrex) con agua a $25^{\circ} \mathrm{C}$ dentro de una caja de $0.034 \mathrm{~m}^{3}$ (38 $\mathrm{cm}$ de largo x $41 \mathrm{~cm}$ de alto x $22 \mathrm{~cm}$ de ancho), forrada de papel reflejante (Reynolds Wrap), e iluminados con una lámpara fluorescente Philips de 15W (760 Im, $54 \mathrm{~lm} / \mathrm{W}$, I=195 mA) durante 1, 2, 3, 5, 10 min y posteriormente se registró su absorbancia a 560 nm para cada tiempo establecido. Para ajustar el espectrofotómetro a una absorbancia de 0 , se empleó la misma mezcla de reacción sin extracto que fue mantenida en oscuridad durante el mismo tiempo de incubación. Una unidad de SOD se define como la actividad que produce un $50 \%$ de la inhibición máxima en la reducción de NBT (Giannopolitis y Ries, 1977).

8. Cuantificación de compuestos oxidorreductores extruidos desde la superficie del escutelo

8.1 Cuantificación del poder reductor extruido: Reducción de XTT por equivalentes de $\mathrm{O}_{2}^{-}$

La capacidad de reducir al tetrazolio XTT (2,3-Bis (2-methoxy-4-nitro-5sulfophenyl)-2H-tetrazolium-5-carboxanilide inner salt; Sigma) se determinó en escutelos de embriones con 18, 24 y 36 h de imbibición obtenidos como se indica en la sección 1. Los embriones se depositaron en una caja de cultivo Costar de 6 pozos orientando la superficie abaxial del escutelo hacia el fondo del pozo; los embriones se incubaron con $1 \mathrm{ml}$ de solución de XTT (Sigma) $500 \mu \mathrm{M}$ (Liszkay et al., 2004) disuelto 
en un amortiguador de citrato de potasio (Sigma) $10 \mathrm{mM}$ (pH 7.4; Sagi y Fluhr, 2001), durante $1 \mathrm{~h}$ en la oscuridad. Transcurrido el tiempo de incubación se recuperó la solución y se registró su absorbancia a $470 \mathrm{~nm}$. Como blanco de lectura se ocupó $1 \mathrm{ml}$ de la misma solución pero que no estuvo en contacto con los embriones.

Para determinar el efecto del NADPH, NADH y $\mathrm{CuCl}_{2}$, se trató a los embriones como se describe en el párrafo anterior, pero a la solución de XTT (Sigma) $500 \mu \mathrm{M}$ en amortiguador de citrato de potasio (Sigma) $10 \mathrm{mM}, \mathrm{pH} 7.4$ se agregó uno de los siguientes reactivos: NADH (Sigma) $200 \mu \mathrm{M}, \mathrm{NADPH}$ (Sigma) $200 \mu \mathrm{M}, \mathrm{CuCl}_{2}$ (Sigma) $50 \mu \mathrm{M}, \mathrm{NADH} 200 \mu \mathrm{M}$ con $\mathrm{CuCl}_{2} 50 \mu \mathrm{M}$ o NADPH $200 \mu \mathrm{M}$ con $\mathrm{CuCl}_{2} 50 \mu \mathrm{M}$. Después de que la solución estuvo en contacto con la cara abaxial de los escutelos se recuperó y se registró su absorbancia a 470 nm; como blanco se utilizó $1 \mathrm{ml}$ de la misma solución pero que no estuvo en contacto con los embriones. Los equivalentes reductores se calcularon empleando el coeficiente de extinción molar del XTT $\left(\varepsilon_{\mathrm{XTT}}=2.16 \mathrm{X} 104 \mathrm{M}^{-1} \mathrm{~s}^{-1}\right)$ reportado por Sutherland y Learmonth (1997).

\subsection{Cuantificación de $\mathrm{H}_{2} \mathrm{O}_{2}$ por permanganometría}

Para cuantificar el $\mathrm{H}_{2} \mathrm{O}_{2}$ desprendido desde la superficie de los escutelos se utilizó la técnica de titulación por permanganometría descrita por Trasar-Cepeda et al. (2003) con ligeras modificaciones. Se emplearon cuatro embriones con 18, 24 o $36 \mathrm{~h}$ de imbibición obtenidos como se indica en la sección 1, se depositaron orientando su superficie abaxial hacia el fondo de una caja de cultivo Costar de 6 pozos, los embriones se incubaron con $1 \mathrm{ml}$ de agua desionizada estéril durante $10 \mathrm{~min}$. Se preparó una mezcla de reacción con $500 \mu$ del agua desionizada que estuvo en contacto con los embriones, 400 de $\mu \mathrm{l}$ de agua desionizada estéril y $100 \mu \mathrm{l}$ de $\mathrm{H}_{2} \mathrm{SO}_{4}$ (J.T. Baker) $1.5 \mathrm{M}$, la mezcla se resuspendió por agitación y se tituló con alícuotas de 
$\mathrm{KMnO}_{4} 0.01 \mathrm{M}$ hasta completar un volumen final de la mezcla de reacción de $1.25 \mathrm{ml}$; en cada adición de $\mathrm{KMnO}_{4}$ se registró la absorbancia de la mezcla de reacción.

Para calcular la cantidad de $\mathrm{H}_{2} \mathrm{O}_{2}$ desprendido desde la superficie de los escutelos se graficó el volumen de $\mathrm{KMnO}_{4}$ añadido y el cambio en el registro de absorbancia en las ordenadas y abscisas respetivamente. Las gráficas presentaron un comportamiento bifásico, de modo que cuando se agregaron los primeros volúmenes de $\mathrm{KMnO}_{4}$ la recta presentó una pendiente cercana a cero; esto indica que el $\mathrm{H}_{2} \mathrm{O}_{2}$ de la muestra reacciona con el $\mathrm{KMnO}_{4}$ eliminando el color de éste por lo cual no se detectan cambios espectrofotométricos. Cuando todo el $\mathrm{H}_{2} \mathrm{O}_{2}$ presente en la mezcla reacciona con el $\mathrm{KMnO}_{4}$ añadido, se genera un punto de inflexión a partir del cual comienza a aumentar la absorbancia producto de la acumulación paulatina de $\mathrm{KMnO}_{4}$ libre, a partir de este punto de inflexión se obtiene una recta con pendiente ascendente. Posteriormente se calculó el volumen de $\mathrm{KMnO}_{4}$ que genera la inflexión, este volumen se transformó en moles de $\mathrm{KMnO}_{4}$ y mediante la estequiometria de la reacción entre el $\mathrm{H}_{2} \mathrm{O}_{2}$ y $\mathrm{KMnO}_{4}\left(5 \mathrm{H}_{2} \mathrm{O}_{2}+2 \mathrm{MnO}_{4}+6 \mathrm{H}^{+} \rightarrow 5 \mathrm{O}_{2}+2 \mathrm{Mn}^{++}+8 \mathrm{H}_{2} \mathrm{O}\right)$ se obtuvo los $\mu$ mol de $\mathrm{H}_{2} \mathrm{O}_{2}$ presentes en la muestra.

Para determinar la sensibilidad de la técnica se titularon por triplicado las mezclas de reacción descritas en la Tabla 2. Se graficaron y se compararon las concentraciones conocidas de $\mathrm{H}_{2} \mathrm{O}_{2}$ contra las concentraciones de $\mathrm{H}_{2} \mathrm{O}_{2}$ determinadas experimentalmente. 
Tabla 2. Mezclas de reacción para determinar sensibilidad de la técnica de cuantificación de $\mathrm{H}_{2} \mathrm{O}_{2}$ por permanganometría

\begin{tabular}{|c|c|c|}
\hline $\begin{array}{c}\mu \mathrm{mol} \mathrm{H}_{2} \mathrm{O}_{2} \\
\text { (conocidos) }\end{array}$ & $\begin{array}{c}\mu \mathrm{l} \text { agua } \\
\text { desionizada }\end{array}$ & $\mu \mathrm{H}_{2} \mathrm{SO}_{4} 1.5 \mathrm{M}$ \\
\hline 0.044 & 895 & 100 \\
\hline 0.088 & 890 & 100 \\
\hline 0.164 & 880 & 100 \\
\hline 0.441 & 850 & 100 \\
\hline 0.661 & 825 & 100 \\
\hline 0.882 & 800 & 100 \\
\hline 1.323 & 750 & 100 \\
\hline 1.764 & 700 & 100 \\
\hline 2.20 & 650 & 100 \\
\hline 2.64 & 600 & 100 \\
\hline
\end{tabular}

\subsection{Liberación de fenoles cuantificada por la reducción de ferricianuro}

Los embriones obtenidos después de su imbibición durante 18, 24 y 36 h como se indica en la sección 1, se depositaron en una placa de cultivo de 6 pozos (Costar) orientando la cara abaxial del escutelo hacia el fondo del pozo. En esta posición los embriones se incubaron con $1 \mathrm{ml}$ de agua destilada durante 10 min evitando que la radícula entrara en contacto con el agua. Se recuperaron alícuotas de $100 \mu \mathrm{l}$ a las que se les agregó $900 \mu \mathrm{l}$ de agua destilada y $60 \mu \mathrm{l}$ de $\mathrm{FeCl}_{3}$ (Sigma) $0.1 \mathrm{M}$ en $\mathrm{HCl}$ (J.T. Baker) $0.1 \mathrm{~N}$. Después de mezclar se agregaron $60 \mu \mathrm{l}$ de $\mathrm{K}_{3} \mathrm{Fe}(\mathrm{CN})_{6}$ (J.T. Baker) 0.008 M disuelto en $\mathrm{HCl}$ (J.T. Baker) 0.1 N. La mezcla se agitó, y se dejó incubar durante 10 min a temperatura ambiente. Finalmente se registró la absorbancia de la mezcla a 720 nm y los resultados se interpolaron en una curva estándar de ácido gálico (Sigma; Price y Butler, 1977; Thoss et al., 2002). 


\subsection{Solutos con capacidad de reducir al XTT}

Para determinar la contribución de otros agentes reductores in vitro en la reducción del XTT, uno de los siguientes reactivos fueron agregados a $1 \mathrm{ml}$ solución XTT (Sigma) $500 \mu \mathrm{M}$ en un amortiguador de citratos (Sigma) $10 \mathrm{mM}(\mathrm{pH}$ 7.4): NADH (Sigma) $200 \mu \mathrm{M}$, NADPH (Sigma) $200 \mu \mathrm{M}$, ácido ascórbico (Sigma) $50 \mathrm{mM}$, (+)-catequina (Sigma) $5 \mathrm{mM}, \mathrm{CuCl}_{2}$ (Sigma) $50 \mu \mathrm{M}$ o ácido gálico (Sigma) $7.8 \mathrm{mM}$. Se registró la absorbancia a $470 \mathrm{~nm}$ después de 5 y 60 min de incubación con el correspondiente agente reductor a temperatura ambiente y en la oscuridad. Los equivalentes reductores se determinaron restando la absorbancia final e inicial y empleando el coeficiente de extinción molar del XTT $\left(\varepsilon_{X T T}=2.16 X 104 \mathrm{M}^{-1} \mathrm{~s}^{-1}\right)$, según lo reportado por Sutherland y Learmonth (1997).

9. Efecto del almacenamiento en la actividad de peroxidasa, vigor y emisión de compuestos endógenos

\subsection{Condiciones de almacenamiento controlado}

Granos de maíz fueron almacenados en contenedores herméticos bajo las siguientes condiciones controladas: a) $40 \%$ de humedad relativa $(\mathrm{HR})$ y $7^{\circ} \mathrm{C}$ en un refrigerador con un sistema de control de humedad integrado (Acros, ART07N). b) $7^{\circ} \mathrm{C}$ en un contenedor hermético con una HR de $88 \%$ generada con una solución de benzoato de sodio al $10 \%$ (Rockland, 1960 ). c) $25^{\circ} \mathrm{C}$ en un contenedor hermético con una HR de $88 \%$ generada de la misma manera que en b). 
9.2 Cuantificación de actividad de peroxidasa en escutelos de granos almacenados en condiciones controladas

Cada 30 días se tomó una muestra de 4 granos de cada una de las tres condiciones de almacenamiento descritas en 9.1 (se realizaron de 3 a 12 réplicas por ensayo). Los embriones se disectaron manualmente, posteriormente se desinfectaron, enjuagaron y embebieron durante $24 \mathrm{~h}$ como se indica en la sección 1 . Después de completar el tiempo de imbibición se registró el porcentaje de germinación y finalmente se recuperaron los escutelos para la obtención de extractos enzimáticos y así cuantificar la actividad de POD siguiendo lo descrito en la sección 6.

\subsection{Ensayos de vigor en granos almacenados en condiciones controladas}

Para determinar el vigor de los granos de maíz almacenados en condiciones controladas, se tomaron muestras después de 22 meses de almacenamiento; los granos fueron desinfectados como se especifica en la sección 1 y posteriormente fueron embebidos durante $12 \mathrm{~h}$ bajo las condiciones referidas en la sección 1 . El vigor se determinó mediante la técnica descrita por DeVries y Goggi (2006) con ligeras modificaciones. Después de las 12 h de imbibición cada grano se disectó longitudinalmente, se escogió una mitad que fue incubada en agua destilada por 10 min, posteriormente el agua fue remplazada con una solución al $0.1 \%$ de MTT (Thiazolyl Blue Tetrazolium Bromide; Sigma). Los granos se incubaron en la solución de MTT durante 70 min a temperatura ambiente, posteriormente se eliminó la solución y los granos fueron enjuagados con abundante agua destilada. Finalmente, se escanearon los granos teñidos para obtener imágenes digitales. La categoría del vigor basada en los patrones de tinción, se determinó según los parámetros descritos por DeVries y Goggi (2006). 
9.4 Cambio en la autofluorescencia de compuestos endógenos de escutelos de granos almacenados en condiciones controladas

Para determinar si el almacenamiento en condiciones controladas generaba un efecto sobre la autofluorescencia de compuestos del escutelo, primero se evaluó la autofluorescencia del escutelo en granos no almacenados, para esto se disectaron embriones de granos maduros, se fijaron en etanol (Sigma) $70 \%$ a temperatura ambiente durante $24 \mathrm{~h}$, posteriormente se deshidrataron, infiltraron e incluyeron con Paraplast (Sigma). Se obtuvieron secciones histológicas de $8 \mu \mathrm{m}$ que fueron montadas en portaobjetos cubiertos con gelatina. Se eliminó el Paraplast (Sigma) de las secciones histológicas y éstas se montaron en medio acuoso a pH 7.0; se registró la emisión del tejido en el espectro visible mediante el sistema de microscopia confocal espectral Carl Zeiss (Microscopy System Model LSM 780 NLO) usando las siguientes longitudes de excitación 405, 458, 488, 514, 561 o 633 nm.

La autofluorescencia del escutelo también se determinó en embriones de granos almacenados en las condiciones controladas descritas en la sección 9.1. Al mes 1 y 9 de almacenamiento se colectaron muestras a partir de las cuales se disectaron embriones que fueron desinfectados y embebidos durante $24 \mathrm{~h}$ como se especifica en la sección 1. A las 24 h de imbibición los embriones se fijaron en etanol al (Sigma) 70\% durante $24 \mathrm{~h}$ a temperatura ambiente y posteriormente se deshidrataron y se infiltraron en Paraplast (Sigma); se obtuvieron secciones de $8 \mu \mathrm{m}$ montadas en portaobjetos cubiertos con gelatina. El paraplast fue removido de las secciones histológicas y éstas fueron hidratadas y posteriormente incubadas con una dilución 1:1000 de una solución de yoduro de propidio ( $1 \mathrm{mg} / \mathrm{ml}$; Sigma) para la localización de núcleos (Ruzin, 1999). Las secciones histológicas se montaron en medio acuoso y fueron analizadas en un 
sistema de microscopia confocal espectral Carl Zeiss (Microscopy System Model LSM 780 NLO) usando tres canales independientes, dos para autofluorescencia y el tercero para la localización de núcleos; se usaron los siguientes parámetros: a) Excitación a 405 nm y emisión a 410-516 nm; b) Excitación a 488 nm y emisión a 490-560nm; c) Excitación a 561 nm y emisión a 566-685nm.

10. Análisis estadístico

Los resultados cuantitativos se expresan como la media \pm desviación estándar de 3 a 12 ensayos independientes por duplicado. Se realizó un análisis de varianza (ANOVA) seguido de una comparación múltiple de Tukey-Kramer empleando un nivel de significancia de $p<0.05$. Las pruebas estadísticas se realizaron con el programa NCSS \& PASS 2000 (Jerry Hintze, Estados Unidos de América). 


\section{RESULTADOS}

1. Composición química de la capa fibrosa

El embrión de un grano maduro de maíz Chalqueño consta de un eje embrionario y un escutelo que lo rodea; el escutelo está constituido por varios tipos celulares: El mayor volumen de la estructura está representado por células del parénquima, que son poliédricas, isodiamétricas y de mayor tamaño que las células epidérmicas que delimitan al órgano. La epidermis consta de una capa monoestratificada de células, fácilmente diferenciables por su forma cuboidal. Envolviendo al escutelo, en íntimo contacto con las células epidérmicas y generando una frontera con el endospermo almidonoso, se localiza la capa fibrosa (Fig. 2a-c).

Las células epidérmicas (epi), las del parénquima del escutelo (cp) y los remanentes del endospermo almidonoso (eca), mostraron una intensa tinción roja cuando se aplicaron las técnicas de Aceite Rojo O (Fig. 2a) y Sudan IV (Fig. 2b), lo cual indicó la presencia de lípidos, consistente con la función de almacenamiento reportada para el escutelo (Szcziparev, 2006; Tan y Morison, 1979) y el endospermo (Singh et al. 2014). Con menor intensidad fue posible detectar lípidos en la capa fibrosa (cf), posiblemente como componentes estructurales. 


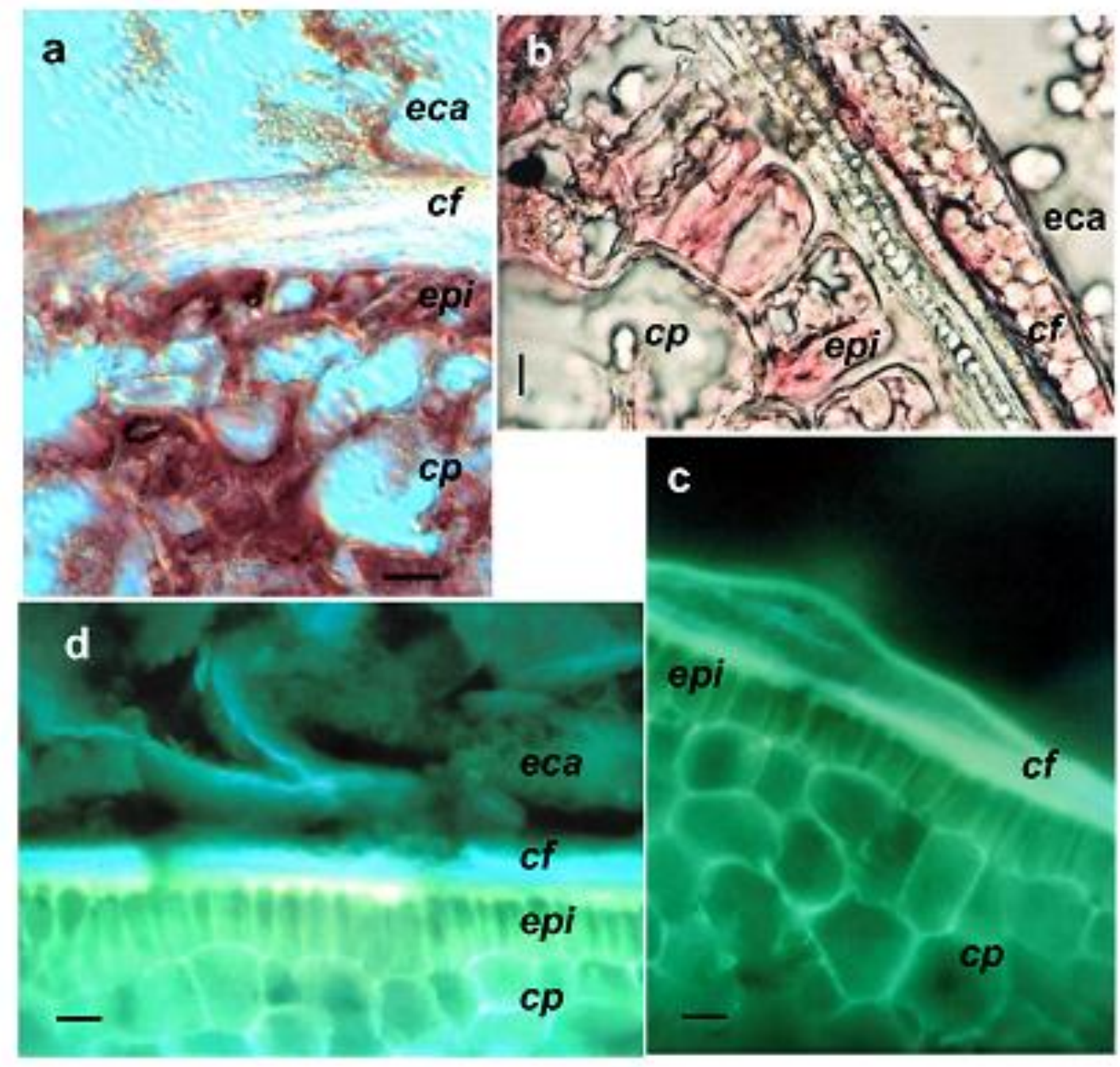

Figura 2. Composición química de la capa fibrosa.

a) Localización de lípidos usando Aceite Rojo-O; b) Localización de lípidos usando Sudan IV; c) Fluorescencia de compuestos fenólicos incrementada con ácido difenilborínico; d) Detección de polímeros tipo calosa con enlaces $\beta-1,3$ usando azul de anilina. Abreviaturas: $c f$, capa fibrosa; $c p$, células del parénquima; eca, endospermo central almidonoso; epi: células epidérmicas. Barra de escala a-d, $50 \mu \mathrm{m}$. 
La capa fibrosa (cf) presentó una gran cantidad de compuestos fenólicos detectados mediante su fluorescencia incrementada con el ácido difenilborínico (Fig. 2c). La reacción indica que también existen fenoles ampliamente distribuidos en las paredes de las células parenquimatosas (cp) y epidérmicas del escutelo (epi).

La aplicación de azul de anilina (Fig. 2d), usado para la detección de polímeros con enlaces $\beta-1,3$ tipo calosa, reveló la existencia de una fluorescencia azul brillante en la capa fibrosa (cf), que contrasta con la fluorescencia blanca de las células epidérmicas (epi) y parenquimatosas del escutelo (cp).

\section{Permeabilidad de la capa fibrosa}

Los cortes longitudinales de granos de maíz Chalqueño maduros y deshidratados, mostraron que en condiciones nativas el pericarpio posee una coloración amarilla, el endospermo presenta un color blanco y el escutelo-eje embrionario es de color amarillo pálido (Fig. 3a). El registro de estos colores permitió contrastar las regiones que se tiñen con el colorante acuoso $\left(\mathrm{I}_{2}-\mathrm{KI}\right)$ y etanólico (verde brillante) usados en las pruebas de difusión a través de la capa fibrosa.

La interacción del colorante acuoso $\mathrm{I}_{2}-\mathrm{KI}$ con los componentes del grano de maíz permitió que éstos desarrollaran una tinción de color café oscuro (Fig. 3b-e), se encontró que los granos sin perforación presentaron una tinción externa en el pericarpio; sin embargo, el colorante no penetró, por ello, ni el endospermo ni el embrión cambiaron de color (Fig. 3b). Cuando el grano fue perforado desde el embrión y se perforó la capa fibrosa, el colorante difundió libremente entre ambas estructuras tiñendo tanto al embrión como al endospermo, y externamente al pericarpio (Fig. 3c). 
Cuando se perforó el embrión, el $\mathrm{I}_{2}$-KI tiñó únicamente al embrión y externamente al pericarpio, sin embargo, el endospermo se mantuvo con su color blanco original (Fig. 3d). La perforación desde el endospermo permitió que éste se tiñera tenuemente, mientras que el embrión conservó su color original (Fig. 3e). La velocidad de difusión del $\mathrm{I}_{2}-\mathrm{KI}$ en el endospermo fue más lenta que en el embrión, lo cual indica la existencia de un índice menor de difusión; sin embargo, cuando el colorante entró en contacto con la capa fibrosa difundió preferentemente rodeándola a través del endospermo sin penetrar hacia el embrión indicando la existencia de una barrera a la difusión entre ambas estructuras (Fig. 3e).

El patrón de difusión del colorante etanólico verde brillante fue similar al encontrado con $\mathrm{I}_{2}-\mathrm{KI}$, tiñendo de color verde las estructuras con las que entró en contacto, de modo que: en los granos, cuyo embrión fue perforado sin generar daño en la capa fibrosa, el embrión se tiñó mientras que el endospermo no cambió de color (Fig. 3f). Cuando la perforación se realizó en el endospermo y la capa fibrosa se mantuvo íntegra, sólo el endospermo se tiñó y el embrión permaneció con su color original (Fig. 3g). Cuando los granos fueron perforados desde el endospermo y después fueron tratados con acetona (Fig. 3h) o cloroformo (Fig. 3i), o bien si los granos fueron perforados desde el embrión y después tratados con una mezcla acetona-cloroformo (Fig. 3j), se encontró una libre difusión del verde brillante entre ambas estructuras de manera independiente al sitio de perforación. 


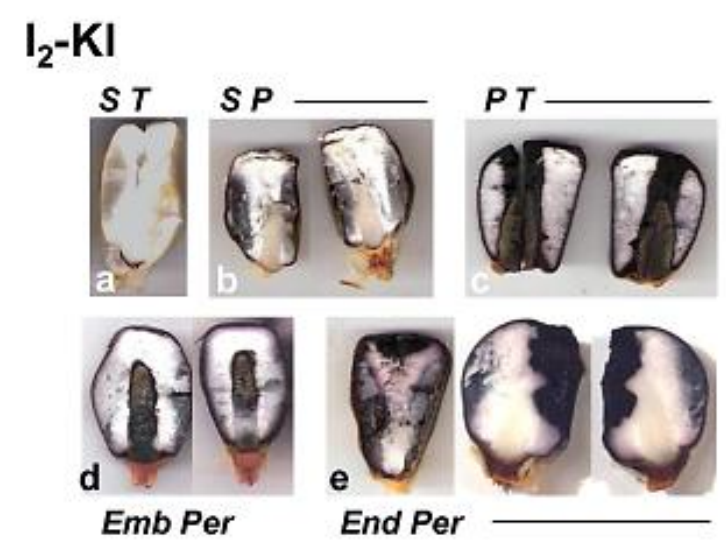

\section{Verde Brillante}
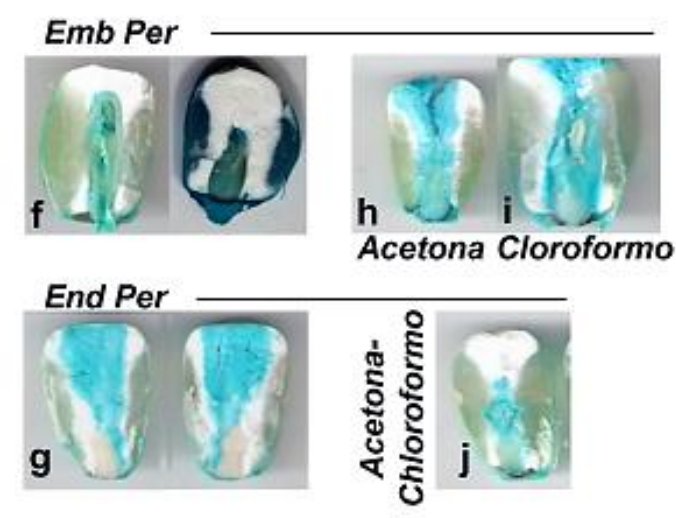

Figura 3. Pruebas de difusión y permeabilidad de la capa fibrosa.

Granos de maíz maduros se perforaron por el lado del embrión o del endospermo y después se evaluó la difusión de colorantes; a) Granos sin tinción; b-e) Difusión de $\left.\mathrm{I}_{2}-\mathrm{KI}, \mathbf{f}-\mathrm{j}\right)$ Difusión de verde brillante; b) Grano sin perforaciones; c) Grano perforado a través de ambas estructuras; d y f) Perforación por el endospermo; h-i) Granos perforados por el endospermo y tratados con: h) Acetona; i) Cloroformo; j) Granos perforados por el embrión y tratados con mezcla de acetona-cloroformo. Abreviaturas: $S T$, sin tinción; SP, sin perforación; PT, perforación total; Emb Per, perforación desde el embrión; End Per, perforación desde el endospermo. 
Estos resultados muestran que: 1) La integridad de la capa fibrosa previene la libre difusión de colorantes acuosos o etanólicos más allá de la estructura por donde fueron administrados. 2) El etanol, solvente del verde brillante, no alteró la estructura de la capa fibrosa durante el tiempo que fue administrado; 3) Los tratamientos con acetona, cloroformo o la mezcla acetona-cloroformo, permitieron la remoción de ciertos componentes no polares presentes en la capa fibrosa, lo cual favoreció la difusión del verde brillante entre ambas estructuras.

3. Transformaciones morfológicas de la epidermis del escutelo y pérdida de la integridad de la capa fibrosa

Después de $24 \mathrm{~h}$ de imbibición, algunas regiones de la epidermis del escutelo adyacentes a la capa fibrosa (Fig. 4a, flechas) permanecieron con su arreglo monoestratificado; mientras que otras células presentaron su polo basal ensanchado (Fig. 4a, puntas de flechas). En otras regiones, la epidermis perdió su arreglo regular monoestratificado (Fig. 4b) al mismo tiempo que las células acumularon in situ actividad de POD con un notable incremento de tinción hacia su región apical (Fig. 4c-e). Algunas de estas células se alargaron (Fig. $\mathbf{4 b}, \mathbf{4 g}$, puntas de flechas) y adquirieron la denominada forma de dedo descrita en Tnani et al. (2011); algunas otras células epidérmicas perforaron sus paredes (Fig. 4f, puntas de flechas). Estas perforaciones permitieron la extrusión del contenido celular hacia el espacio apoplástico entre la epidermis y la capa fibrosa (Fig. $\mathbf{4 g}, \mathbf{4 h}$, puntas de flechas). Los extruidos desarrollaron una tinción roja-café al reaccionar con $A E C$, indicando la presencia de actividad de peroxidasa (Fig. 4i, puntas de flechas). 
La epidermis del escutelo adyacente al endospermo almidonoso mostró la mayor actividad de POD (Fig. 4j) y parte de esa actividad fue extruida al espacio apoplástico (Fig. 4h-i, estrellas), lo cual pudo ser confirmado mediante tinciones con AEC o con guayacol en el soporte del germinador (Fig. 4k).

Una recapitulación de las modificaciones observadas en las células epidérmicas después de 24 h de imbibición se muestra en la Fig. 4I; la última fotografía de la serie corresponde a una célula alargada que se extiende hacia el endospermo encontrada después de 36 h de imbibición; este tipo de células se denominan papiladas y han sido descritas por Szcziparev (2006) para un epitelio funcional.

Se observó que las modificaciones tisulares descritas anteriormente ocurren de manera asincrónica en el tiempo y en el espacio sobre la superficie epidérmica del escutelo, y se relacionan con la transformación estructural de la capa fibrosa; de esta manera fue posible describir tres regiones con diferentes etapas del proceso: se visualizó una región con una epidermis (epi) monoestratificada con una capa fibrosa (cf) íntegra y bien estructurada (Fig. 4ma), seguida de una región epidérmica (epi) con células modificadas con una capa fibrosa (cf) alterada y poco estructurada (Fig. 4mb), finalizando con la presencia de una epidermis secretora con una capa fibrosa (cf) totalmente desarreglada (Fig. 4mc). El resultado final de estas modificaciones estructurales puede generar una permeabilidad que hace accesible el flujo de sustancias a través de lo que previamente representaba una barrera (Fig. 4a, flechas vs 4g-h). 


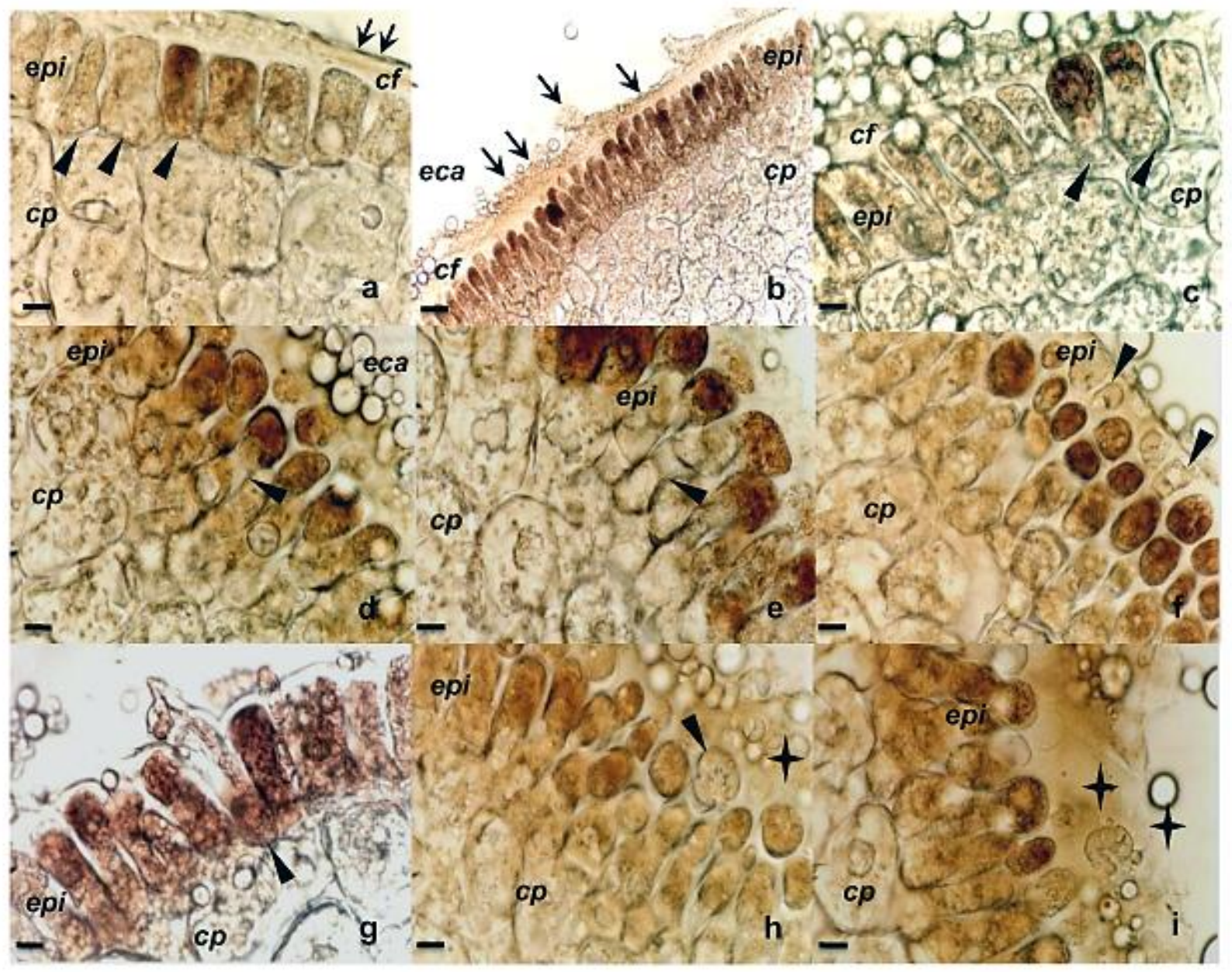

Figura 4. Transformación de la epidermis del escutelo a las 24 horas de imbibición.

a-j) Actividad in situ de la peroxidasa (tinción $\mathrm{AEC}+\mathrm{H}_{2} \mathrm{O}_{2}$ ); $\mathbf{a}$-b) Vista de la epidermis y el parénquima del escutelo; c-i) Modificaciones de la epidermis, presencia de la actividad de la peroxidasa en el apoplasto, alteración regional de la capa fibrosa. Continúa en la siguiente página. 


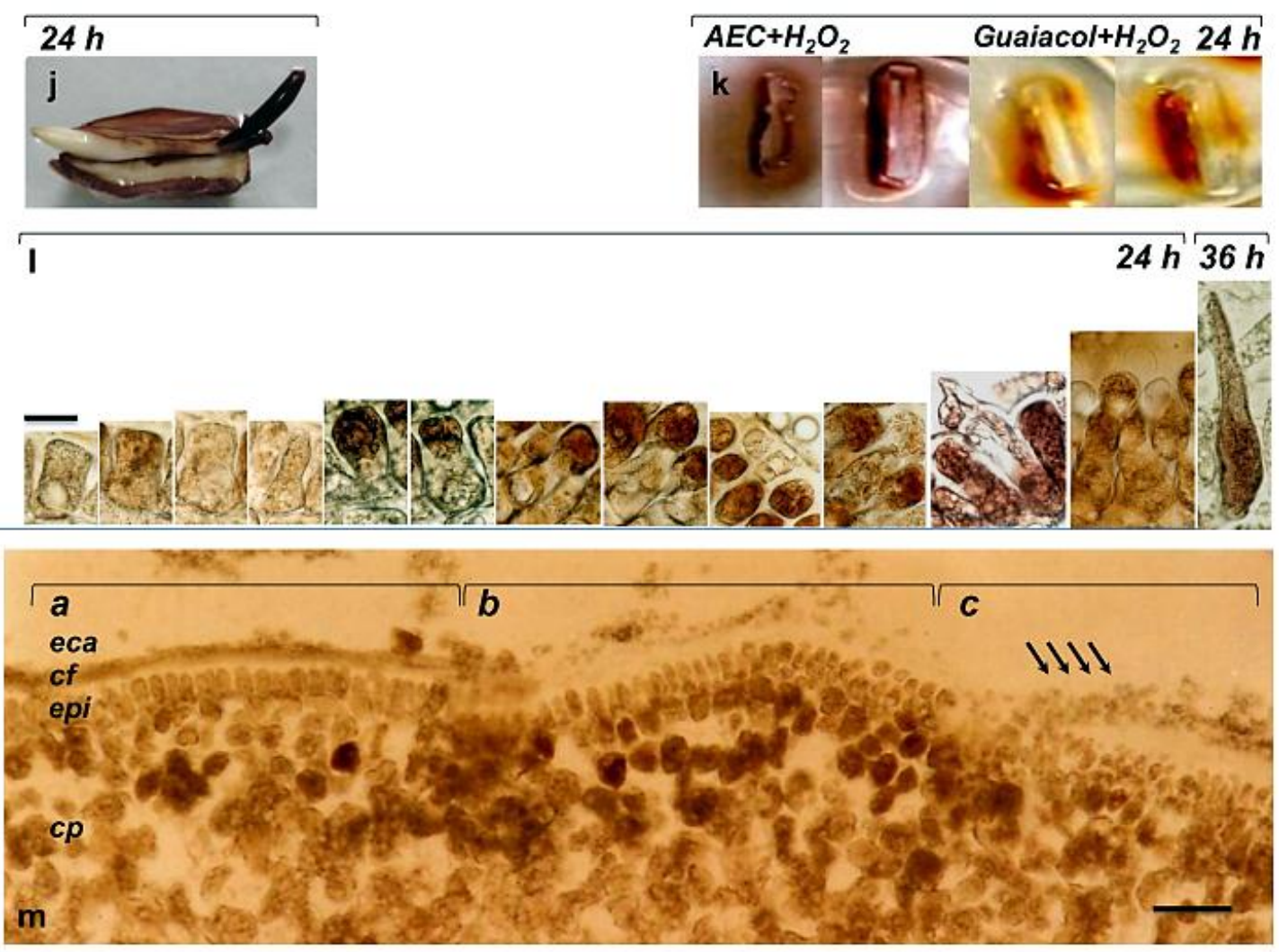

Figura 4. Continuación; j) Actividad de la peroxidasa en el embrión; k) Actividad de la peroxidasa extruida desde el embrión hacia el germinador a las $24 \mathrm{~h}$ de imbibición; I) Recapitulación de la morfología de las células epidérmicas, la última figura de la serie corresponde a una célula papilada detectada a las 36 h de imbibición; m) Superficie del escutelo donde se observan tres regiones que demuestran la asincronía del proceso de transformación de la epidermis y capa fibrosa (tinción AEC sin $\mathrm{H}_{2} \mathrm{O}_{2}$ que muestra los sitios de producción endógena de $\mathrm{H}_{2} \mathrm{O}_{2}$ ). Abreviaturas: epi, células epidérmicas; cf, capa fibrosa; $c p$, células del parénquima; eca, endospermo central almidonoso. Símbolos: $\boldsymbol{\Lambda}$, células epidérmica en proceso de transformación; $\uparrow$, cambios estructurales en la capa fibrosa; +, actividad apoplástica de peroxidasa. Barra: a, c-j) $50 \mu \mathrm{m}$; k) $500 \mu \mathrm{m}$. 
4. Inmunolocalización de peroxidasa y superóxido dismutasa

La presencia y acumulación de la actividad de peroxidasa en las regiones de la epidermis del escutelo cercanas a los sitios de modificación estructural de la capa fibrosa, sugieren que en estas regiones del tejido se producen ERO. En virtud del potencial dañino de estas especies químicas, el escutelo debe presentar actividad antioxidante, de la cual se evaluó la presencia de las principales enzimas antioxidantes, SOD y POD, mediante inmunolocalización.

La detección de los complejos enzima (SOD o POD)-anticuerpo primario (anti POD o anti SOD)-anticuerpo secundario, se realizó al excitar el fluoróforo acoplado al anticuerpo secundario con una longitud de onda de $561 \mathrm{~nm}$, y registrando su emisión entre 578-599 nm mediante el uso de un sistema de microscopía confocal. La emisión detectada fue transformada a un seudocolor amarillo durante la localización de peroxidasa o bien a un seudocolor anaranjado para distinguir la localización de la SOD.

Se detectó POD principalmente en la periferia de las células epidérmicas (epi) (Fig. 5a, flechas) aunque la presencia de la enzima fue abundante en las células parenquimatosas del escutelo (cp) dentro de pequeñas vacuolas (Fig. 5b, flechas). La enzima también se encontró en la región de la capa fibrosa (cf) próxima al endospermo almidonoso (eca), corroborando que a las 24 h de iniciada la imbibición, la ubicación de la enzima POD estába vinculada con las regiones de la epidermis del escutelo (epi) y de la capa fibrosa (cf) pierde su estructura uniforme y compacta.

La enzima Mn-SOD se detectó ampliamente distribuida en la región citoplasmática de las células del parénquima (cp) del escutelo (Fig. $\mathbf{5 d}$, flechas); en la epidermis (epi), la localización de SOD se detectó en menor proporción comparada con 
la registrada en el parénquima (cp) pero igualmente distribuida en todo el citoplasma (Fig. 5c, flechas).
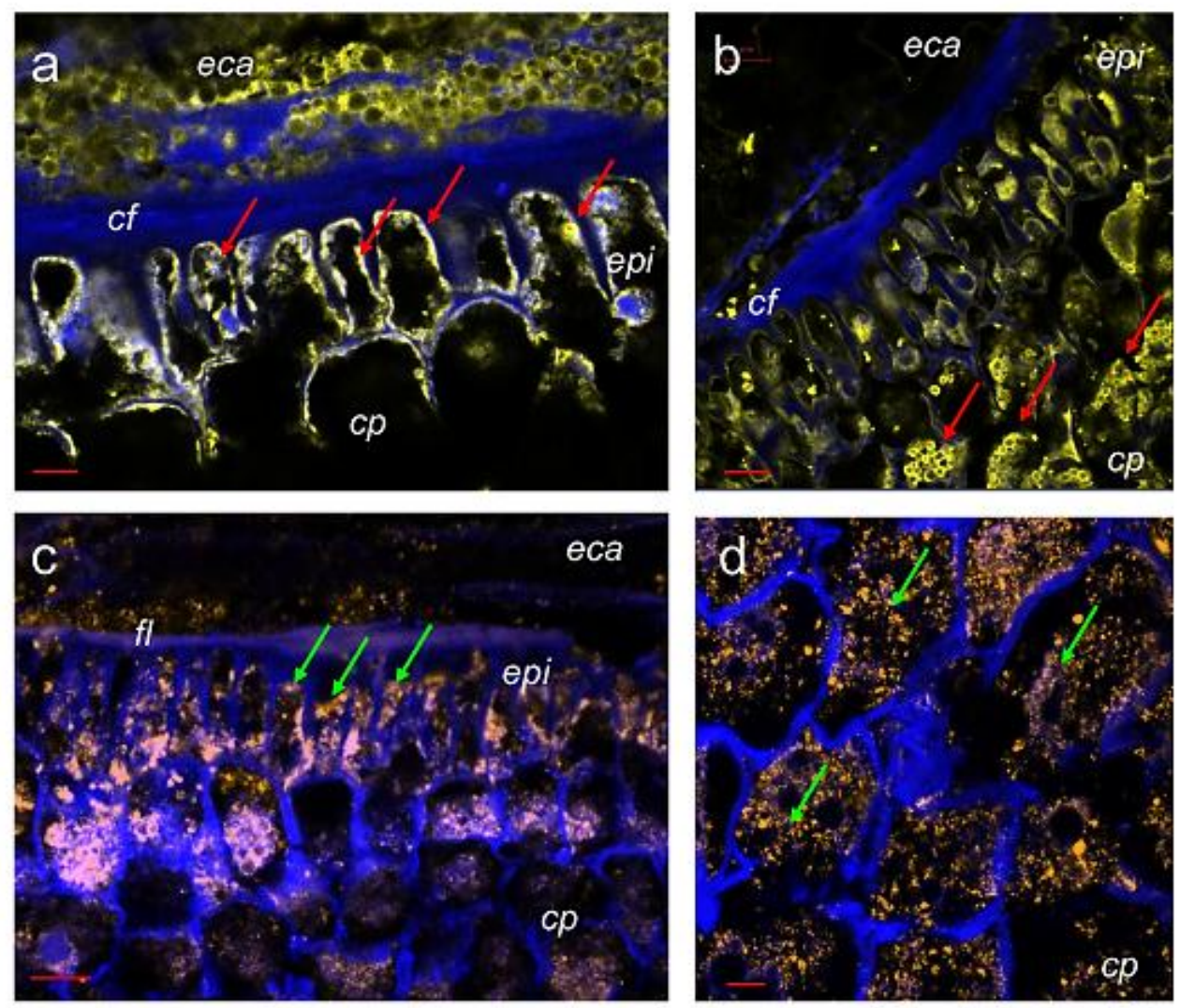

Figura 5. Inmunolocalización de peroxidasa y superóxido dismutasa en escutelos con 24 h de imbibición.

a-b) Localización mediante la asignación de un seudocolor amarillo a la POD presente en las células epidérmicas y del parénquima del escutelo; c-d) Localización mediante la asignación de un seudocolor anaranjado a la Mn-SOD detectada en la epidermis y parénquima del escutelo. Abreviaturas: epi, células epidérmicas; $c f$, capa fibrosa; $c p$, células del parénquima; eca, endospermo central almidonoso. Símbolos: $\downarrow$ principales sitios de inmunodetección de POD o SOD. Barra: a, b, d: $10 \mu \mathrm{m}$; c: $20 \mu \mathrm{m}$. 
Estos resultados sugieren que: 1) El parénquima del escutelo es muy activo metabólicamente, por lo cual requiere de la participación de POD y SOD que son enzimas consideradas como antioxidantes. 2) La epidermis del escutelo con $24 \mathrm{~h}$ de imbibición presenta proporcionalmente mayor cantidad de POD, localizada en la periferia de las células y en vesículas citoplasmáticas, mientras que la Mn-SOD se encuentra en menor proporción y está distribuida en todo el citoplasma.

5. Cuantificación de la actividad de la peroxidasa y superóxido dismutasa en escutelos

Toda vez que se comprobó la presencia de las enzimas POD y SOD en la epidermis y el parénquima del escutelo, se decidió cuantificar su actividad durante la transición de la germinación a la postgerminación temprana para correlacionar la localización de las enzimas con su actividad en el escutelo.

Para cuantificar la actividad de la peroxidasa se empleó guayacol, que es el sustrato con el que tradicionalmente se cuantifican las POD clase III; también se cuantificó la actividad con catequina como un flavonoide modelo. Los resultados obtenidos indican que a las $24 \mathrm{~h}$ de iniciada la imbibición, cuando se empleó catequina - guayacol como sustratos, la actividad de POD se incrementó 30 y $22 \%$ respectivamente, con respecto a la actividad registrada a las $18 \mathrm{~h}$ (Fig. 6a, 6c). El aumento en la actividad fue estadísticamente significativo a las $36 \mathrm{~h}$ que corresponde a un aumento de $282 \%$ con catequina y $92 \%$ con guayacol, con respecto a la actividad registrada a las 24 h (Fig. 6a, 6c). La proporción en la actividad de la POD cuantificada con catequina y guayacol implica un aumento proporcional de 8.9 veces a las $18 \mathrm{~h}, 8.3$ 
veces a las $24 \mathrm{~h}$ y únicamente 4.1 veces a las $36 \mathrm{~h}$; esto indica un incremento diferencial en la actividad de la POD dependiendo del sustrato empleado.
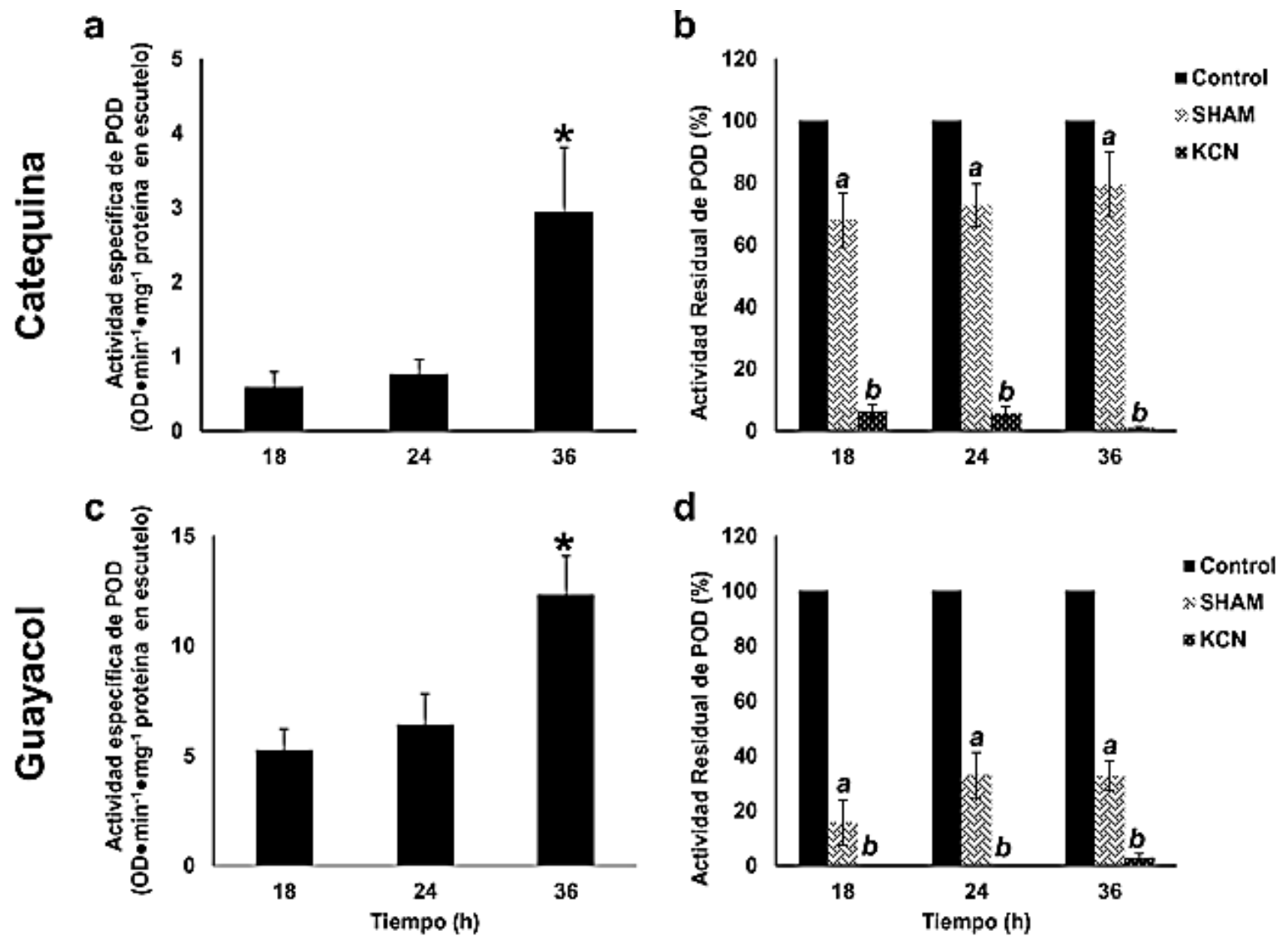

Figura 6. Actividad de peroxidasa en escutelos.

a) Actividad cuantificada con catequina $+\mathrm{H}_{2} \mathrm{O}_{2}$; b) Efecto inhibidor de $\mathrm{KCN}$ y $\mathrm{SHAM}$ en presencia de catequina $+\mathrm{H}_{2} \mathrm{O}_{2}$; c) Actividad cuantificada con guayacol+ $\mathrm{H}_{2} \mathrm{O}_{2}$; d) Efecto inhibidor de KCN y SHAM en presencia de guayacol+ $\mathrm{H}_{2} \mathrm{O}_{2}$. Se muestra la media \pm desviación estándar de $n=6$. Se realizó una prueba de ANOVA seguida de una comparación múltiple de Tukey-Kramer con una $p<0.05$. Símbolos: *, grupo estadísticamente significativo; $a$, efecto estadísticamente significativo de SHAM con respecto a su control; $b$, efecto significativo de $\mathrm{KCN}$ con respecto a su control. 
Se emplearon inhibidores para caracterizar la actividad de la POD y se encontró que cuando se cuantificó la actividad con catequina, el KCN indujo una inhibición entre el 93 al 99\% de la actividad entre 18 a 36 h de imbibición (Fig. 6b); cuando la actividad se cuantificó con guayacol la inhibición fue de 96 a 99\% en el mismo lapso (Fig. 6d). uso de SHAM durante el mismo periodo de tiempo indujo una inhibición en la actividad del 20 al 30\% cuando se cuantificó con catequina (Fig. 6b), y de 67 a 84\% de inhibición cuando se cuantificó con guayacol (Fig. 6d). Estos resultados confirman la presencia de diferentes isoformas de peroxidasas de fenoles presentes en el escutelo.

La cuantificación de la actividad total de la enzima SOD en escutelos de maíz durante la germinación y la postgerminación temprana, mostró que a las 24 h de imbibición, existe un abatimiento del $40 \%$ o $42 \%$ con respecto a la actividad registrada a las 18 o $36 \mathrm{~h}$, tiempos en los que no se registraron cambios estadísticos significativos (Fig. 7). Esto sugiere, que a las $24 \mathrm{~h}$ de iniciada la imbibición, existe una disminución en la capacidad de remoción de $\mathrm{O}_{2}{ }^{-}$, misma que correlaciona con el aumento en la capacidad de reducción del XTT y su quelación con $\mathrm{Cu}^{2+}$ en el apoplasto (Fig. 8), y con la disminución de la inmunoreactividad de la SOD en la epidermis del escutelo (Fig. 5), indicando la acumulación de $\mathrm{O}_{2}{ }^{-}$en el escutelo a las $24 \mathrm{~h}$ y que este órgano se encuentra a ese tiempo en una condición de mayor oxidación. 


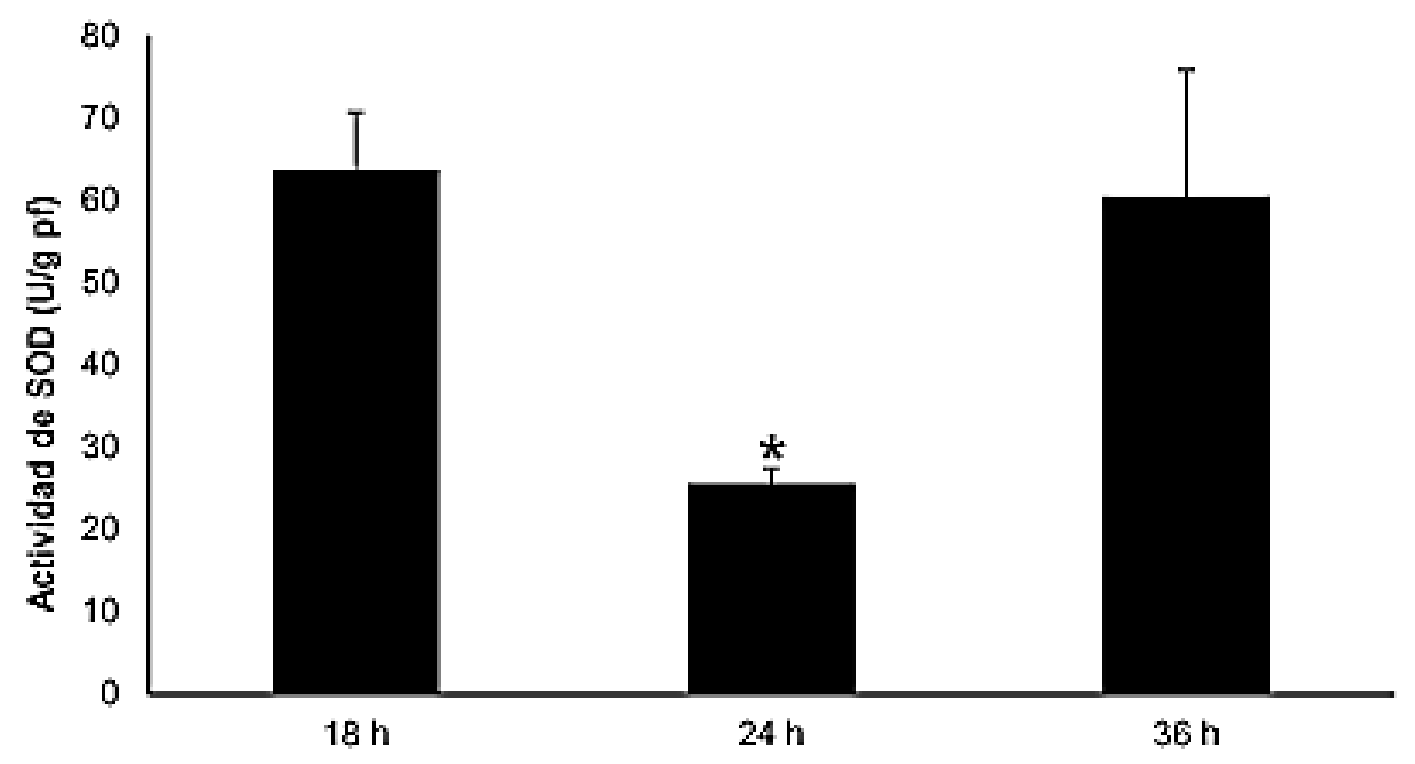

Figura 7. Actividad de SOD en escutelos.

Actividad de SOD cuantificada por el método riboflavina/NBT (Giannopolitis y Ries, 1977) en escutelos de maíz con 18, 24 y 36 h de imbibición. Se muestra media \pm desviación estándar de $n=4$ ensayos independientes. Se realizó una prueba de ANOVA seguida de una comparación múltiple de Tukey-Kramer con una $p<0.05$. Símbolos: *, implica que la actividad de SOD a las 24 h es estadísticamente diferente de la actividad a 18 h y $36 \mathrm{~h}$. 
6 Cuantificación de compuestos oxidorreductores extruidos desde la superficie del escutelo

6.1 Cuantificación del poder reductor extruido: Reducción de XTT por equivalentes de $\mathrm{O}_{2}^{-}$

La presencia de las enzimas SOD y POD en las regiones de la epidermis del escutelo cercanas a los sitios de modificación estructural de la capa fibrosa, representan una evidencia de la generación de ERO en estas regiones del tejido, por lo cual se decidió cuantificar la producción de $\mathrm{O}_{2}^{-}$y $\mathrm{H}_{2} \mathrm{O}_{2}$, que son los productos de su actividad catalítica.

Se encontró que desde la superficie del escutelo se difundió un compuesto con capacidad de reducir al XTT (Fig. 8). Los niveles de reducción del XTT fueron similares en los extruidos de escutelos con 18, 24 y 36 h de imbibición (Fig. 8, columna XTT); la adición a la solución con que se incubaron los escutelos de $200 \mu \mathrm{M}$ de NADH, $200 \mu \mathrm{M}$ de $\mathrm{NADPH}, 50 \mu \mathrm{M}$ de $\mathrm{CuCl}_{2}, \mathrm{NADH}+\mathrm{CuCl}_{2} \circ \mathrm{NADPH}+\mathrm{CuCl}_{2}$ en las concentraciones previamente indicadas no generaron modificaciones en la capacidad basal de reducción de XTT en escutelos con 18 o 36 h de imbibición (Fig. 8a, 8c).

En escutelos con 24 h de imbibición, la reducción de XTT mostró un incremento estadísticamente significativo de un $91 \%$ después de la adición de $200 \mu \mathrm{M}$ de NADH, o $56 \%$ después de agregar $200 \mu \mathrm{M}$ de NADPH al medio (Fig. 8b). La adición de $50 \mu \mathrm{M}$ de $\mathrm{CuCl}_{2}$, que se ha reportado como un atrapador de $\mathrm{O}_{2}{ }^{-}$(Liszkay et al., 2004) no produjo cambios en la capacidad basal de reducción de XTT in vivo (Fig. 8b, columna XTT$\mathrm{CuCl}_{2}$ ); sin embargo, la adición de $\mathrm{CuCl}_{2}$ en presencia de NADH produjo un descenso estadísticamente significativo de $29 \%$ en la reducción de XTT (Fig. $\mathbf{8 b}$, columna XTT- 
$\mathrm{NADH}-\mathrm{CuCl}_{2}$ ) y una disminución de $24 \%$ en presencia de NADPH (Fig. 8b, columna XTT-NADPH-CuCl 2 ). Esto implica la presencia de $\mathrm{O}_{2}{ }^{--}$entre los compuestos extruidos desde la superficie del escutelo. Resultados similares han sido descritos en raíces de maíz durante el ablandamiento de las paredes celulares y el crecimiento por elongación (Liszkay et al., 2004). 

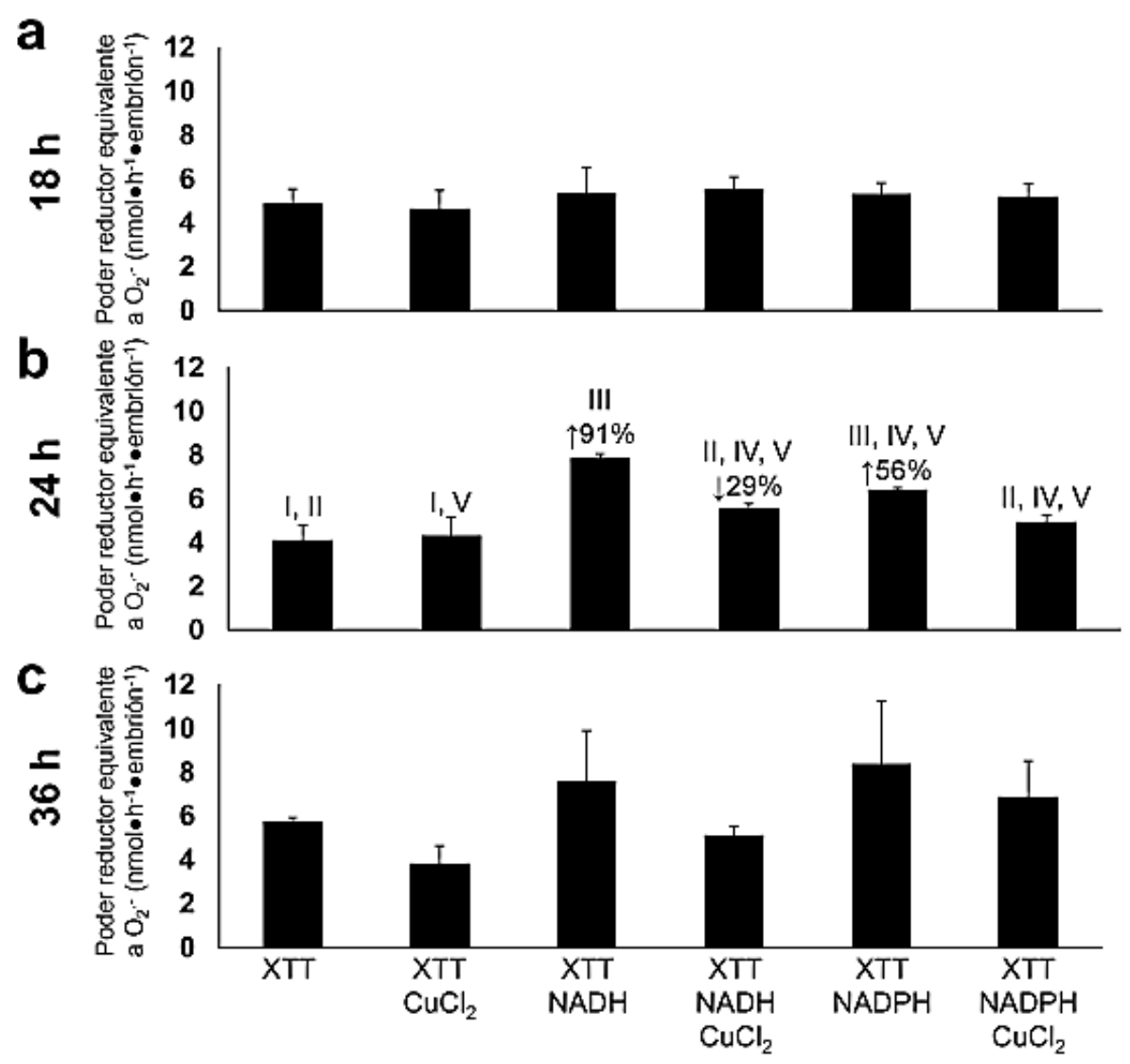

Figura 8. Cuantificación de poder reductor de XTT.

Reducción de XTT por sustancias extruidas desde la superficie del escutelo in vitro y en presencia de alguna de las siguientes condiciones: $\mathrm{CuCl}_{2}, \mathrm{NADH}, \mathrm{NADPH}$, $\mathrm{NADH}+\mathrm{CuCl}_{2}$ o $\mathrm{NADPH}+\mathrm{CuCl}_{2}$; a) Después de $18 \mathrm{~h}$; b) Después de $24 \mathrm{~h}$; c) Después de $36 \mathrm{~h}$ de iniciada la imbibición. Se muestra la media \pm desviación estándar de $n=3$. Se realizó una prueba de ANOVA seguida de una comparación múltiple de Tukey-Kramer con una $p<0.05$. Símbolos: grupos de datos con números romanos diferentes implican diferencias estadísticamente significativas entre tratamientos; $\uparrow \%$, representa el incremento porcentual en la capacidad reductora; $\downarrow \%$, representa el decremento porcentual en la capacidad reductora. 


\subsection{Cuantificación de $\mathrm{H}_{2} \mathrm{O}_{2}$ por permanganometría}

Dado que fue detectada y cuantificada la presencia de SOD (Fig. 5c-d, Fig. 7), que es la enzima encargada de la transformación de $\mathrm{O}_{2}{ }^{-}$en $\mathrm{H}_{2} \mathrm{O}_{2}$, se decidió cuantificar la difusión del $\mathrm{H}_{2} \mathrm{O}_{2}$ desde la superficie del escutelo mediante una modificación a la técnica de permanganometría descrita por Trasar-Cepeda et al. (2003). La modificación a la técnica original se fundamenta en el registro espectrofotométrico del cambio de absorbancia de la titulación de $\mathrm{H}_{2} \mathrm{O}_{2}$ con $\mathrm{KMnO}_{4}$, de modo que mientras el $\mathrm{H}_{2} \mathrm{O}_{2}$ presente en la mezcla de reacción interactúa con $\mathrm{KMnO}_{4}$, no se detectan grandes cambios de absorbancia. Cuando todo el $\mathrm{H}_{2} \mathrm{O}_{2}$ ha reaccionado comienza una acumulación de $\mathrm{KMnO}_{4}$ que genera aumentos en la absorbancia (Fig. 9a).

Previo a la cuantificación del $\mathrm{H}_{2} \mathrm{O}_{2}$ desprendido desde la superficie del escutelo, se determinó la sensibilidad de la técnica implementada comparando los resultados de la titulación de cantidades conocidas de un estándar de $\mathrm{H}_{2} \mathrm{O}_{2}$ (Tabla 2) con los valores experimentales que ésta genera (Fig. 9b). El graficado del cambio de la absorbancia durante la titulación con $\mathrm{KMnO}_{4}$ de volúmenes conocidos de $\mathrm{H}_{2} \mathrm{O}_{2}$ presentó un comportamiento bifásico: inicialmente no se detectaron grandes cambios de absorbancia generando una recta de pendiente cercana a cero, posteriormente ocurre un aumento progresivo en la absorbancia lo cual genera una recta con pendiente ascendente; entre ambas rectas de pendiente diferenciable existe un punto de inflexión que representa el volumen de $\mathrm{KMnO}_{4}$ a partir del cual todo el $\mathrm{H}_{2} \mathrm{O}_{2}$ ha reaccionado (Fig. 9a, flecha). Este volumen de $\mathrm{KMnO}_{4}$ fue transformado a $\mu$ moles y con éstos se determinó la cantidad experimental de $\mathrm{H}_{2} \mathrm{O}_{2}$ mediante la estequiometría descrita en la siguiente reacción: $5 \mathrm{H}_{2} \mathrm{O}_{2}+2 \mathrm{MnO}_{4}+6 \mathrm{H}^{+} \rightarrow 5 \mathrm{O}_{2}+2 \mathrm{Mn}^{++}+8 \mathrm{H}_{2} \mathrm{O}$. 


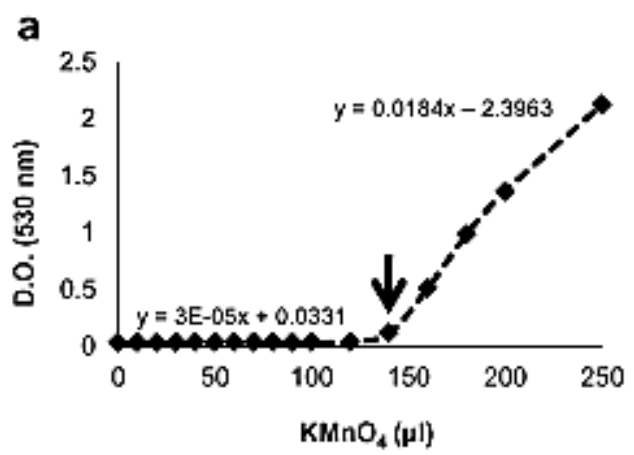

b

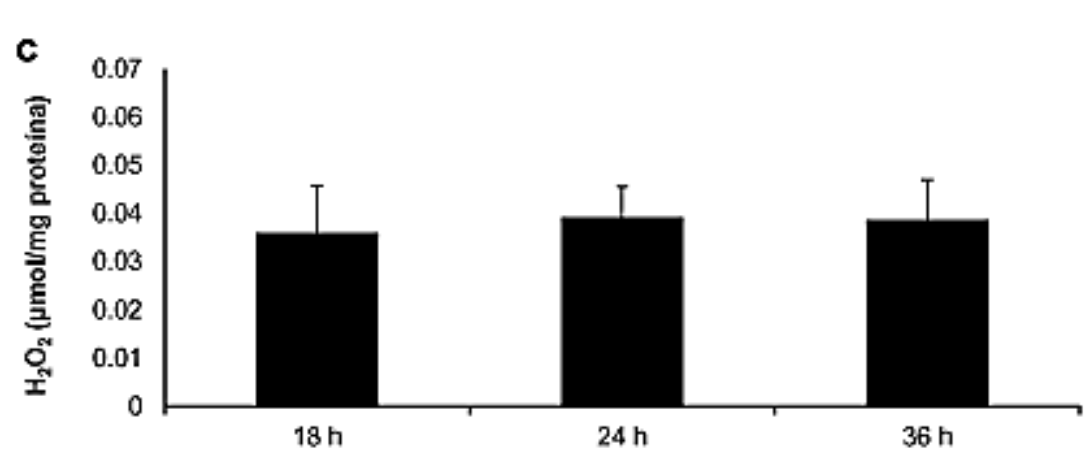

Figura 9. Sensibilidad de la técnica de cuantificación de $\mathrm{H}_{2} \mathrm{O}_{2}$ por permanganometría y determinación de $\mathrm{H}_{2} \mathrm{O}_{2}$ desprendido desde la superficie del escutelo.

a) Titulación de $2.64 \mu \mathrm{mol}$ de $\mathrm{H}_{2} \mathrm{O}_{2}$, puede observarse el comportamiento bifásico en el cambio de absorbancias y el punto de inflexión señalizado con una flecha. La determinación del volumen de $\mathrm{KMnO}_{4}$ que reacciona con la totalidad del $\mathrm{H}_{2} \mathrm{O}_{2}$ se calculó como el cociente de la diferencia de las ordenadas al origen de la recta de pendiente ascendente y la recta de pendiente cercana a cero entre, la pendiente de la recta de pendiente ascendente. b) Determinación de la linealidad y sensibilidad de la técnica de cuantificación de $\mathrm{H}_{2} \mathrm{O}_{2}$; el intervalo óptimo es de 0.4 a $0.882 \mathrm{mM}$. c) Cuantificación del $\mathrm{H}_{2} \mathrm{O}_{2}$ liberado desde la superficie de escutelos con diferentes tiempos de imbibición hacia el apoplasto. Se muestra media \pm desviación estándar de $n=3$ ensayos independientes. Se realizó una prueba de ANOVA seguida de una comparación múltiple de Tukey-Kramer con una $p<0.05$. 
La comparación entre las cantidades de $\mathrm{H}_{2} \mathrm{O}_{2}$ conocidas y las obtenidas experimentalmente permitieron determinar que mediante esta técnica se pueden cuantificar cantidades de $\mathrm{H}_{2} \mathrm{O}_{2}$ desde 0.4 hasta $2.64 \mu \mathrm{mol}(0.4$ a $2.64 \mathrm{mM})$, ya que en este intervalo se observó un comportamiento lineal cuyo coeficiente de correlación es muy cercano a 1 (Fig. 9b); sin embargo, es evidente que cantidades de $\mathrm{H}_{2} \mathrm{O}_{2}$ mayores a $0.882 \mu \mathrm{mol}$ podrían ser sobreestimadas dado que la recta de valores experimentales se encuentra por arriba de la recta de valores conocidos (Fig. 9b). Este análisis permite concluir que la técnica implementada puede ser empleada únicamente para determinar cantidades de $\mathrm{H}_{2} \mathrm{O}_{2}$ en el intervalo de 0.4 a $0.882 \mu \mathrm{mol}(0.4$ a $0.882 \mathrm{mM})$.

La cantidad de $\mathrm{H}_{2} \mathrm{O}_{2}$ desprendido desde la superficie del escutelo no cambió entre ninguno de los tres tiempos ensayados (Fig. 9c). Esto indicó que la producción o liberación apoplástica del $\mathrm{H}_{2} \mathrm{O}_{2}$ no se altera con el tiempo de germinación, o bien que en el medio apoplástico existe una capacidad antioxidante que mantiene en niveles constantes las pozas de $\mathrm{H}_{2} \mathrm{O}_{2}$.

6.3 Liberación de fenoles desde la superficie del escutelo, cuantificados por la reducción de ferricianuro

En los ensayos para la Fig. 1c, se demostró que la capa fibrosa y las paredes de células de la epidermis del escutelo contienen fenoles, por tal razón se cuantificó el desprendimiento de éstos desde la superficie del escutelo durante la germinación mediante su reacción con el ferricianuro $\left(\mathrm{K}_{3} \mathrm{Fe}(\mathrm{CN})_{6}\right)$. El análisis de los resultados indicó que el mayor desprendimiento de fenoles ocurrió a las 24 h de iniciada la imbibición, y representó un incremento del $17 \%$ con respecto a las $18 \mathrm{~h}$ y un aumento del $47 \%$ con 
respecto a los niveles detectados en escutelos con 36 h de imbibición; dichos aumentos no representaron diferencias estadísticas significativas (Fig. 10). Esto sugiere que la presencia de fenoles libres en el apoplasto está estrictamente regulada. In vivo, estos compuestos fenólicos podrían ser responsables de los niveles basales de reducción del XTT que fueron detectados (Fig. 8a-c, columna XTT) aunque in vitro se determinó que otros compuestos también pueden reducir al XTT (Tabla 3); sin embargo, esto se explica con más detalle en la siguiente sección.

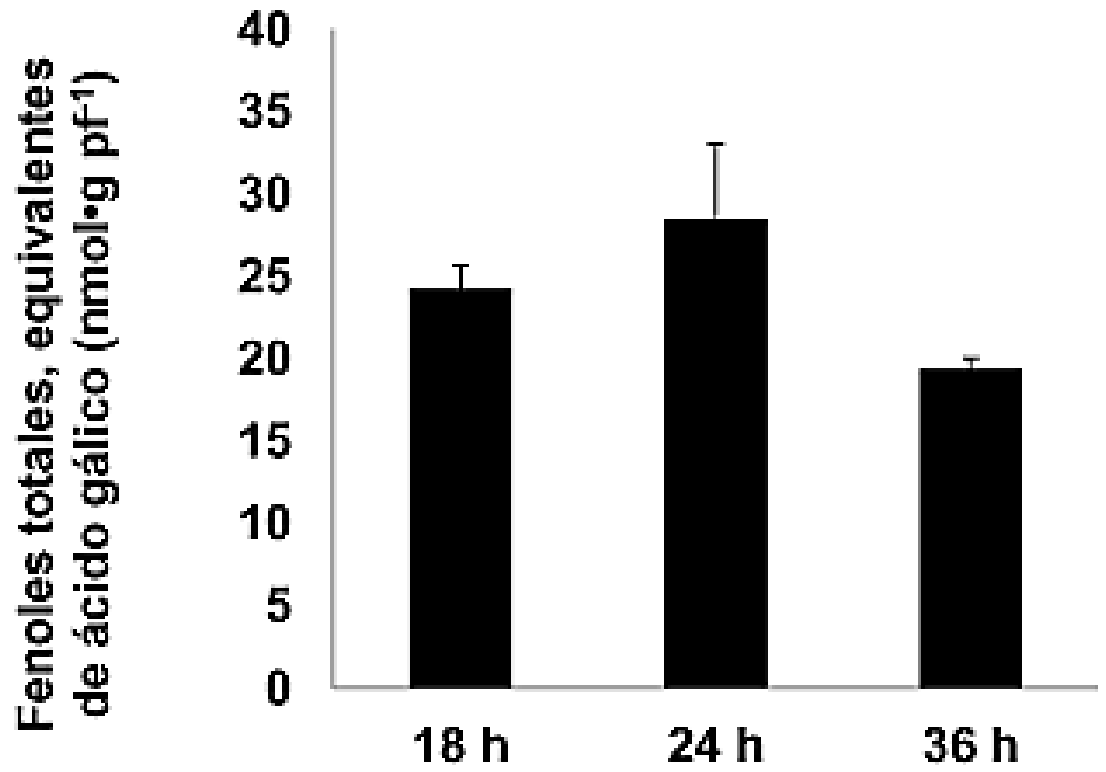

Figura 10. Capacidad de reducción de $\mathrm{FeCl}_{3}-\mathrm{K}_{3}(\mathrm{CN})_{6}$.

Cantidad de fenoles reducidos desprendidos desde la superficie del escutelo que interactúan con $\mathrm{FeCl}_{3}-\mathrm{K}_{3}(\mathrm{CN})_{6}$. Se muestra la media \pm desviación estándar de $n=3$. Se realizó una prueba de ANOVA seguida de una comparación múltiple de Tukey-Kramer con una $p<0.05$. 
6.4 Otros solutos con capacidad de reducir al XTT in vitro

Como se estableció anteriormente, desde la superficie del escutelo difunden compuestos que tienen capacidad de reducir al XTT, entre ellos, el $\mathrm{O}_{2}{ }^{-}$(Fig. 8), para identificar otros compuestos, se evaluó in vitro la interacción de diversos reductores con el XTT. En la Tabla 3 se muestran los resultados encontrados; se determinó que a concentraciones en el intervalo de mM, la mayor capacidad de reducción la presentó la catequina, la menor capacidad se registró con ácido gálico, y una capacidad intermedia se observó con el ácido ascórbico. En concentraciones con intervalo de $\mu \mathrm{M}$, el $\mathrm{CuCl}_{2}$ presentó el mismo poder reductor que el ácido gálico. La capacidad del NADH para reducir al XTT fue similar a la del $\mathrm{CuCl}_{2}$, mientras que la capacidad del NADPH fue ligeramente menor a concentraciones equimolares.

Los resultados implican que entre los compuestos extruidos desde el escutelo (Fig. 8a-c, columna XTT), pueden estar incluidos algunos otros reductores como los descritos en la Tabla 3, además de los fenoles descritos en la Fig. 10. 
Tabla 3. Efecto de solutos reductores sobre XTT, in vitro.

\begin{tabular}{|l|c|}
\hline \multicolumn{2}{|c|}{ Efecto de solutos reductores sobre XTT } \\
\hline Sustancia & Equivalentes de reducción de XTT (nmol) ${ }^{a}$ \\
\hline $\mathrm{CuCl}_{2}(50 \mu \mathrm{M})^{b}$ & $1.71 \pm 0.28$ \\
\hline Ácido gálico $(7.8 \mathrm{mM})^{c}$ & $1.72 \pm 0.87$ \\
\hline $\mathrm{NADPH}(200 \mu \mathrm{M})^{d}$ & $4.36 \pm 1.26$ \\
\hline $\mathrm{NADH}(200 \mu \mathrm{M})^{d}$ & $6.79 \pm 0.39$ \\
\hline Ácido ascórbico $(50 \mathrm{mM})^{d}$ & $26.45 \pm 0.22$ \\
\hline Catequina $(5 \mathrm{mM})^{e}$ & $48.04 \pm 5.75$ \\
\hline
\end{tabular}

a, los equivalentes reductores se determinaron usando el coeficiente de extinción molar del XTT $\left(\varepsilon X T T=2.16 \times 104 \mathrm{~mol}^{-1} \mathrm{~cm}^{-1}\right.$; Sutherland y Learmonth, 1997); $\boldsymbol{b}$, concentraciones reportadas como atrapadoras de $\mathrm{O}_{2}{ }^{-} ; \boldsymbol{c}$, concentraciones de fenoles por embrión desprendidas de la superficie escutelar de embriones con $24 \mathrm{~h}$ de imbibición; d, concentraciones reportadas por Frahry y Schopfer (2001); $\boldsymbol{e}$, concentración calculada de tasas constantes de captura de ERO.

7. Efecto del almacenamiento en condiciones controladas sobre la actividad de peroxidasa del escutelo y el vigor de los granos

A las $24 \mathrm{~h}$ de iniciada la imbibición, los escutelos de granos almacenados en condiciones de $88 \circ 40 \%$ HR y $7^{\circ} \mathrm{C}$ presentaron una actividad basal de POD, cuantificada con catequina o guayacol, que se mantuvo sin cambios estadísticos significativos aunque con cierta fluctuación sobre un valor constante durante los primeros 6 meses de almacenamiento (Fig. 11a-b); durante este tiempo de 
almacenamiento los granos presentaron altos niveles de germinación (Fig. 11c). En comparación, las muestras analizadas de granos almacenados en $88 \%$ de $\mathrm{HR}$ y $25^{\circ} \mathrm{C}$ presentaron una disminución constante en la germinación y en la actividad de la POD presente en los escutelos, que en ambos casos llegó a cero en el tercer mes de almacenamiento (Fig. 11a-c).

En granos almacenados durante 8 a 12 meses en condiciones de $40 \%$ de $\mathrm{HR}$ y $7^{\circ} \mathrm{C}$, la actividad de POD de los escutelos con 24 h de imbibición mostró un incremento estadísticamente significativo para los meses 8 y 9 al cuantificar la actividad con catequina (Fig. 11a), el incremento estadísticamente significativo se registró al mes 8 con guayacol (Fig. 11b), posteriormente la actividad de la enzima se mantuvo alta hasta los 12 meses de almacenamiento. La actividad de POD cuantificada con catequina en escutelos de granos almacenados en condiciones de $88 \%$ de $\mathrm{HR}$ y $7^{\circ} \mathrm{C}$ fluctuó sobre un valor similar al detectado entre el tercer y sexto mese de almacenamiento (Fig. 11a), mientras que al cuantificar con guayacol se registró un aumento estadísticamente significativo en el mes 8 y posteriormente la actividad disminuyó hacia los 12 y 13 meses a niveles similares a los detectados al inicio de los ensayos (Fig. 11b). La capacidad germinativa de los embriones de granos almacenados a $40 \%$ de $\mathrm{HR}$ y $7^{\circ} \mathrm{C}$ se mantuvo en un nivel promedio de $90 \%$ hasta el mes 12 de almacenamiento, mientras que los embriones de granos almacenados en $88 \%$ de $\mathrm{HR}$ y $7^{\circ} \mathrm{C}$ presentaron una germinación promedio de $78.8 \%$ durante los primeros tres meses y posteriormente alcanzaron una menor germinación estadísticamente significativa de 42\% (Fig. 11c). 

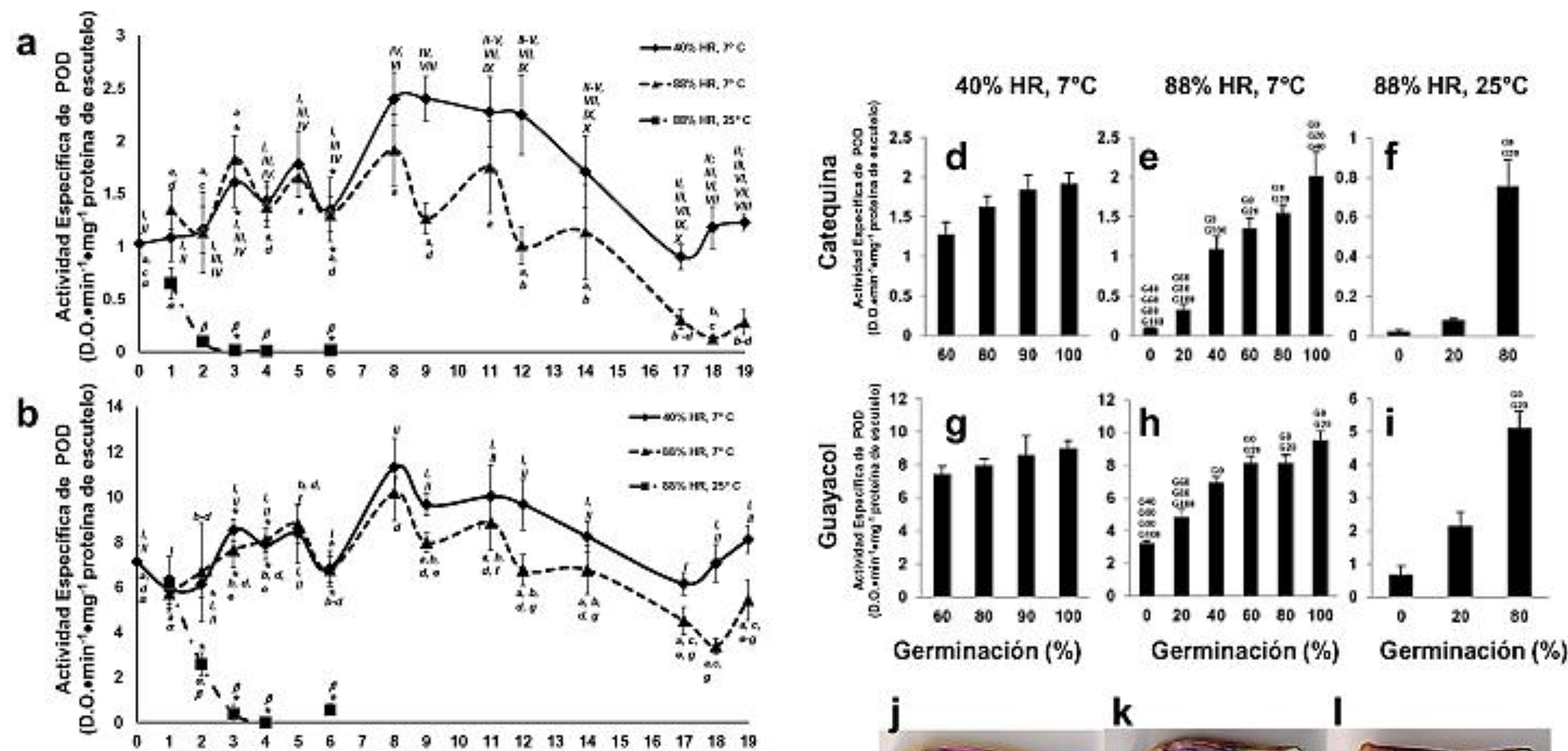

c
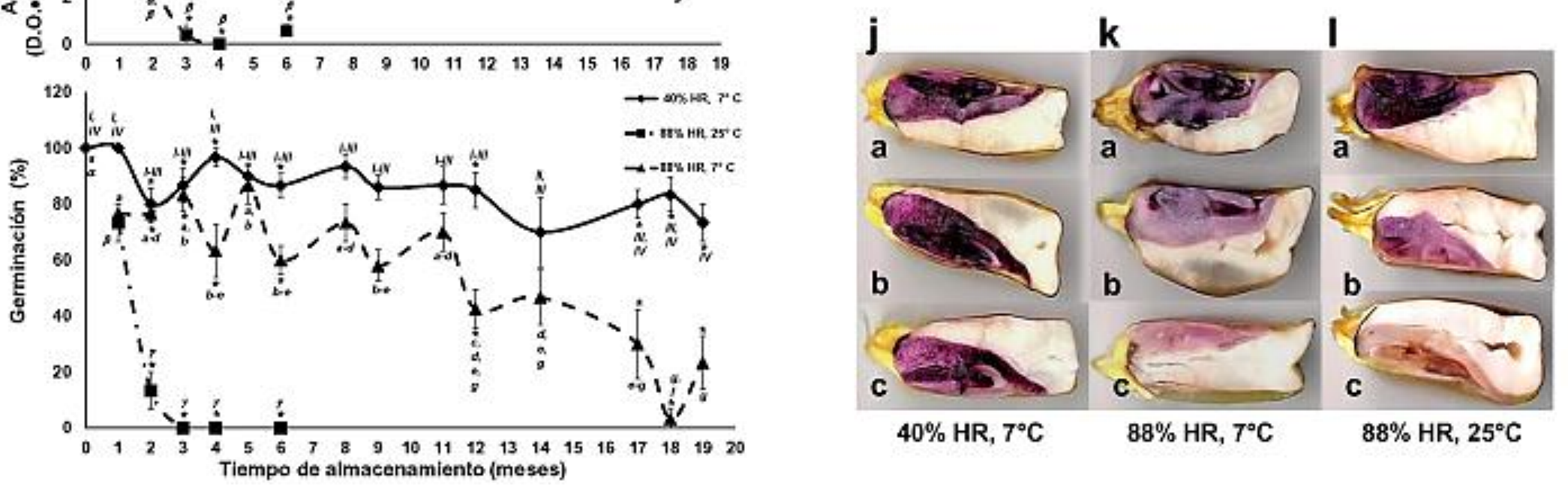
Figura 11. Cuantificación de actividad de la peroxidasa en escutelos de granos almacenados en condiciones controladas, ensayos de germinación y vigor.

Se muestra la actividad de la peroxidasa en extractos de escutelos de maíz con $24 \mathrm{~h}$ de imbibición que fueron almacenados por 19 meses en condiciones controladas, la actividad se cuantificó con: a) Catequina $+\mathrm{H}_{2} \mathrm{O}_{2}$; b) Guayacol $+\mathrm{H}_{2} \mathrm{O}_{2}$; c) Porcentaje de germinación después de $24 \mathrm{~h}$ de imbibición. Correlación entre germinación y actividad de peroxidasa: $\mathbf{d}-\mathbf{f}$ ) Cuantificada con catequina $+\mathrm{H}_{2} \mathrm{O}_{2} ; \mathbf{g}-\mathbf{i}$ ) Cuantificada con guayacol $\left.+\mathrm{H}_{2} \mathrm{O}_{2} ; \mathrm{j}-\mathrm{I}\right)$ Pruebas de vigor con MTT aplicadas a granos al final del almacenamiento. Se muestra la media \pm desviación estándar de $\mathrm{n}$ de 3 hasta 12 ensayos independientes. Se realizó una prueba de ANOVA seguida de una comparación múltiple de Tukey-Kramer con una $p<0.05$. Símbolos: datos de la misma condición de almacenamiento con diferente letra o número en la misma condición de almacenamiento implica diferencias estadísticas significativas; *, diferencias estadísticas significativas comparando los diferentes tratamientos con el mismo tiempo de almacenamiento. 
Después de 12 meses de almacenamiento a $40 \%$ de $\mathrm{HR}$ y $7^{\circ} \mathrm{C}$, la actividad de POD del escutelo, cuantificada con catequina o guayacol, disminuyó alcanzando niveles basales; esta actividad es significativamente menor a los máximos valores encontrados entre los meses 8 y 9 , pero similar a la registrada al inicio de los experimentos (Fig. 11a-b). En el mismo periodo de tiempo, la actividad de la enzima de escutelos de granos almacenados en $88 \%$ de $\mathrm{HR}$ y $7^{\circ} \mathrm{C}$ disminuyó por debajo de los niveles iniciales y presentó un valor mínimo entre los meses 17 a 19 (Fig. 11a-b). Durante este periodo de tiempo la tasa de germinación de embriones de granos almacenados en $40 \%$ de $\mathrm{HR}$ y $7^{\circ} \mathrm{C}$ se mantuvo similar a la encontrada al inicio del estudio, sin embargo en embriones de granos almacenados a $88 \%$ de $\mathrm{HR}$ y $7^{\circ} \mathrm{C}$ disminuyó por debajo del 30\% registrando un valor mínimo de 3.3\% a los 18 meses. Comparando la capacidad germinativa entre las dos condiciones de almacenamiento descritas, se encontró una diferencia significativa entre los meses 17 a 18 (Fig. 11c).

Se realizaron ensayos con el tetrazolio MTT para determinar el vigor de los granos después de 22 meses de almacenamiento, se encontró que los granos almacenados en $40 \%$ de $\mathrm{HR}$ y $7^{\circ} \mathrm{C}$ conservaron un vigor de alto (Fig. 11jc) a medio (Fig. 11ja-b); mientras que los granos almacenados a $88 \%$ de $\mathrm{HR}$ y 7 ० $25^{\circ} \mathrm{C}$ presentaron un vigor bajo (Fig. 11ka, la) o bien eran no germinables (Fig.11kb, kc, Ib, Ic). 
Por los datos obtenidos puede interpretarse que las condiciones de almacenamiento en atmósferas de $88 \%$ de $\mathrm{HR}$ y $25 \circ 7^{\circ} \mathrm{C}$ de temperatura, generan un deterioro rápido o lento respectivamente. Asociado a esto se encontró que los granos pierden viabilidad al tiempo que la actividad de la peroxidasa del escutelo disminuye por debajo de los valores basales encontrados al inicio de los ensayos en embriones con $24 \mathrm{~h}$ de imbibición (Fig. 11e, f, h, i). Por otra parte, en granos almacenados en $40 \%$ de $\mathrm{HR}$ y $7^{\circ} \mathrm{C}$ se conservan altos niveles de vigor y germinación que coinciden con la conservación o el aumento de los niveles basales de la actividad de peroxidasa del escutelo a las 24 h de imbibición (Fig. 11d, i).

8. Efecto del almacenamiento en la fluorescencia de componentes tisulares del escutelo

Para evaluar si el almacenamiento en condiciones controladas generaba alteraciones en los patrones de emisión de fluorescencia de los componentes tisulares de escutelos de maíz, se caracterizó la fluorescencia del tejido en secciones histológicas de escutelos de granos sin imbibición. Se encontró que la capa fibrosa, la epidermis y el parénquima del escutelo presentan tres máximos de emisión de autofluorescencia que corresponden a las siguientes regiones del espectro visible: rojo $\left(F_{626-635 ~ n m}\right)>$ verde $\left(F_{512 n m}\right)>$ azul $\left(F_{460 ~ n m}\right)$; la anatomía del escutelo se mantuvo bien estructurada al presentar una capa fibrosa continua y compacta, adyacente a una epidermis del escutelo monoestratificada (Fig. 12). 


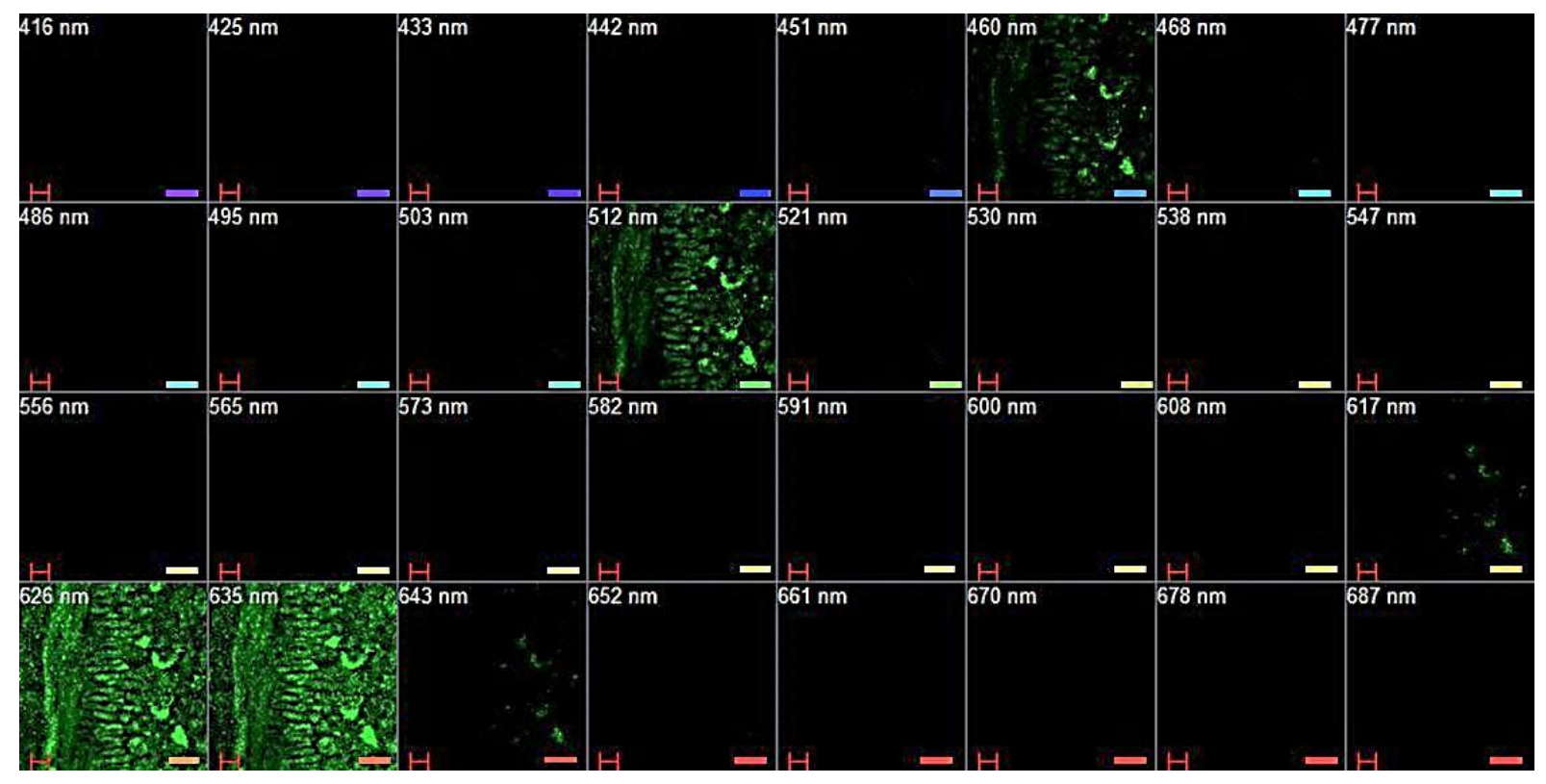

Figura 12. Espectros de emisión de componentes endógenos del escutelo a las $0 \mathrm{~h}$ de imbibición.

Secciones de escutelos de embriones sin imbibición, en los que se identifican la epidermis, la capa fibrosa y parte del parénquima subyacente, se irradiaron con las siguientes longitudes de onda: 405, 458, 488, 514, 561, o $633 \mathrm{~nm}$, y posteriormente se registró su espectro de emisión. El espectro de emisión presentó tres máximos: rojo $\left(F_{626-635 n m}\right)>$ verde $\left(F_{512 n m}\right)>$ azul $\left(F_{460} \mathrm{~nm}\right)$. Cada recuadro de la figura contiene la longitud de emisión así como el color que corresponde en el espectro visible. Barras: $20 \mu \mathrm{m}$. 
Posteriormente, se realizó un estudio comparativo de la anatomía del escutelo y la capa fibrosa de embriones de maíz con 24 h de imbibición provenientes de granos almacenados 1 y 9 meses en condiciones controladas en $40 \%$ de $\mathrm{HR}$ a $7^{\circ} \mathrm{C}$ y $88 \%$ de HR a $7 \circ 25^{\circ} \mathrm{C}$. Los resultados muestran que en los meses analizados, las células epidérmicas (epi) permanecieron uninucleadas y monoestratificadas de manera independiente a las condiciones de almacenamiento (Fig. 13).

Los patrones de emisión de autofluorescencia sí resultaron afectados de modo que, después de 24 h de imbibición, los escutelos de los granos almacenados en $40 \%$ de HR y $7^{\circ} \mathrm{C}$ durante 1 o 9 meses presentaron una variación en la proporción entre la emisión verde y azul ya que es la azul la que predomina (Fig. 13a-b) comparado con los escutelos de granos deshidratados (Fig. 12). La capa fibrosa (cf) se visualizó con fluorescencia azul, variando su apariencia entre una estructura fibrosa y compacta (Fig. 13a) a una con consistencia desarreglada (Fig. 13g); en algunas áreas específicas no se registró autofluorescencia (Fig. 13b, flechas) a pesar de que el escutelo se muestra bien estructurado (Fig. 13h).

La epidermis del escutelo (epi) y la capa fibrosa (cf) de embriones de granos almacenados por un mes en $88 \% \mathrm{HR}$ a $7^{\circ} \mathrm{C}$ presentaron una autofluorescencia predominantemente verde, mientras que el resto del escutelo se observó azul (Fig.13c). En el área basal del escutelo, donde la epidermis (epi), el endospermo central almidonoso (eca) y la aleurona (al) coinciden, la capa fibrosa (cf) presentó una fluorescencia verde (Fig. 13d). Después de 9 meses de almacenamiento, el parénquima conservó el mismo patrón de emisión azul mientras que la fluorescencia 
de la capa fibrosa y la epidermis fue predominantemente verde (Fig. 13i) o azul (Fig. 13j).

Después de un mes de almacenamiento a $88 \% \mathrm{HR}$ y $25^{\circ} \mathrm{C}$, los escutelos presentaron una epidermis (epi) con una autofluorescencia azul (Fig. 13e); en otras áreas la región apical de la epidermis (epi) presentó una fluorescencia verde a comparación de la parte basal de la célula que se encontró predominantemente azul (Fig. 13f). La capa fibrosa (cf) presentó principalmente una emisión verde de manera continua o en pequeñas secciones mientras que las células del parénquima ( $c p$ ) emitieron en el azul (Fig. 13e-f, flechas).

Los resultados obtenidos sugieren que debido a procesos derivados del almacenamiento de los granos en diferentes condiciones de humedad y temperatura, ciertos compuestos estructurales del escutelo y de la capa fibrosa modifican su patrón de fluorescencia, esto podría ocurrir en función de un cambio en la proporción de los componentes estructurales, o bien, debido a que existen condiciones microambientales diferentes, lo cual propicia que las emisiones sean más intensas hacia el verde o el azul. El cambio en la emisión con predominancia hacia el verde podría ser empleado como un marcador de deterioro. 


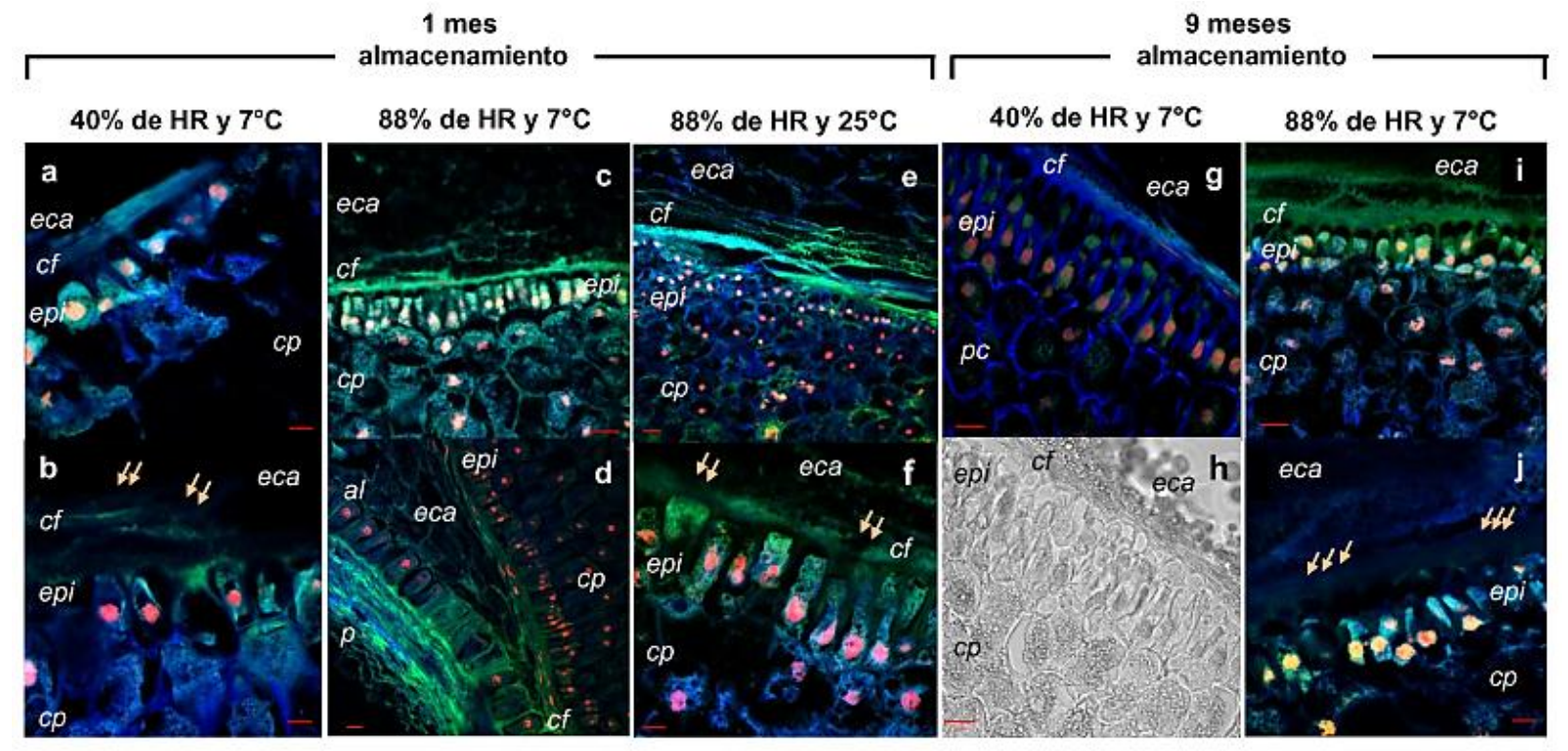

Figura 13. Autofluorescencia de los escutelos en medio acuoso, después de $24 \mathrm{~h}$ de imbibición de granos almacenados en condiciones controladas.

a-f) 1 mes de almacenamiento; g-j) 9 meses de almacenamiento. $\mathbf{a}, \mathbf{b}, \mathbf{g}, \mathbf{h}$ ) almacenados en $40 \%$ de $\mathrm{HR}$ y $7^{\circ} \mathrm{C}$; c, d, i, j) almacenados en $88 \%$ de $\mathrm{HR}$ y $7^{\circ} \mathrm{C}$; e, f) almacenados a $88 \%$ de HR y $25^{\circ} \mathrm{C}$. Abreviaturas: al, aleurona; epi, células epidérmicas; $c f$, capa fibrosa; $p$, pericarpio; $c p$, células del parénquima; eca, endospermo central almidonoso. Símbolos $\downarrow$, modificaciones en la emisión de la capa fibrosa. Barras: a, b y f: $10 \mu \mathrm{m}$; c-e y g-j: $20 \mu \mathrm{m}$. 


\section{DISCUSIÓN}

1. Composición de la capa fibrosa y sus funciones durante la germinación

Los granos de maíz Chalqueño presentaron la capa fibrosa reportada previamente por Enríquez-Arredondo et al. (2005). Se observó que la capa fibrosa envuelve al embrión desde la región basal colindante con la zona de protrusión de la radícula hasta la parte apical del escutelo. Se conoce que en el maíz, la capa fibrosa se compone de paredes celulares compactadas que provienen de los estratos periféricos del endospermo central almidonoso que están en contacto con el escutelo (Brown y Morris, 1890; Horning y Petrie, 1927). Se han encontrado estructuras similares en diversos cereales (Tabla 1), incluyendo arroz (Bechtel y Pomeraz, 1977; Okamoto et al., 1982), trigo (Swift y O'brien, 1972) y cebada (MacGregor y Matsuo, 1982; MacGregor y Dushnicky, 1989).

De manera complementaria a lo ya publicado por otros investigadores, en este trabajo se determinó que la composición química de la capa fibrosa consiste de paredes celulares colapsadas que contienen depósitos de un $\beta$-glucano tipo calosa, lípidos y fenoles (Fig. 2).

La detección de lípidos en la capa fibrosa (Fig. 2a-b) sugiere que estos cumplen una función estructural, ya que comparado con la presencia de lípidos en el escutelo y endospermo resultan menos abundantes y no se encuentran almacenados en cuerpos lipídicos; se ha reportado que el escutelo y el endospermo contienen 
cuerpos lipídicos compuestos por lípidos neutros rodeados por una capa de fosfolípidos y proteínas, además de ácidos grasos libres que funcionan como recursos de almacenamiento (Tan y Morrison, 1979; Wang y Huang, 1987; Szcziparev, 2006; Tnani et al., 2011b; Singh et al., 2014).

La detección de fenoles sobre la capa fibrosa se facilitó debido a que se incrementa su fluorescencia en presencia de ácido difenilborínico (Reich et al., 2006), lo cual permite su detección por microscopía de fluorescencia. La distribución de los fenoles en la capa fibrosa (Fig. 2c) concuerda con el reporte de Sen et al. (1994) que indican la presencia de ácidos fenólicos, flavonoides, ácido ferúlico y aminas conjugadas sobre la periferia del escutelo adyacente al endospermo aunque en una menor proporción que en el pericarpio que es la estructura en la que centran su discusión; por otro lado, Bergvinson y García-Lara (2004) también indican la presencia de ácidos fenólicos sobre la periferia del embrión; sin embargo, al igual que Sen et al. (1994) no describen la presencia de los fenoles y tampoco sugieren alguna función. Dado que se ha propuesto que los fenoles participan en el ensamblaje de polisacáridos, proteínas estructurales, suberina y lignina contribuyendo a mantener estructuradas las paredes celulares (Kolattukudy, 1981; Saulnier y Thibault, 1999; Fry et al., 2000), planteamos que su presencia en la capa fibrosa contribuye al mantenimiento de su estructura.

La ubicación de $\beta$-glucanos tipo calosa se determinó empleando el reactivo azul de anilina que al interactuar con los residuos de glucosa con enlaces $\beta-1,3$ forma complejos que generan fluorescencia (Smith y McCully, 1978); el principal 
depósito de polímeros tipo calosa se encontró sobre la capa fibrosa (Fig. 2d). La presencia de calosa en paredes celulares establece un cierre hermético en los tejidos en los que es depositada (Parre y Geitmann, 2005) y proporciona una matriz para el depósito de otros componentes de la pared celular (Eschrich, 1975) contribuyendo a la impermeabilidad. Tal es el caso del saco embrionario de Torenia fournieri (Tiwari, 1982) y de estructuras semipermeables como la envoltura del perispermoendospermo encontrado en semillas de melón y pepino (Amritphale et al., 2010; Ramakrishna y Amritphale, 2005; Yim y Bradford, 1998). Los reportes de Amritphale et al. (2010), Ramakrishna y Amritphale (2005) y Yim y Bradford (1998) indican que la envoltura del perispermo-endospermo está constituida por calosa y lípidos que generan una semipermeabilidad en las semillas que analizaron. Debido a la semejanza en composición química con respecto a la capa fibrosa de granos de maíz, se evaluó la capacidad de difusión y la permeabilidad de esta estructura para colorantes acuosos y etanólicos (Fig. 3); se encontró que la capa fibrosa genera una barrera que impide el paso de los colorantes verde brillante y $\mathrm{I}_{2}-\mathrm{KI}$ en granos maduros deshidratados. Esta impermeabilidad puede ser eliminada por una punción mecánica directa (Fig. 3c) o por la remoción de componentes hidrofóbicos empleando solventes de mayor hidrofobicidad que el etanol, tal es el caso de cloroformo, acetona o una mezcla de éstos últimos (Fig. 3 h-j).

Por estos resultados, proponemos que la capa fibrosa, constituida por paredes celulares colapsadas con importantes depósitos de calosa, constituye una malla en la cual lípidos y fenoles taponan los poros que quedan en el entramado de ésta, es 
posible que parte de los lípidos y fenoles se conjuguen químicamente formando suberina (Kolattukudy, 1981; Jeffree, 2006), contribuyendo a que la capa fibrosa sea impermeable en granos deshidratados.

La impermeabilidad de la capa fibrosa permitiría en primera instancia mantener aislado al embrión del endospermo, lo cual puede redundar en un beneficio para el embrión al permitir compartimentar las señales y los procesos metabólicos que se generen durante la fase de germinación, impidiendo la difusión de señales y otros componentes al resto del grano $y$, por consiguiente, manteniendo en concentraciones óptimas los metabolitos requeridos en esta etapa. Durante la postgerminación temprana, en la cual el desarrollo de la radícula y el coleoptilo dependen de los materiales de reserva del endospermo (Weitbrecht et al., 2011), la capa fibrosa representaría un obstáculo para la absorción de los metabolitos generados por la hidrólisis del endospermo por lo cual debe existir un mecanismo que permita la eliminación de esta barrera.

2. Modificaciones de la epidermis del escutelo y eliminación regional de la capa fibrosa por métodos pro-oxidantes

En estudios histológicos realizados en embriones con 24 h de imbibición tiempo en el cual se registró la protrusión de la radícula, evento que es referido como el inicio de la postgerminación (Weitbrecht et al., 2011), se encontró que ciertas 
regiones de la capa fibrosa comienzan a modificarse (Fig. $\mathbf{4 m b}$ ) al tiempo que la epidermis del escutelo también se modifica (Fig. 4).

Las células epidérmicas del escutelo, que en granos deshidratados se encontraban como una capa de células cuboidales (Fig. 2), comienzan a alargarse mientras que su polo basal se ensancha, adquiriendo la denominada forma de dedos (Bewley y Black, 1994; Szcziparev, 2006; Tnani, et al. 2011); algunas de estas células acumularon actividad de peroxidasa, y otras presentaron sus paredes celulares perforadas permitiendo la extrusión de su contenido hacia el apoplasto colindante con la capa fibrosa, por lo cual fue posible detectar actividad de peroxidasa apoplástica (Fig.4h-i) así como como en el germinador (Fig. 4k).

Además de la extrusión de la actividad de peroxidasa, también fue posible detectar la enzima sobre la capa fibrosa (Fig. 5a), junto con esto también se encontró que desde la superficie del escutelo se desprende un poder reductor con capacidad de interactuar con el XTT. Debido a que los niveles de este reductor aumentan a las $24 \mathrm{~h}$ de imbibición al agregar al medio $\mathrm{NAD}(\mathrm{P}) \mathrm{H}$, y que disminuyen en presencia de $\mathrm{CuCl}_{2}$, puede concluirse que el poder reductor es $\mathrm{O}_{2}{ }^{--}$(Fig. 8b). Cabe señalar que existen otros compuestos con capacidad de reducir al XTT y estos se enlistan en la Tabla 3. Se ha propuesto que en adición a la enzima $N A D(P) H$ oxidasa o a la flavoenzima tipo $\mathrm{RBOH}$ que es el equivalente en plantas de la subunidad gp9 ${ }^{\text {phox }}$ de la NADPH oxidasa de fagocitos de mamíferos (Sagi y Fluhr, 2006), la peroxidasa es una fuente de producción de $\mathrm{O}_{2}{ }^{--}$apoplástico in vivo (Bolwell et al., 2002; Minibayeva et al., 2009). Las peroxidasas exhiben una actividad productora de $\mathrm{O}_{2}{ }^{-}$solo si se les 
adiciona exógenamente un donador de electrones como el $\mathrm{NAD}(\mathrm{P}) \mathrm{H}$ en altas concentraciones (Chen y Schopfer, 1999). Sin embargo, los intentos para identificar un donador de electrones para las peroxidasas in vivo no han sido exitosos (Heyno et al., 2011).

Adicionalmente, se encontró que los escutelos también generan y desprenden $\mathrm{H}_{2} \mathrm{O}_{2}$; aunque, los niveles de estos se mantienen sin cambios durante la transición de germinación a postgerminación temprana (Fig. 9c); sin embargo, estos niveles deben ser confirmados mediante otra técnica, ya que el límite inferior de la sensibilidad de la técnica de permanganometría coincide con los niveles cuantificados en escutelos de maíz durante la germinación y postgerminación temprana (Fig. 9).

Considerando estos resultados, existe la posibilidad de que a las $24 \mathrm{~h}$ de iniciada la imbibición, el escutelo genere condiciones pro-oxidantes exclusivamente a nivel microambiental, es decir se favorece la generación de ERO en pequeñas

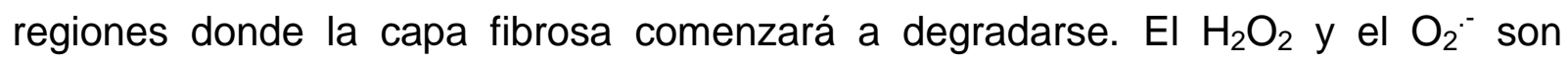
especies químicas moderadamente reactivas, por lo cual su producción no bastaría para degradar la capa fibrosa; sin embargo, ambas ERO son sustrato para la generación de ${ }^{\circ} \mathrm{OH}$, que es una molécula altamente reactiva y con capacidad de degradar cualquier biomolécula (Møller et al., 2007).

En modelos in vitro, la formación de ${ }^{\circ} \mathrm{OH}$ es dependiente de $\mathrm{O}_{2}{ }^{-}$y $\mathrm{H}_{2} \mathrm{O}_{2}$ mediante la reacción de Haber-Weiss (Sharma et al., 2012), en la cual la generación de ${ }^{\circ} \mathrm{OH}$ ocurre de la siguiente manera: primero una molécula de $\mathrm{O}_{2}{ }^{--}$cambia el 
estado de un $\mathrm{Fe}^{3+}$ a un $\mathrm{Fe}^{2+}$ con la liberación de oxígeno $\left(\mathrm{Fe}^{3+}+\mathrm{O}_{2} \cdot-\mathrm{Fe}^{2+}+\mathrm{O}_{2}\right)$. Posterior a esto, ocurre la reacción de Fenton, en la cual una molécula de $\mathrm{H}_{2} \mathrm{O}_{2}$ regresa al Fe a su estado original y produce una molécula de ${ }^{\circ} \mathrm{OH}\left(\mathrm{Fe}^{2+}+\mathrm{H}_{2} \mathrm{O}_{2} \rightarrow\right.$ $\left.\mathrm{Fe}^{3+}+\mathrm{OH}^{-}+{ }^{\circ} \mathrm{OH}\right)$. De todas las $\mathrm{ERO}$, el ${ }^{\circ} \mathrm{OH}$ es la más reactiva, interactúa con diversas moléculas biológicas causando daños celulares como la peroxidación lipídica, el daño a proteínas y la destrucción de membranas, además que puede modificar diversos carbohidratos (Møller et al., 2007; Sharma et al., 2012).

Aunque la presencia de iones Fe en las regiones del escutelo cercanas a los sitios de degradación de la capa fibrosa queda por esclarecer, la generación de ${ }^{\circ} \mathrm{OH}$ en el sistema estudiado podría ser dependiente del ciclo hidroxílico reportado para las POD, durante el cual el $\mathrm{Fe}^{3+}$ del grupo hemo de la enzima es reducido a $\mathrm{Fe}^{2+}$ por acción de $\mathrm{O}_{2}{ }^{--}$posteriormente el $\mathrm{Fe}^{2+}$ puede reducir $\mathrm{H}_{2} \mathrm{O}_{2}$ y producir ${ }^{\circ} \mathrm{OH}$ (Liszkay et al., 2003; Passardi et al., 2005; Cosio y Dunand 2009). La generación de ${ }^{\circ} \mathrm{OH}$ por el ciclo hidroxílico de las peroxidasas se ha reportado para el modelo de crecimiento por elongación en raíces y coleoptilos de maíz (Schopfer, 2001; Schopfer et al., 2002; Liszkay et al., 2003; Liszkay et al., 2004).

Además de la localización de la enzima POD (Fig. 5a), la liberación de $\mathrm{O}_{2}{ }^{-}$ (Fig. 8b) y $\mathrm{H}_{2} \mathrm{O}_{2}$ (Fig. 9c) desde la superficie del escutelo, también se encontró que durante el progreso de la germinación se libera una cantidad constante de un producto con capacidad de interactuar con el ferricianuro (Fig. 10), lo cual se ha reportado como fenoles (Price y Butler, 1977; Thoss et al., 2002; Szcziparev, 2006). La liberación de compuestos fenólicos a las 24 h de imbibición aumentó 17 o 47\% 
con respecto a los niveles cuantificados a las 18 o $36 \mathrm{~h}$ de imbibición respectivamente (Fig. 10), pese a que los compuestos fenólicos son considerados tradicionalmente como elementos antioxidantes (Sharma et al., 2012), se ha reportado que en modelos in vitro bajo condiciones alcalinas algunos flavonoides como la catequina, pueden iniciar un ciclo autooxidativo que puede producir $\mathrm{O}_{2}{ }^{--}$y $\mathrm{H}_{2} \mathrm{O}_{2}$ (Mochizuki et al., 2002); también se ha reportado que los polifenoles pueden ser convertidos a pro-oxidantes mediante su hidrólisis. La actividad pro-oxidante de los fenoles depende de su capacidad de quelación, de sus propiedades de reducir metales, y de la reducción de $\mathrm{O}_{2}{ }^{-}$, que están vinculadas a los potenciales redox de las especies oxidadas y de la vida media de los radicales fenoxilo (Sakihama et al., 2002).

Mediante el análisis de los resultados obtenidos, proponemos que la interacción de los componentes vertidos al apoplasto, entre ellos la actividad de POD, $\mathrm{O}_{2}-\mathrm{H}_{2} \mathrm{O}_{2}$, y fenoles, con los componentes estructurales de la capa fibrosa permiten que ésta comience a modificarse en microambientes o regiones delimitadas (Fig. 4mc), de modo que el aislamiento entre el embrión y el endospermo se elimina. Posteriormente, las células con forma de dedo del epitelio del escutelo (Fig. $\mathbf{4 b}, \mathbf{4 g}$ ) permitirían la secreción de enzimas amilolíticas hacia el endospermo así como la difusión de señales hormonales para la inducción de amilasas en la aleurona, finalmente las células del epitelio podrían transportar hacia el escutelo los carbohidratos generados por la acción de las amilasas (Okamoto et al., 1982; Szcziparev, 2006; Taiz y Zieger, 2010). Con esto se sostiene el crecimiento de la 
radícula y del coleoptilo durante la postgerminación; sin embargo, debido al riesgo latente que representa la generación de especies pro-oxidantes, el escutelo debe presentar mecanismos antioxidantes que a nivel macroambiental eviten daños oxidantes.

3. Mecanismos antioxidantes del escutelo y su importancia durante el almacenamiento controlado

La eliminación regional de la capa fibrosa mediante mecanismos pro-oxidantes involucra un riesgo potencial de daño al resto del tejido, en consecuencia el escutelo debe desarrollar mecanismos antioxidantes eficientes que garanticen la transición de la germinación a la postgerminación.

La SOD es considerada la primera línea de defensa antioxidante, ya que elimina al $\mathrm{O}_{2} \cdot{ }^{--}$con lo cual disminuye el riesgo de generación de ${ }^{\circ} \mathrm{OH}$ (Sharma et al., 2012). La cuantificación de la actividad total de la enzima SOD en extractos de escutelos de maíz indica que la enzima se encuentra más activa a las 18 y $36 \mathrm{~h}$ de iniciada la imbibición (Fig. 7). El aumento registrado a las 18 h se explicaría como un mecanismo para prevenir los daños oxidativos que ocurren durante las primeras horas de imbibición de las semillas (Weitbrecht et al., 2011). Mientras que a las $36 \mathrm{~h}$ la actividad de SOD es fundamental para contrarrestar los niveles de ERO generados durante la movilización de sustancias de reserva (Prodanović et al., 2007). La disminución de la actividad de SOD a las 24 h confirma que solo en este tiempo se 
registró un aumento estadístico significativo en la liberación de $\mathrm{O}_{2}{ }^{-}$desde la superficie del escutelo (Fig. 8b) lo cual apoyaría que la acumulación microambiental de ERO es importante y fundamental para el escutelo.

Las variaciones en la actividad de SOD en conjunto con la inmunodetección de la isoforma mitocondrial (Mn-SOD) que es más abundante en el parénquima que en la epidermis del escutelo (Fig. 5c y 5d) indican que a nivel intracelular existe una mayor acumulación de $\mathrm{H}_{2} \mathrm{O}_{2}$ principalmente a las 18 y 36 h de imbibición, de hecho histoquímicamente se comprobó la generación de $\mathrm{H}_{2} \mathrm{O}_{2}$ en el escutelo (Fig. 4m).

Para evitar que el $\mathrm{H}_{2} \mathrm{O}_{2}$ genere daños en el escutelo, la actividad de las peroxidasas es fundamental. En este sentido, la cuantificación de la actividad de las POD en extractos de escutelos muestra que al emplear catequina o guayacol como sustrato, existe un aumento progresivo en su actividad que alcanza un máximo a las 36 h de iniciada la imbibición (Fig. 6a, 6c), misma que pudo ser abatida por inhibidores (Fig. 6b, 6d). La inmunolocalización de la enzima indica que se encuentra abundantemente en vesículas de las células parenquimatosas, en las células epidérmicas su presencia también es destacada pero se localiza principalmente en la periferia de las células (Fig. 5a-b). Estos resultados confirman que la POD presenta una función dual, pues mientras que a nivel de escutelo su actividad fundamental es antioxidante, a nivel apoplástico presentarían una función pro-oxidante que coadyuvaría a la degradación regional de la capa fibrosa. 
La importancia de la POD se corroboró durante el almacenamiento de granos de maíz en condiciones controladas. Se ha establecido que durante el almacenamiento de semillas ocurre una pérdida de vigor y de germinación, y que el grado de degeneración de las semillas depende de mecanismos de protección específicos que incluyen la actividad de enzimas antioxidantes como la SOD, CAT y peroxidasas (Goel y Sheoran, 2003; Balešević-Tubić et al., 2005, 2010; Chauhan et al., 2011). La POD actúa como antioxidante debido a su ciclo peroxidativo durante el cual se consume el $\mathrm{H}_{2} \mathrm{O}_{2}$ mediante la oxidación de diversos sustratos, entre ellos los fenoles (Liszkay et al., 2003).

Se ha reportado que la disminución en la actividad de peroxidasas está asociada con la pérdida de la viabilidad y de la capacidad germinativa durante el almacenamiento de diversas semillas (Scialabba et al., 2002; Goel y Sheoran, 2003; Balešević-Tubić et al., 2005, 2011; Bao et al., 2011; Chauhan et al., 2011). También están involucrados otros factores como la temperatura, el tiempo y la humedad del almacenamiento, el tipo y contenido de humedad en la semilla (Yanping et al., 1999). Nuestros resultados muestran que los granos de maíz almacenados en condiciones de alta humedad y temperatura $\left(88 \%\right.$ de $\mathrm{HR}$ y $\left.25^{\circ} \mathrm{C}\right)$ se deterioraron rápidamente y después de tres meses de almacenamiento su capacidad germinativa y actividad de POD del escutelo a las $24 \mathrm{~h}$ de imbibición disminuyeron abruptamente (Fig. 11a-c).

Estos resultados son comparables con los obtenidos por Bernal-Lugo y Leopold (1992) que almacenaron granos de maíz a $75 \%$ de HR y $35^{\circ} \mathrm{C}$ y encontraron que, después de 90 días de almacenamiento, la germinación decaía abruptamente. 
Alhamdan et al. (2011) reportaron que durante el almacenamiento de semillas de zanahoria, calabaza, cebolla y tomate a $84.3 \%$ de $\mathrm{HR}$ y $25^{\circ} \mathrm{C}$, el porcentaje de germinación disminuye desde el primer y hasta el decimosegundo mes de almacenamiento. De manera similar, Mettananda et al. (2001) concluyen que el almacenamiento de semillas de maíz de la variedad Ruwan en condiciones de humedad relativa mayor a $70 \%$ y $20^{\circ} \mathrm{C}$ acorta la viabilidad del grano debido a que incrementa el contenido de humedad de la semilla lo cual acelera el deterioro del grano.

Los embriones de granos almacenados a $88 \% \mathrm{HR}$ y $7^{\circ} \mathrm{C}$ presentaron, durante los primeros once meses de almacenamiento una actividad de POD y un porcentaje de germinación que fluctuaron sobre el nivel basal que se registró al inicio del estudio. A partir del mes 12 se registraron pérdidas considerables en la actividad de POD y en la capacidad germinativa (Fig. 11a-c). Análisis histológicos de autofluorescencia de embriones de granos almacenados en condiciones de alta humedad ( $88 \%$ de HR) mostraron que tanto la capa fibrosa como la epidermis del escutelo exhibían una fluorescencia mayoritariamente verde (Fig. 13c-f, 13i-j), en comparación de la emisión azul de los mismos tejidos de embriones de granos almacenados a $40 \%$ de HR (Fig. 13a-b, 13g), que son cualitativamente igual a los escutelos de granos deshidratados (Fig. 12). Esto indica que los embriones de granos almacenados a $88 \%$ de $\mathrm{HR}$ y $7^{\circ} \mathrm{C}$ no completaron alteraciones en los componentes de la epidermis del escutelo y la capa fibrosa a las 24 h de imbibición, 
coincidiendo con que los granos presentaran intervalos de bajo vigor a no germinables a los 22 meses de almacenamiento (Fig. 11k-I).

El análisis de los resultados hasta aquí obtenidos nos permite sugerir que el almacenamiento con altos niveles de humedad ( $88 \%$ de $\mathrm{HR})$ genera un estrés oxidante acumulable que excede los niveles tolerables por el embrión, de modo que concuerda con el modelo propuesto por Bailly et al. (2008), en que la generación de estrés que supera una ventana oxidativa causa deterioro de la semilla con la concomitante pérdida de vigor. Este proceso de deterioro ocurre más rápido en altas temperaturas $\left(25^{\circ} \mathrm{C}\right)$ y más lento a bajas temperaturas $\left(7^{\circ} \mathrm{C}\right)$, originando una pérdida en la capacidad para inducir niveles antioxidantes basales, como puede ser la actividad de POD del escutelo durante la germinación (Fig. 11d-i). Esta relación en la disminución en actividad de POD y la disminución en la viabilidad de las semillas también ha sido reportada en semillas de girasol, soya, pera, algodón y cacahuate (Sung y Jeng, 1994; Goel y Sheoran, 2003; Balešević-Tubić et al., 2005, 2011; Bao et al., 2011).

Los granos almacenados a $40 \%$ de $\mathrm{HR}$ y $7^{\circ} \mathrm{C}$ mantuvieron una alta capacidad germinativa (Fig. 11c) mientras que la actividad de POD en el escutelo después de 24 h de imbibición aumentó entre los meses de almacenamiento 6 y 12 (Fig. 11a-b). Estos resultados indican que los granos, a partir de los 6 meses de almacenamiento, están sometidos a un nivel de estrés menor al generado por el almacenamiento en $88 \%$ de HR y $7^{\circ} \mathrm{C}$. En función de que el deterioro es menos severo, el vigor de los granos se mantiene en niveles medio-alto por periodos prolongados (Fig. 11j). El 
mantenimiento de un vigor medio-alto es suficiente para inducir un incremento en los mecanismos de protección durante la imbibición, de esta forma los niveles de ERO se mantienen dentro de un intervalo aceptable. Durante estas condiciones de almacenamiento, la actividad de POD protege al escutelo contrarrestando el estrés que es provocado por el almacenamiento y la germinación, ayudando a mantener las condiciones oxidantes dentro de una ventana oxidativa aceptable (Bailly et al., 2008), esto permitiría a la raíz embrionaria crecer vigorosamente y posteriormente establecerse exitosamente como plántula.

Resultados similares a los encontrados se han publicado en semillas de pera, las cuales al ser almacenadas a $4^{\circ} \mathrm{C}$ mantuvieron altos porcentajes de germinación y altos niveles de actividad de peroxidasa durante 12 meses de almacenamiento en comparación con los niveles encontrados en condiciones almacenamiento en condiciones ambientales (Bao et al., 2011). Alhamdan et al. (2011) encontraron que las semillas de zanahoria, calabaza, cebolla y tomate presentaron un porcentaje mayor de germinación cuando fueron almacenadas hasta por 12 meses a $5{ }^{\circ} \mathrm{C}$; de manera similar, el almacenamiento de las semillas bajo condiciones de humedad relativa por debajo de $58.4 \%$ permiten mantener porcentajes de germinación entre 86 y $88 \%$, similares a los obtenidos en esta investigación. Se ha postulado que el almacenamiento a $4^{\circ} \mathrm{C}$ puede mantener la viabilidad por periodos más largos, por lo cual, Pradhan y Badola (2012) recomiendan esta temperatura para el almacenamiento de la semilla de Swertia chirayita, hierba medicinal del Himalaya. 
Mantener altos niveles de vigor y germinación asociados a niveles de POD que exceden la basal registrada al inicio del almacenamiento (Fig. 11a-b), permiten que la proporción de fluorescencia verde en el escutelo después de $24 \mathrm{~h}$ de imbibición disminuya, y favorece la observación de fluorescencia azul en algunas regiones de la epidermis y la capa fibrosa (Fig. 13a-b, 13g-h). Las diferencias en las proporciones de fluorescencia azul y verde bajo las condiciones estudiadas indican que existen alteraciones en las propiedades de emisión (por ejemplo causadas por efecto de $\mathrm{pH}$ o fuerza iónica) o modificaciones en la proporción de componentes integrales de la capa fibrosa y la epidermis; entre éstos pueden incluirse fenoles como los ácidos cinámicos y la catequina que fluorescen en azul, o antocianinas, quercitrina, quercitina y kaempferol que fluorescen principalmente en verde pero que poseen un hombro basal que emite en la región del azul (Harborne, 1973; Lang et al., 1991), estos cambios de fluorescencia correlacionan con las modificaciones y cambios en la anatomía de la capa fibrosa y el escutelo.

Con los resultados obtenidos puede interpretarse que el almacenamiento en baja humedad y temperatura, permite la conservación por tiempos mayores del vigor y viabilidad del grano en comparación con el almacenamiento con humedades y temperatura mayores, lo cual concuerda con las observaciones de Eskandari (2012). El mantenimiento de un alto vigor permite el incremento de la actividad de POD en escutelo como un mecanismo de protección contra el estrés generado por el almacenamiento y germinación. 


\section{CONCLUSIONES}

Con las evidencias hasta ahora encontradas concluimos que, por su composición química, la capa fibrosa representa una barrera física que impide el libre flujo entre el escutelo y el endospermo manteniéndolos aislados en compartimentos independientes. Durante el inicio de la germinación, esta compartimentación resulta benéfica para el embrión al impedir que los recursos presentes difundan hacia el endospermo, así la cantidad de metabolitos queda en concentraciones óptimas. Los requerimientos nutricionales aumentan cuando la raíz embrionaria empieza su alargamiento, por lo que se requiere la eliminación parcial de la capa fibrosa; para que este evento se realice, la epidermis del escutelo se modifica y correlaciona con cambios en la actividad de POD y generación de compuestos reductores como fenoles, $\mathrm{O}_{2}-$ y $_{2} \mathrm{O}_{2}$.

Debido a su función dual, la POD podría participar en el proceso de eliminación de la capa fibrosa en zonas puntuales o microambientes mediante la generación de ERO cuando es necesaria la comunicación del escutelo hacia el endospermo, o bien en una forma más amplia, funcionando como una enzima antioxidante, que junto con la actividad de SOD, controlan las pozas de ERO para evitar daños y mantener la integridad y funcionalidad del escutelo durante procesos que generan estrés como el almacenamiento de los granos. 
Se comprobó que existe una correlación entre el decremento de la actividad de POD, el decremento en el porcentaje de germinación y del vigor, cuando los granos de maíz son almacenados en condiciones de alta humedad relativa y temperatura, mientras que el almacenamiento en bajas temperaturas y humedades relativas genera un menor daño y es recomendable para el almacenamiento de maíz por periodos prolongados. Estos elementos deben ser considerados durante el almacenamiento de granos en zonas costeras en las cuales al no tener control sobre las condiciones de almacenamiento se puede provocar un decremento en la calidad de los granos, que derive en pérdidas económicas por daños post-cosecha; estos daños pueden agravarse por el cambio climático generado por el calentamiento global.

Se encontró que el epitelio del escutelo a las 24 h de imbibición presenta variaciones en su autofluorescencia en función de la condición de almacenamiento y esta evidencia, junto con la disminución de la actividad de POD del escutelo podría ser usado como un marcador del grado del deterioro de granos de maíz en almacenamiento.

Este trabajo contribuye sustancialmente con conocimientos básicos del proceso germinativo en embriones de maíz, incluyendo la caracterización y la descripción de algunas funciones de la capa fibrosa, que es una estructura poco estudiada y que es muy importante para la transición de la germinación a la postgermination; sin embargo, diversos elementos quedan por ser estudiados; de 
manera que algunas perspectivas de la presente investigación, pueden agruparse en las siguientes categorías:

1) Determinación de otros elementos prooxidantes y antioxidantes durante la eliminación microambiental de la capa fibrosa. Dentro de los elementos prooxidantes es importante determinar la presencia y actividad de la enzima $N A D(P) H$ oxidasa o sus homólogos, en las regiones colindantes con la capa fibrosa; ligado a este mismo proceso es necesario determinar la presencia de metales como el $\mathrm{Fe}$ o el $\mathrm{Cu}$ que puedan coadyuvar a la generación de ERO en las regiones próximas a los sitios de degradación de la capa fibrosa.

Entre los mecanismos antioxidantes quedan pendientes por determinar, la actividad de peroxidasas de clase I al igual que de elementos antioxidantes no enzimáticos como el glutatión, el ácido ascórbico y compuestos fenólicos que pudieran evitar que la producción de ERO genere daños en el escutelo, ya sea durante el proceso de eliminación de la capa fibrosa o de procesos como el almacenamiento de los granos.

2) Regulación de la actividad de la peroxidasa durante la eliminación regional de la capa fibrosa. Toda vez que determinamos la importancia de la actividad de las peroxidasas de clase III durante la progresión de germinación a postgerminación, es necesario determinar la presencia de un mecanismo regulador del aumento de la actitud de la enzima, entre los candidatos se encuentran las fitohormonas, particularmente la auxina. Resultados preliminares de nuestro grupo de trabajo 
muestran que la actividad de peroxidasa aumenta cuando los escutelos son expuestos a la auxina sintética ácido naftalenácetico.

3) Almacenamiento prolongado de granos de maíz. Debido a que la pérdida de viabilidad ocurre durante el almacenamiento de los granos, es necesario establecer condiciones de almacenamiento que permitan conservar los granos con un alto vigor más allá de los 19 meses que hemos determinado en esta investigación.

4) Regeneración de la viabilidad de los granos deteriorados. Relacionado con el punto anterior y en función de que el establecimiento de humedades relativas y temperaturas controladas es difícil en el campo, una posibilidad es generar tratamientos que recuperen la viabilidad de los granos. Nuevamente entre los candidatos se encuentran las auxinas, aunque recientemente hemos encontrado que la imbibición de embriones con soluciones de $\mathrm{ZnCl}_{2}$ favorecen el crecimiento de la radícula en embriones que presentaban baja viabilidad.

5) Almacenamiento y cambio climático. Ya que es bien sabido que las condiciones climáticas cambiaran durante los años por venir, es necesario prever el impacto de la alteración de la humedad y de la temperatura ambiental durante el almacenamiento de granos criollos o no mejorados en condiciones ambientales. 


\section{BIBLIOGRAFÍA}

Alhamdan, M.A., Alsadon, A.A., Khalil, S.O., Wahb-Allah, M.A., Nagar, M.E. \& Ibrahim, A.A. 2011, "Influence of storage conditions on seed quality and longevity of four vegetable crops", American-Eurasian J. Agric. \& Environ. Sci., 11 (3), pp. 353-359.

Amritphale, D., Ramakrishna, P., Singh, B. \& Sharma, S.K. 2010, "Solute permeation across the apoplastic barrier in the perisperm-endosperm envelope in cucumber seeds", Planta, 231. 6, pp. 483-1494.

Apel, K. \& Hirt, H. 2004, "Reactive oxygen species: Metabolism, oxidative stress, and signal transduction", Annu Rev. Plant Biol., 55 (1), pp. 373-399.

Asakura, T., Shota, H., S., Asatsuma, S., Nanjo, Y., Nakaizumi, T., Itoh, K., Hori, H., Komatsu, S. \& Mitsui, T. 2007, "Proteomic characterization of tissue expansion of rice scutellum stimulated by abscisic acid", Biosci. Biotechnol. Biochem., 71 (5), pp. 1260-1268.

Bailly, C. 2004, "Active oxygen species and antioxidants in seed biology", Seed Sci. Res., 14 (2), pp. 93-107.

Bailly, C., El-Maarouf-Bouteau, H. \& Corbineau, F. 2008, "From intracellular signaling networks to cell death: the dual role of reactive oxygen species in seed physiology", C. R. Biol., 331 (10), pp. 806-814.

Balešević-Tubić, S., Malenčić, Đ., Tatić, M. \& Miladinović, J. 2005, "Influence of aging process on biochemical changes in sunflower seed", Helia, 28 (42), pp. 107-114.

Balešević-Tubić, S., Tatić, M., Đorđević, V., Nikolić, Z. \& Đukić, V. 2010, "Seed viability of oil crops depending on storage conditions", Helia, 33 (52), pp. 153159.

Balešević-Tubić, S., Tatić, M., Đorđević, V., Nikolić, Z., Subić, J. \& Đukić, V. 2011, "Changes in soybean seeds as affected by accelerated and natural aging", Rom Biotechnol. Lett., 16 (6), pp. 6740-6747.

Bao, J., Sha, S. \& Zhang, S. 2011, "Changes in germinability, lipid peroxidation, and antioxidant enzyme activities in pear stock (Pyrus betulaefolia Bge.) seeds during room- and low-temperature storage", Acta Physiol. Plant., 33 (5), pp. 2035-2040. 
Bechtel, D.B. \& Pomeranz, Y. 1977, "Ultrastructure of the mature ungerminated Rice (Oryza sativa) caryopsis. The caryopsis coat and the aleurone cells", Am. J. Bot., 64 (8), pp. 966-973.

Bechtel, D.B. \& Pomeranz, Y. 1978, "Ultrastructure of the mature ungerminated Rice (Oryza sativa) caryopsis. The germ", Am. J. Bot., 65 (1), pp. 75-85.

Becraft, P.W. 2007, "Aleurone cell development" en Plant Cell Monogr., 8: Endosperm, ed. O. Olsen, Springer-Verlag, Berlin, pp. 45-56.

Benz, B.F. 2001, "Archaeological evidence of teosinte domestication from Guilá Naquitz, Oaxaca", Proc. Natl. Acad. Sci., 98 (4), pp. 2104-2106.

Berger, F. 2003, "Endosperm: the crossroad of seed development", Curr. Opin. Plant Biol., 6 (1), pp. 42-50.

Bergvinson, D. \& García-Lara, S. 2004, "Genetic approaches to reducing losses of stored grain to insects and diseases ", Curr. Opin. Plant Biol., 7 (4), pp. 480-485.

Bernal-Lugo, I. \& Leopold, A.C. 1992, "Changes in soluble carbohydrates during seed storage", Plant Physiol., 98 (3), pp. 1207-1210.

Bernards, M.A. \& Lewis, N.G. 1998, "The macromolecular aromatic domain in suberized tissue: A changing paradigm", Phytochemistry, 47 (6), pp. 915-933.

Bewley, J.D. \& Black, M. 1994, Seeds: Physiology of development and germination, Plenum Press, NewYork. pp. 296-301.

Bleckmann, A., Alter, S. \& Dresselhaus, T. 2014, "The beginning of a seed: regulatory mechanisms of double fertilization", Front. Plant Sci., 5, pp. 1-12.

Bolwell, G.P., Bindschedler, L.V., Blee, K.A., Butt, V.S., Davies, D.R., Gardner, S.L., Gerrish, C. \& Minibayeva, F. 2002, "The apoplastic oxidative burst in response to biotic stress in plants: a three-component system", J. Exp. Bot., 53 (372), pp. 1367-1376.

Bourdu, R. \& Bousser, A. 1991, "Structures et infrastructures du mais au cours de la germination" in Physiologie et Production du Mais, ed. D. Picard, INRA, Paris. pp. 19-28

Brown, H.T. \& Morris, G.H. 1890, "XXX.-Researches on the germination of some of the gramineae. Part I", J. Chem. Soc. Trans., 57, pp. 458-528. 
Chauhan, D.S., Deswal, D.P., Dahiya, O.S. \& Punia, R.C. 2011, "Change in storage enzymes activities in natural and accelerated aged seed of wheat (Triticum aestivum)", Indian J. Agr. Sci., 81 (11), pp. 1037-1040.

Chen, S. \& Schopfer, P. 1999, "Hydroxyl-radical production in physiological reactions", Eur. J. Biochem., 260 (3), pp. 726-735.

Consonni, G., Gavazzi, G. \& Dolfini, S. 2005, "Genetic analysis as a tool to investigate the molecular mechanisms underlying seed development in maize", Ann. Bot., 96 (3), pp. 353-362.

Cosio, C. \& Dunand, C. 2009, "Specific functions of individual class III peroxidase genes", J. Exp. Bot., 60 (2), pp. 391-408.

Cosségal, M., Vernoud, V., Depège, N. \& Rogowsky, P.M. 2007, "The embryo surrounding region", Plant Cell Monogr., 8, pp. 57-71.

DeVries, M. \& Goggi, A.S. 2006, "Determining the extent of frost damage in maize seed using the tetrazolium test", Crop Manag (Online)., 5. doi:10.1094/CM-20060414-01-RS.

DOF, 2006. Acuerdo por el que se publican las conclusiones contenidas en los estudios del Instituto Nacional de Investigaciones Forestales, Agrícolas y Pecuarias (INIFAP) y de la Dirección General de Impacto y Riesgo Ambiental (DGIRA), para determinar los centros de origen y centros de diversidad genética de maíz en el territorio de los Estados Unidos Mexicanos. Disponible en internet desde:

http://www.dof.gob.mx/nota_detalle.php?codigo=4937236\&fecha=10/11/2006 [Con acceso el día 4 de diciembre de 2014].

DOF, 2012. Acuerdo por el que se determinan Centros de Origen y Centros de Diversidad Genética del Maíz. Disponible en internet desde: http://www.dof.gob.mx/nota_detalle.php?codigo=5276453\&fecha=02/11/2012. [Con acceso el día 4 de diciembre de 2014].

Dolfini, S., Consonni, G., Viotti, C., Prà, M.D., Saltini, G., Giulini, A., Pilu, R., Malgioglio, A. \& Gavazzi, G. 2007, "A mutational approach to the study of seed development in maize", J. Exp. Bot., 58 (5), pp. 1197-1205.

Domínguez, F. \& Cejudo, F.J. 2014, "Programmed cell death (PCD): an essential process of cereal seed development and germination", Front. Plant Sci., 5, pp. 111. 
Dumas, C. \& Rogowsky, P. 2008, "Fertilization and early seed formation", C. R. Biol., 331 (10), pp. 715-725.

Enríquez-Arredondo, C., Sánchez-Nieto, S., Rendón-Huerta, E., González-Halphen, D., Gavilanes-Ruíz, M. \& Díaz-Pontones, D. 2005, "The plasma membrane $\mathrm{H}^{+}$ATPase of maize embryos localizes in regions that are critical during the onset of germination", Plant Sci., 169, pp. 11-19.

Eschrich, W. 1975, "Sealing systems in phloem" in Encyclopedia of Plant Physiology, eds. M.H. Zimmermann \& J.A. Milburn, Springer-Verlag, Berlin, pp. 39-56.

Eskandari, H. 2012, "Seed quality variation of crop plants during seed development and maturation", Intl. J. Agron. Plant Prod., 3 (11), pp. 557-560.

Evers, T. \& Millar, S. 2002, "Cereal grain structure and development: Some Implications for quality", J. Cereal Sci., 36 (3), pp. 261-284.

Faure, J., Rusche, M.L., Thomas, A., Keim, P., Dumas, C., Mogensen, H.L., Rougier, M. \& Chaboud, A. 2003, "Double fertilization in maize: the two male gametes from a pollen grain have the ability to fuse with egg cells", Plant J., 33 (6), pp. 1051-1062.

Frahry, G. \& Schopfer, P. 2001, "NADH-stimulated, cyanide-resistant superoxide production in maize coleoptiles analyzed with a tetrazolium-based assay", Planta, 212 (2), pp. 175-183.

Fry, S.C., Willis, S.C. \& Paterson, A.E.J. 2000, "Intraprotoplasmic and wall-localised formation of arabinoxylan-bound diferulates and larger ferulate coupling-products in maize cell-suspension cultures", Planta, 211 (5), pp. 679-692.

Fry, S.C. 2004, "Oxidative coupling of tyrosine and ferulic acid residues: Intra- and extra-protoplasmic occurrence, predominance of trimers and larger products, and possible role in inter-polymeric cross-linking", Phytochem. Rev., 3, pp. 97-111.

García-Lara, S., Arnason, J.T., Díaz-Pontones, D., Gonzalez, E. \& Bergvinson, D.J. 2007, "Soluble peroxidase activity in maize endosperm associated with maize weevil resistance", Crop Sci., 47 (3), pp. 1125-1130.

Geiser-Lee, J. \& Gallie, R.D. 2005, "Aleurone cell identity is suppressed following connotation in maize kernels", Plant Physiol., 139, pp. 204-212.

Giannopolitis, C.N. \& Ries, S.K. 1977, "Superoxide dismutases. I. Occurrence in higher plants [maize, oats, peas]", Plant Physiol., 59 (2), pp. 309-314. 
Gill, S.S. \& Tuteja, N. 2010, "Reactive oxygen species and antioxidant machinery in abiotic stress tolerance in crop plants", Plant Physiol. Biochem., 48 (12), pp. 909930.

Goel, A. \& Sheoran, I.S. 2003, "Lipid peroxidation and peroxide-scavenging enzymes in cotton seeds under natural ageing", Biol. Plant., 46 (3), pp. 429-434.

Gómez, E., Royo, J., Guo, Y., Thompson, R. \& Hueros, G. 2002, "Establishment of cereal endosperm expression domains: Identification and properties of a Maize transfer cell-specific transcription factor, ZmMRP-1", Plant Cell, 14 (3), pp. 599610.

González, A.U. 1995, El maíz y su conservación. México, Trillas, México. pp. 11-16.

Graham, R.C.J., Lundholm, U. \& Karnovsky, M.J. 1965, "Cytochemical demonstration of peroxidase activity with 3-amino-9ethylcarbazole", J. Histochem. Cytochem., 13, pp. 150-152.

Harborne, J.B. 1973, "Phenolic compounds" en Phytochemical Methods. A guide to modern techniques of plant analysis, Chapman and Hall, London, pp. 33-80.

Heyno, E., Mary, V., Schopfer, P. \& Krieger-Liszkay, A. 2011, "Oxygen activation at the plasma membrane: relation between superoxide and hydroxyl radical production by isolated membranes", Planta, 234, pp. 35-45.

Hiraga, S., Sasaki, K., Ito, H., Ohashi, Y. \& Matsui, H. 2001, "A large family of class III plant peroxidases", Plant Cell Physiol., 42 (5), pp. 462-468.

Hollmann, F. \& Arends, I.W.C.E. 2012, "Enzyme initiated radical polymerizations", Polymers, 4, pp. 759-793.

Horning, E.S. \& Petrie, A.H.K. 1927, "The enzymatic function of mitochondria in the germination of cereals", Proc. R. Soc. Lond., B, Biol. Sci., 102 (716), pp. 188-206.

Jeffree, C.E. 2006, "The fine structure of the plant cuticle" en Biology of the Plant Cuticle, eds. M. Riederer \& C. Müller, Blackwell Publishing, India, pp. 11-110.

Kiesselbach, T.A. \& Walker, E.R. 1952, "Structure of certain specialized tissue in the kernel of corn", Am. J. Bot., 39 (8), pp. 561-569.

Kolattukudy, P.E. 1981, "Structure, biosynthesis, and biodegradation of cutin and suberin", Annu. Rev. Plant Physiol., 32 pp. 539-567. 
Kranner, I., Roach, T., Beckett, R.P., Whitaker, C. \& Minibayeva, F.V. 2010, "Extracellular production of reactive oxygen species during seed germination and early seedling growth in Pisum sativum", J. Plant Physiol., 167 (10), pp. 805-811.

Krishnamurty, K.V. 1988, Methods in plant histochemistry, S. Viswanathan, Chennai. pp 59-60.

Kruth, H.S. 1984, "Filipin-positive, oil red O-negative particles in atherosclerotic lesions induced by cholesterol feeding", Lab. Invest., 50, pp. 87-93.

Locquin, M. \& Langeron, M. 1995, Manual de Microscopía, Labor, España. pp. 232234.

Lagrimini, L.M. 1991, "Wound-induced deposition of polyphenols in transgenic plants overexpressing peroxidase", Plant Physiol., 96 (2), pp. 577-583.

Landry, L.G. \& Smyth, D.A. 1988, "Characterization of starch produced by suspension cell cultures of Indica rice (Oryza sativa L.)", Plant Cell Tissue Organ Cult., 15, pp. 23-32.

Lang, M., Stober, F. \& Lichtenthaler, H.K. 1991, "Fluorescence emission spectra of plant leaves and plant constituents", Radiat. Environ. Biophys., 30 (4), pp. 333347.

Liszkay, A., Kenk, B. \& Schopfer, P. 2003, "Evidence for the involvement of cell wall peroxidase in the generation of hydroxyl radicals mediating extension growth", Planta, 217 (4), pp. 658-667.

Liszkay, A., van der Zalm, E. \& Schopfer, P. 2004, "Production of reactive oxygen intermediates $\left(\mathrm{O}_{2}^{--}, \mathrm{H}_{2} \mathrm{O}_{2}\right.$, and $\left.\mathrm{OH}\right)$ by maize roots and their role in wall loosening and elongation growth", Plant Physiol., 136 (2), pp. 3114-3123.

Lopes, M.A. \& Larkins, B.A. 1993, "Endosperm origin, development, and function", Plant Cell, 5 (10), pp. 1383-1399.

Lowry, O.H., Rosebrough, N.J., Farr, A.L. \& Randall, R.J. 1951, "Protein measurement with the folin phenol reagent", J. Biol. Chem., 193, pp. 265-275.

MacGregor, A.W. \& Matsuo, R.R. 1982, "Starch degradation in endosperms of barley and wheat Kernels during initial stages of germination", Cereal Chem., 59, pp. 210-216.

MacGregor, A.W. \& Dushnicky, L. 1989, "Starch degradation in endosperms of developing barley kernels", J. Inst. Brew., 95 (5), pp. 321-325. 
Marino, D., Dunand, C., Puppo, A. \& Pauly, N. 2012, "A burst of plant NADPH oxidases", Trends Plant Sci., 17, pp. 9-15.

Mettananda, K.A., Weerasena, S.L. \& Liyanage, Y. 2001, "Effect of storage environment, packing material and seed moisture content on storability of maize (Zea mays L.) seeds", Annal Sri Lanka Depart. Agric., 3, pp. 131-142.

Mika, A. \& Lüthje, S. 2003, "Properties of guaiacol peroxidase activities isolated from corn root plasma membranes", Plant Physiol., 132 (3), pp. 1489-1498.

Minibayeva, F., Kolesnikov, O., Chasov, A., Beckett, R.P., Lüthje, S., Vylegzhanina, N., Buck, F. \& Böttger, M. 2009, "Wound-induced apoplastic peroxidase activities: their roles in the production and detoxification of reactive oxygen species", Plant Cell Environ., 32 (5), pp. 497-508.

Mochizuki, M., Yamazaki, S., Kano, K. \& Ikeda, T. 2002, "Kinetic analysis and mechanistic aspects of autoxidation of catechins", Biochim. Biophys. Acta,. 1569 (1-3), pp. 35-44.

Møller, I.M., Jensen, P.E. \& Hansson, A. 2007, "Oxidative modifications to cellular components in plants", Annu. Rev. Plant Biol., 58, pp. 459-481.

Noctor, G., Mhamdi, A. \& Foyer, C.H. 2014, "The roles of reactive oxygen metabolism in drought: not so cut and dried", Plant Physiol., 164 (4), pp.1636-1648.

Okamoto, K., Murai, T., Eguchi, G., Okamoto, M. \& Akazawa, T. 1982, "Enzymic mechanism of starch breakdown in germinating rice seeds: II. Ultrastructural changes in scutellar epithelium", Plant Physiol., 70 (3), pp. 905-911.

Olsen, O., Linnestad, C. \& Nichols, S.E. 1999, "Developmental biology of the cereal endosperm", Trends Plant Sci., 4 (7), pp. 253-257.

Olsen, O. 2001, "Endosperm development: cellularization and cell fate specification", Annu. Rev. Plant Physiol. Plant Mol. Biol., 52, pp. 233-267.

Olsen, O.A. 2004, "Nuclear endosperm development in cereals and Arabidopsis thaliana", Plant Cell, 16, pp. S214-S227.

Parre, E. \& Geitmann, A. 2005, "More than a leak sealant. The mechanical properties of callose in pollen tubes", Plant Physiol., 137, pp. 274-286.

Passardi, F., Penel, C. \& Dunand, C. 2004, Performing the paradoxical: how plant peroxidases modify the cell wall, Trends Plant Sci., 9 (11), pp. 534-540. 
Passardi, F., Cosio, C., Penel, C. \& Dunand, C. 2005, "Peroxidases have more functions than a Swiss army knife", Plant Cell Rep., vol. 24 (5), pp. 255-265.

Pearse, A.G.E. 1968, Histochemistry. Theroretical and applied. 3ra ed, Churchill, London. pp. 1090.

Piperno, D.R. \& Flannery, K.V. 2001, "The earliest archaeological maize (Zea mays L.) from highland Mexico: New accelerator mass spectrometry dates and their implications", Proc. Natl. Acad. Sci., 98 (4), pp. 2101-2103.

Pradhan, K.B. \& Badola, K.H. 2012, "Effect of storage conditions and storage periods on seed germination in eleven populations of Swertia chirayita: A critically endangered medicinal herb in Himalaya", ScientificWorldJournal, 2012, pp. 1-9.

Pressoir, G. \& Berthaud, J. 2004, "Patterns of population structure in maize landraces from the Central Valleys of Oaxaca in Mexico", Heredity, 92, pp. 88-94.

Price, M.L. \& Butler, L.G. 1977, "Rapid visual estimation and spectrophotometric determination of tannin content of sorghum grain", J. Agric. Food Chem., 25 (6), pp. 1268-1273.

Prodanović, O., Prodanović, R., Bogdanović, J., Mitrović, A., Milosavić, N. \& Radotić, K. 2007, "Antioxidative enzymes during germination of two lines of Serbian spruce [Picea omorika (Pan) Purkyně]", Arch. Biol. Sci., 59 (3), pp. 209-216.

Ramakrishna, P. \& Amritphale, D. 2005, "The perisperm-endosperm envelope in Cucumis: structure, proton diffusion and cell wall hydrolysing activity", Ann. Bot., 96 (5), pp. 769-778.

Reich, E., Schibli, A., Widmer, V., Jorns, R., Wolfram, E. \& DeBatt, A. 2006, "HPTLC methods for identification of green tea and green tea extract", J. Liq. Chromatogr. Relat. Technol., 29 (14), pp. 2141-2151.

Rockland, L.B. 1960, "Saturated salt solutions for static control of relative humidity between $5^{\circ}$ and $40^{\circ} \mathrm{C}$ ", Anal. Chem., 32 (10), pp. 1375-1376.

Rong-Lin, W., Stec, A., Hey, J., Lukens, L. \& Doebley, J. 1999, "The limits of selection during maize domestication", Nature, 398 (6724), pp. 236-239.

Ruzin, E.S. 1999, Plant microtechnique and microscopy, Oxford University Press, USA., pp 145-176.

Sabelli, P.A. \& Larkins, B.A. 2009, "The development of endosperm in grasses", Plant Physiol., 149, pp. 14-26. 
SAGARPA, 2010. Estudio de gran visión y factibilidad económica y financiera para el desarrollo de infraestructura de almacenamiento y distribución de granos y oleaginosas para el mediano y largo plazo a nivel nacional. Disponible desde: http://www.sagarpa.gob.mx/agronegocios/Documents/Estudios_promercado/GR ANOS.pdf. [Con acceso el día 4 de diciembre de 2014].

Sagi, M. \& Fluhr, R. 2001, "Superoxide production by plant homologues of the gp91 ${ }^{\text {phox }}$ NADPH Oxidase. Modulation of activity by calcium and by tobacco mosaic virus infection", Plant Physiol., 126 (3), pp. 1281-1290.

Sagi, M. \& Fluhr, R. 2006, "Production of reactive oxygen species by plant NADPH Oxidases", Plant Physiol., 141 (2), pp. 336-340.

Sakihama, Y., Cohen, M.F., Grace, S.C. \& Yamasaki, H. 2002, "Plant phenolic antioxidant and prooxidant activities: phenolics-induced oxidative damage mediated by metals in plants", Toxicology, 177, 1, pp. 67-80.

Sánchez-Linares, L., Gavilanes-Ruíz, M., Díaz-Pontones, D., Guzmán-Chávez, F., Calzada-Alejo, V., Zurita-Villegas, V., Luna-Loaiza, V., Moreno-Sánchez, R., Bernal-Lugo, I. \& Sánchez-Nieto, S. 2012, "Early carbon mobilization and radicle protrusion in maize germination", J. Exp. Bot., 63 (12), pp4513-4526.

Saulnier, L. \& Thibault, J. 1999, "Ferulic acid and diferulic acids as components of sugar-beet pectins and maize bran heteroxylans", J. Sci. Food Agric., 79 (3), pp. 396-402.

Scanlon, M.J. \& Takacs, E.M. 2009, "Kernel biology" en, Handbook of maize: Its biology", eds. J.L. Bennetzen \& S.C. Hake, Springer, New York, pp. 121-143.

Schopfer, P. 2001, "Hydroxyl radical-induced cell-wall loosening in vitro and in vivo: implications for the control of elongation growth", Plant J., 28 (6), pp. 679-688.

Schopfer, P., Liszkay, A., Bechtold, M., Frahry, G. \& Wagner, A. 2002, "Evidence that hydroxyl radicals mediate auxin-induced extension growth", Planta, 214, pp. 821828.

Scialabba, A., Bellani, L.M. \& Dell'Aquila, A. 2002, "Effects of ageing on peroxidase activity and localization in radish (Raphanus sativus L.) seeds", Eur J Histochem., 46 (4), pp. 351-358.

Sen, A., Bergvinson, D., Miller, S.S., Atkinson, J., Fulcher, G.R. \& Arnason, J.T. 1994, "Distribution and microchemical detection of phenolic acids, flavonoids, and phenolic acid amides in maize kernels", J. Agric. Food Chem., 42 (9), pp. 18791883. 
Sharma, P., Jha, A.B., Dubey, R.S. \& Pessarakli, M. 2012, "Reactive oxygen species, oxidative damage, and antioxidative defense mechanism in plants under stressful conditions", J. Bot., 2012, pp. 1-26.

Shirley, B.W. 1998, "Flavonoids in seeds and grains: physiological function, agronomic importance and the genetics of biosynthesis", Seed Sci. Res., 8 (4), pp. 415-422.

Singh, N., Kaur, A. \& Shevkani, K. 2014, "Maize: Grain structure, composition, milling, and starch characteristics" en Maize: Nutrition dynamics and novel uses, eds. D.P. Chaudhary, S. Kumar \& S. Langyan, Springer, India, pp. 65-76.

Smith, M.M. \& McCully, M.E. 1978, "A critical evaluation of the specificity of aniline blue induced fluorescence", Protoplasma, 95 (3), pp. 229-254.

Strable, J. \& Scanlon, M.J. 2009, "Maize (Zea mays): A model organism for basic and applied research in plant biology", Cold Spring Harb. Protoc., 2009 (10), pp. 3341.

Sung, J.M. \& Jeng, T.L. 1994, "Lipid peroxidation and peroxide-scavenging enzymes associated with accelerated aging of peanut seed", Physiol. Plant., 91, pp. 51-55.

Sutherland, M.W., Learmonth B.A. 1997, "The tetrazolium dyes MTS and XTT provide new quantitative assays for superoxide and superoxide dismutase", Free Radic. Res., 27(3), pp. 283-289.

Swift, J.G. \& O'brien, T.P. 1972, "The fine structure of the wheat scutellum during germination", Aust. J. Biol. Sci., 25(3), pp. 469-486.

Sytykiewicz, H. 2014, "Differential expression of superoxide dismutase genes in aphid-stressed maize (Zea mays L.) Seedlings", PLoS ONE, 9 (4), pp. e94847.

Szcziparev, S.M. 2006, "Scutellum and its role in germination" en Embriology of flowering plants. Terminology and concepts, Vol 2: Seed, ed. T.B. Batygina, Science Publishers, USA, pp. 443-446.

Taiz, L. \& Zieger, E. 2010, Plant Physiology, Fifth Edition, Sinauer Associates Inc, U.S.A., pp. 583-619.

Tan, S. \& Morrison, W. 1979, "Lipids in the germ, endosperm and pericarp of the developing maize kernel", J. Am. Oil Chem. Soc., 56 (8), pp. 759-764. 
Thomas, B.R. \& Rodriguez, R.L. 1994, "Metabolite signals regulate gene expression and source/sink relations in cereal seedlings", Plant Physiol., 106 (4), pp. 12351239.

Thoss, V., Baird, M.S., Lock, M.A. \& Courty, P.V. 2002, "Quantifying the phenolic content of freshwaters using simple assays with different underlying reaction mechanisms", J. Environ. Monit., 4 (2), pp. 270-275.

Tiwari, S.C. 1982, "Callose in the walls of mature embryo sac of Torenia fournieri", Protoplasma, 110, pp. 1-4.

Tnani, H., López, I. \& Vicient, C.M. 2011, "Control of the scutellar epithelial cell elongation during germination in maize (Zea mays L.)", Seed Sci. \& Technol., 39, pp. 253-258.

Tnani, H., López, I., Jouenne, T. \& Vicient, C.M. 2011b, "Protein composition analysis of oil bodies from maize embryos during germination", J. Plant Physiol., 168 (5), pp. 510-513.

Trasar-Cepeda, C., Gil-Sotres, F. \& Leiros de la Peña, M.C. 2003, "Determinación de la actividad catalasa del suelo" en Técnicas de análisis de parámetros bioquímicos en suelos: medida de actividades enzimáticas y biomasa microbiana, eds. C. García, F. Gil, T. Hernández \& C. Trasar, Ediciones MundiPrensa, España, pp. 232-244.

Vallejos, D.E. 1983, "Enzyme activity staining" en Isozymes in plant genetics and breeding, Part A, eds. S.O. Tanksley \& T.J. Orton, Elsevier, Amsterdan, pp. 469516.

Wang, S.M. \& Huang, A.H. 1987, "Biosynthesis of lipase in the scutellum of maize kernel", J. Biol. Chem., 262 (5), pp. 2270-2274.

Weitbrecht, K., Müller, K. \& Leubner-Metzger, G. 2011, "First off the mark: early seed germination", J. Exp. Bot., 62 (10), pp. 3289-3309.

Yamasaki, M., Tenaillon, M.I., Vroh Bi, I., Schroeder, S.G., Sanchez-Villeda, H., Doebley, J.F., Gaut, B.S. \& McMullen, M.D. 2005, "A large-scale screen for artificial selection in maize identifies candidate agronomic loci for domestication and crop improvement", Plant Cell, 17 (11), pp. 2859-2872.

Yan, D., Duermeyer, L., Leoveanu, C. \& Nambara, E. 2014, "The functions of the endosperm during seed germination", Plant Cell Physiol., 55 (9), pp. 1521-1533. 
Yanping, Y., Rongqi, G., Qingquan, S. \& Shengfu, L. 1999, "Effects of storage temperature and container type on the vigour of Welsh onion seeds with low moisture content", Aust. J. Exp. Agric., 39 (8), pp. 1025-1028.

Yim, K.O. \& Bradford, K.J. 1998, "Callose deposition is responsible for apoplastic semipermeability of the endosperm envelope of muskmelon seeds 1", Plant Physiol., 118 (1), pp. 83-90.

Young, T.E. \& Gallie, D.R. 2000, "Programmed cell death during endosperm development", Plant Mol. Biol., 44 (3), pp. 283-301. 


\section{ANEXO 1. ARTÍCULO PUBLICADO}

Peroxidase activity in scutella of maize in association with anatomical changes during germination and grain storage.

José Isaac Corona-Carrillo, Mitzi Flores-Ponce, Gerardo Chávez-Nájera y David Manuel Díaz-Pontones. 


\title{
Peroxidase activity in scutella of maize in association with anatomical changes during germination and grain storage
}

\author{
José Isaac Corona-Carrillo ${ }^{12}$, Mitzi Flores-Ponce', Gerardo Chávez-Nájera' and David Manuel Díaz-Pontones ${ }^{1 *}$
}

\begin{abstract}
The embryo of the maize grain (Zea mays L.) is separated from the starchy endosperm by a fibrous structure, which is called the fibrous layer (FL). Using histochemical staining, it was determined that the FL is composed of collapsed cellular layers that contain phenols, neutral lipids, and 1,3- $\beta$-glucan. Due to its composition, the FL prevents free diffusion and separates the embryo from the endosperm during germination. Twenty-four hours after imbibition, the scutellum epidermis initiated a series of asynchronous spatial modifications, including cell growth, the perforation of cell walls, increased peroxidase activity in the apoplastic space, and elevated levels of superoxide, phenols, and other components that interact with the fibrous layer, enabling its transformation in addition to the free flow between compartments. During storage at high relative humidity levels, which leads to fast or slow deterioration depending on the temperature, the activity of phenol peroxidase in the scutellum was associated with a loss of vigor and reduced germination capacity when compared with low temperature and low relative humidity conditions. Such deterioration is associated with alterations in autofluorescent emissions from endogenous compounds in the scutellum, indicating changes in the microenvironment or in the differential proportions of epidermal and FL components.
\end{abstract}

Keywords: Maize (Zea mays L.); Fibrous layer; Controlled deterioration; Epidermis; Scutellum; Peroxidase

\section{Background}

Maize is one of the most important crops in the world along with wheat and rice because it is used as human and cattle food and as raw material for industrial purposes (Consonni et al. 2005). Creole maize is a variety that has been generated from Prehispanic times in the central region of Mexico, which has not been fully characterized. It is a material that has been cultivated and has adapted to the conditions of Mexico, preserving diversity and genomic variability that gives to maize an ability to adapt to different environmental conditions and facilitated their dispersion. Therefore the study of these creoles maizes allows to know the common morphological-functional characteristics that after domestication have been preserved, so far some of them are unknown, and may be key factors in development, germination and seedling establishment

- Correspondence dmapaxanumuammx

'Department of Health Sciences, Division of Biological and Health Sciences, Laboratory for Tissue Biochemistry, Universidad Autónoma

Metropolitana- Lztapa lapa, Mexico Gity, Mexico

Full list of author information is available at the end of the article
These features must be taken into account for future plans of phytoimprovement.

In cereals, the endosperm is a persistent tissue (Sabelli and Larkins 2009) that works as an embryonic appendix whose primary function is the storage of carbohydrates, proteins, lipids, and minerals that feed the embryo following germination (Berger 1999). The maize endosperm is composed of the basal endosperm transfer layer, the embryo surrounding region, and the central starchy endosperm (SE), which includes the aleurone (Scanlon and Takacs 2009). For barley grain, it has been reported that the SE adjacent to the embryo consists of a layer of multistratified cells. During grain ripening, these cells are compressed and tightly packed together, while the few starch granules that are contained in the cell layer are degraded. This layer of cells was described as the crushed cell layer by MacGregor and Dushnicky (1989). The presence of a cell layer that is similar to the crushed cell layer has been reported in maize. Enriquez-Arredondo et al. (2005) found a layer with a fibrous appearance that is located between the scutellum and the endosperm

\footnotetext{
Springer

O 2014 Corona Carrillo et al; licensee Springer. This is an Open Access article distributed under the terns of the Creative Commons Attribution License (httr//aeativecammonsorg/icenses/by/40), which permits untestricted use, distribution, and reproduction in arty medium, provided the original work is properly credited.
} 
in embryos of the maize landrace Montecillos A6우 2 . Additionally, a similar structure that is located in the fibrous layer (FL) region has been described pictorially (Figure twenty one in Kiesselbach and Walker 1952; Figure one A in Tnani et al. 2011). However, these authors made no direct reference to the mentioned structure, and no specific function was assigned to it.

The embryo is formed by two structures: the embryonic axis and scutellum. The scutellum acts as a reserve that secretes, absorbs, and transfers nutrients (Dolfini et al. 2007). It is composed of epidermal cells, parenchymal cells, and components of the vascular system (EnríquezArredondo et al. 2005). Following germination, the epidermal cells are elongated towards the surface of the structure, and spaces appear between them, turning them into finger-like extensions that grow towards the SE. These modifications are typical of an epithelium (Bewley and Black 1994; Szcziparev 2006; Tnani et al. 2011).

The maize scutellum shows phenol peroxidase activity (PODa) in the basal area of the surface of the scutellum, in the root vascular cylinder, and in the aleurone layer (García-Lara et al. 2007). Class III plant peroxidases (EC 1.11.1.7) are a group of apoplastic and plasma membrane-bound enzymes that are monomeric, Nglycosylated, and contain a heme group that catalyzes the reduction of $\mathrm{H}_{2} \mathrm{O}_{2}$. Peroxidases receive electrons from various reducing donors that accumulate in most seeds, including phenolic groups, such as lignin precursors and flavonoids (Hiraga et al. 2001; Passardi et al. 2005; Winkel-Shirley 2002). These compounds act as antioxidants and are involved in latency, germination, and viability (Pourcel et al. 2007; Winkel-Shirley 2002). A wide range of physiological functions have been assigned to peroxidases, such as the cross-linking of phenolic compounds to proteins and polysaccharides (Fry 2004; Hollmann and Arends 2012), the deposit of polyphenols (Lagrimini 1991), and suberization (Bernards and Lewis 1998). Peroxidases play a dual role, functioning either as antioxidants, in which they consume $\mathrm{H}_{2} \mathrm{O}_{2}$ using a reduced molecule, or as pro-oxidants, in which they produce reactive oxygen species (ROS), such as $\mathrm{O}_{2}^{-}$or ${ }^{\circ} \mathrm{OH}$, via oxidative and hydroxylic cycles, respectively (Liszkay et al. 2003).

ROS are molecules that are produced continuously in cells by normal metabolism during development, germination, and the storage of seeds. They play a dual role, acting either in signaling pathways or as toxic products that accumulate due to stress (Apel and Hirt 2004). Therefore, their production must be finely regulated. Due to their reactivities, ROS can oxidize all types of cellular components (Møller et al. 2007); however, when their concentrations are regulated within a specific window (Bailly et al. 2008), they participate in diverse favorable processes, such as cellular elongation, which is caused by the modification and wall-loosening as a result of the hydrolysis of polysaccharide bonds by ${ }^{\circ} \mathrm{OH}$ (Schopfer 2001). When ROS concentrations exceed the oxidative window, stress is generated. This may compromise seed viability, for example, during storage (Goel and Sheoran 2003). Excessive ROS concentrations are also associated with decreased PODa in various seeds, including sunflower, soybean, pear stock, wheat, cotton and radish (Balešević-Tubić et al. 2005, 2011; Bao et al. 2011; Chauhan et al. 2011 Goel and Sheoran 2003; Scialabba et al. 2002).

The loss or reduction of germination capacity is one of the primary problem that is faced by farmers. It has been proposed that seeds have the highest vigor during physiological ripeness, which decreases slowly during storage (Goel and Sheoran 2003). Various factors affect seed viability during events that precede sowing, such as the degree of maturity, state of seed development, and mechanical damage that is caused during harvesting (Eskandari 2012) or storage. The loss of seed viability is an inevitable consequence of storage and depends primarily on the temperature and relative humidity of the storage conditions, the moisture content of the seed, the duration of storage, and the type and initial quality of the seeds (Daniel 2007).

The FL is strategically positioned between the scutellum and endosperm. Accordingly, the objective of this work was to analyze the chemical composition of the FL and its ability to generate two separate compartments: the embryo from the endosperm. At the end of germination, which is characterized by the protrusion of the radicle, we assessed the transformations that occurred in the epidermal cells of the scutellum, the spatial correlation of peroxidase activity, and modifications in the FL that paralleled changes in permeability. Likewise, we evaluated the deterioration of the embryo and corresponding alterations that occurred during storage, the epidermal cells of the scutellum, the FL and peroxidase activity following germination.

\section{Results}

Chemical composition of fibrous layer

The epidermis of the scutellum in a mature embryo is constituted of a monostratified layer of cuboidal cells (Figure 1a-d). Enveloping the scutellum is the FL, which is in intimate contact with the epidermal cells of the scutellum and generates the border of the SE as previously reported by Enríquez-Arredondo et al. (2005). The epidermal cells, the parenchyma of the scutellum, and the SE remnants show intense red staining with Oil Red O (Figure 1a) and Sudan IV (Figure 1b), indicating the presence of lipids, as expected due to their storage functions (Szcziparev 2006; Tan and Morrison 1979). Lipids are also visible in the FL region, although they are less prominent. The greatest level of fluorescence was 


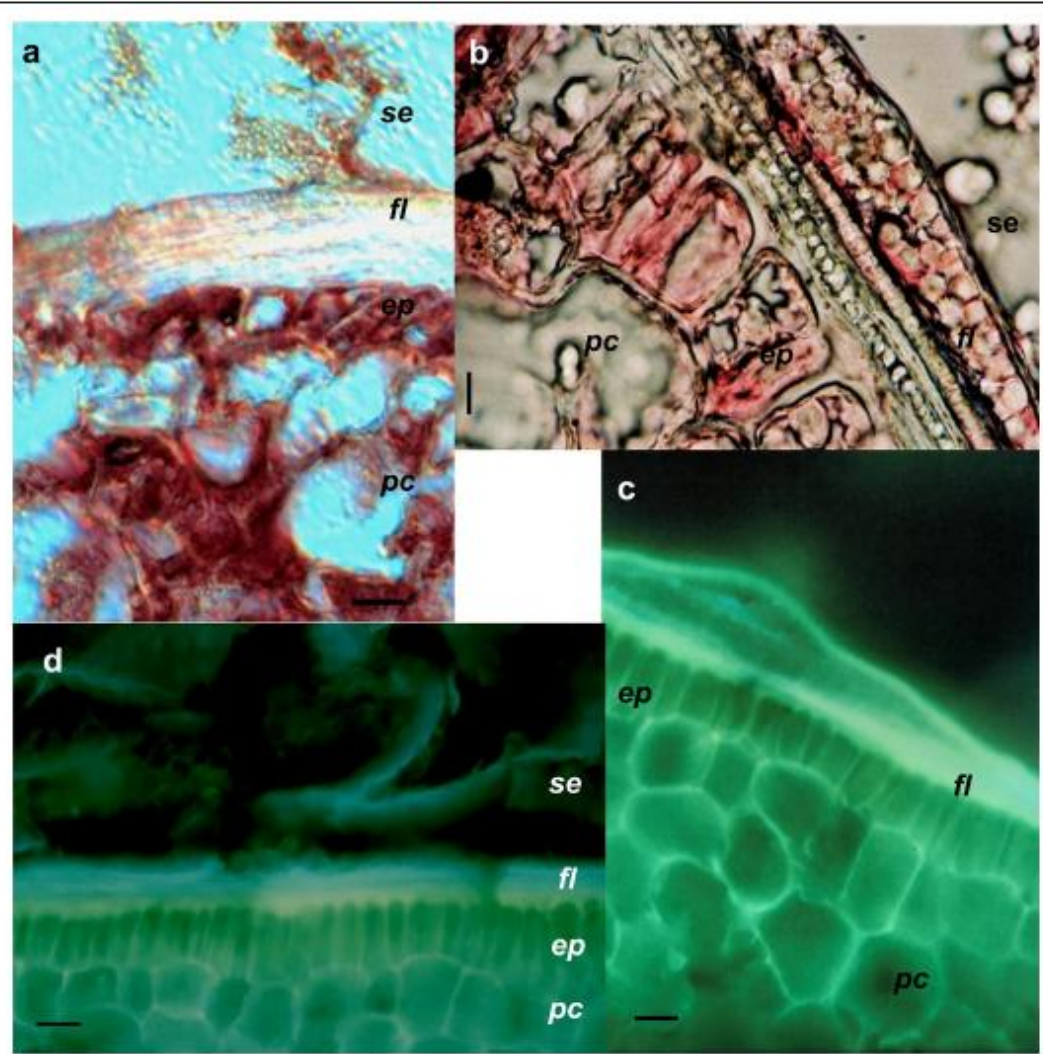

Figure 1 Chemical composition of fibrous layer. a, location of lipids detected by Oil Red O; b, location of lipids detected by Sudan IV c, fluorescence of phenols enhanced with diphenylborinic acid, $\mathbf{d}$, presence of $\beta$-glucan of the callose type identified by aniline blue Abbreviations: ep, epidermal cells; fi, fibrous layer; $p c$, parenchyma cells; se, central starchy endosperm. Bar: a-d, $50 \mu \mathrm{m}$.

detected in the FL due to the presence of phenolic compounds (Figure 1c), whereas the phenols were widely distributed on the walls of the parenchyma and the epidermal cells of the scutellum. Aniline blue, which detects $\beta$-glucanes of the callose type, showed bright blue fluorescence in the FL in contrast with the white fluorescence that was observed of the cells from the epidermis and parenchyma (Figure 1d).

\section{Permeability of fibrous layer}

Under native conditions, a longitudinal cut of a dry grain of maize showed a yellow coloration in the pericarp, white in the endosperm, and pale yellow in the scutellum-embryonic axis (Figure 2a). This allowed for the visual contrast of regions during the assay and the examination of stain diffusion through the FL. In those grains where structural integrity was maintained, an external brown staining of the pericarp by $\mathrm{I}_{2}$-KI was evident without penetration of the dye, and the endosperm and embryo displayed their natural colors (Figure 2b).
Perforation through the embryo or endosperm without causing damage to the $\mathrm{FL}$ enabled the diffusion of $\mathrm{I}_{2}-\mathrm{KI}$ or Brilliant Green, which stained either the embryo (Figure 2d, 2f) or the endosperm (Figure $2 \mathrm{~g}$ ) exclusively, depending on which of the two structures had been punctured. The diffusion speed of $\mathrm{I}_{2}$ - $\mathrm{KI}$ in the endosperm was slower than that in the embryo, indicating a lower diffusion index. However, when the dye came into contact with the FL, it diffused preferentially, surrounding the FL through the endosperm without penetrating the embryo, indicating the existence of a barrier to diffusion between the two structures (Figure 2e). When the grains were perforated from the embryo through the FL, $\mathrm{I}_{2}-\mathrm{KI}$ diffused freely, staining the embryo and the endosperm (Figure 2c). Grains that were perforated from the endosperm and then treated with acetone (Figure $2 \mathrm{~h}$ ) or chloroform (Figure 2i) and those that were perforated from the embryonic chamber and treated with acetone:chloroform (Figure 2j) showed the free diffusion of Brilliant Green between the two organs, independent of the perforation site. 


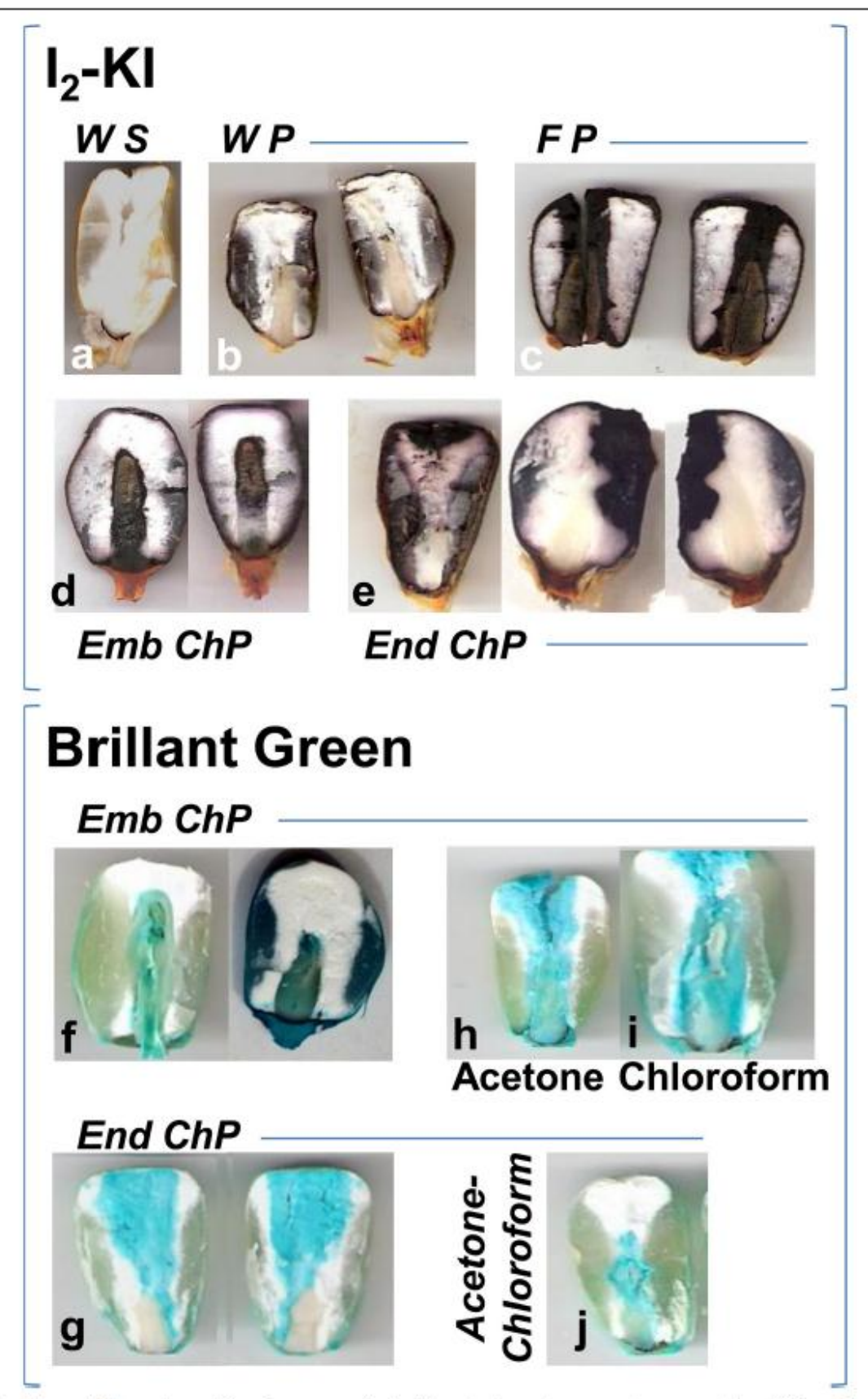

Figure 2 Diffusion through fibrous layer. Dry grains were perforated through the embryo or endosperm, and the diffusion of aqueous or ethanol dyes was assessed; $\mathbf{a}$, grain without stain; $\mathbf{b}$-e, diffusion of $\mathrm{I}_{2}-\mathrm{K}$; $\mathbf{f - j}$, diffusion of Brilliant Green; $\mathbf{b}$, grain without perforation; $\mathbf{c}$, grain perforated through both compartments; $\mathbf{d}$ and $\mathbf{f}$, perforation through embryo; $\mathbf{e}$ and $\mathbf{g}$, perforation through endosperm; $\mathbf{h}$ and $\mathbf{i}$, grains perforated through endosperm, and $\mathbf{h}$, treated with acetone, or $\mathbf{i}$, treated with chloroform; $\mathbf{j}$ grains perforated through embryo and treated with acetone:chloroform. Abbreviations: WS, without stain; WP, without perforation; FP, full perforation; Emb ChP, embryo chamber perforation; End ChP, endosperm chamber perforation. 
These results imply the following with respect to dry grains: 1) the integrity of the FL prevents the free diffusion of aqueous or ethanol-based dyes beyond the point of administration; 2) ethanol, which was the solvent that was used for the Brilliant Green dye, does not alter the structure of the FL within the time frame of the present study; and 3) treatments with acetone, chloroform, or an acetone:chloroform mixture allows for the removal of non-polar components that are present in the FL, thus favoring the diffusion of the ethanol-based stain between the two compartments.

\section{Effect of imbibition on morphology of epidermal cells of scutellum}

After $24 \mathrm{~h}$ of imbibition, the epidermis that was adjacent to the FL showed monostratified areas (Figure 3a), similar to that which was reported by (Enríquez-Arredondo et al.
2005). Some of the epidermal cells were cuboid, while others showed expanded basal poles (Figure 3a). In other regions, the epidermal cells had lost their regular monostratified arrangements (Figure $3 \mathrm{~b}$ ) and showed PODa in situ with increasing staining intensities towards their apical regions (Figure $3 c, 3 d$ and $3 e$; Additional file 1a). Some cells developed elongated finger-like extensions (Figure $3 \mathrm{~b}, 3 \mathrm{~g}$ ), while others had perforated cell walls (Figure 3f), allowing for the extrusion of the cellular contents into the apoplastic space between the epidermis and the FL (Figure $3 \mathrm{~g}$ and $3 \mathrm{~h}$ ), which turned red-brown as a result of PODa (Figure 3i). These findings were confirmed by the activity that was detected by aminoethylcarbazole (AEC) or guaiacol in the germinator (Additional file 1b).

The aforementioned anatomical changes are asynchronous over the surface of the scutellum, occurring three

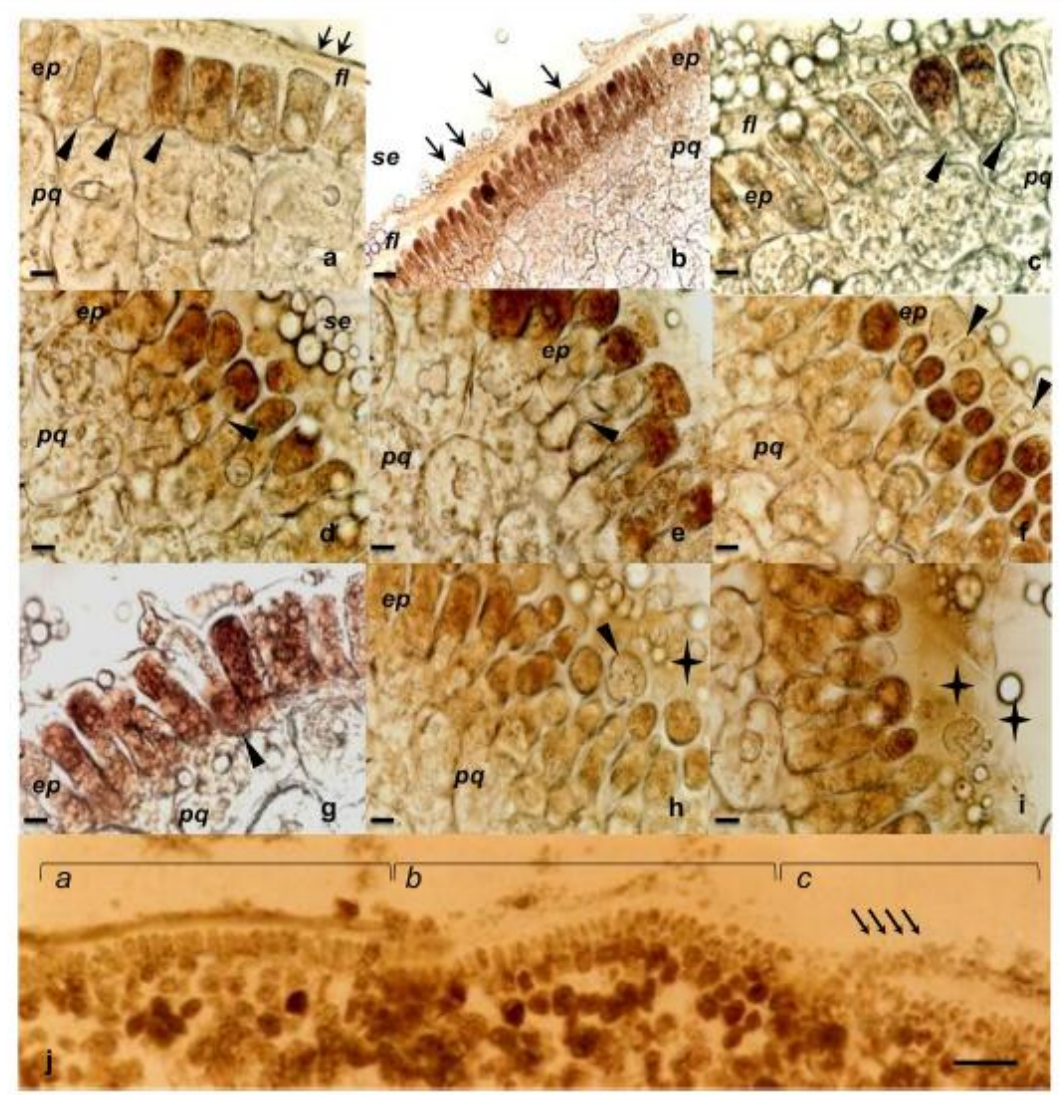

Figure 3 Changes in epidermal cell morphologies following 24 hrs of imbibition. $\mathbf{a}-\mathrm{j}$, in situ PODa, $\mathrm{AEC}+\mathrm{H}_{2} \mathrm{O}_{2}$; $\mathbf{a}-\mathbf{b}$, view of scutellum epidermis and parenchyma; $\mathbf{c}-\mathbf{i}$, transformation of epidermis, presence of $\mathrm{PODa}$ in apoplast, and regional alterations of $\mathrm{FL} ; \mathbf{j}$, ares of scutellum where 3 regions are observed, showing asynchrony of transformation process for epidermis and FL; the section was incubated with AEC without $\mathrm{H}_{2} \mathrm{O}_{2}$ showing sites of production of endogenous peroxides. Abbreviations: ep, epidermal cells; ff, fibrous layer; $p c$, parenchyma cells; se, central starchy endosperm. Symbols: $\mathbf{A}$, epidermal cells in the process of transformation; $\uparrow$, structural changes in fibrous layer; $\downarrow$, apoplastic PODa. Bar: a, c-i: $50 \mu \mathrm{m} ;$ b: $125 \mu \mathrm{m} ;$; $500 \mu \mathrm{m}$. 
regions that possess different degrees of modifications of the epidermis and fibrous layer. For example, the monolayered (Figure 3ja) region passes through the epidermis, which extrudes its contents (Figure 3jb) to a region with extensive changes in the FL (Figure 3jc). Later, at $36 \mathrm{~h}$ imbibition, the epidermal cells becomes papillate cells (Additional file 1c), which have been reported by Szcziparev (2006) to acquire the characteristics of an epithelium.

\section{Quantification of peroxidase activity in scutellum}

Because of the correlation between the alterations in the tissues on the scutellum surface and the location of $\mathrm{PODa}$, it was of interest to quantify the PODa in the scutellum between 18 and $36 \mathrm{~h}$ of imbibition. The results indicated the presence of $30 \%$ and $22 \%$ increased PODa levels when catechin and guaiacol were the substrates between 18 and $24 \mathrm{~h}$, and more dramatic increases (282\% and $92 \%$, respectively) between 24 and $36 \mathrm{~h}$ (Figure $4 \mathrm{a}$ and $4 \mathrm{c}$ ). The differential proportion of activity between catechin and guaiacol amounted to 8.9-fold at $18 \mathrm{~h}, 8.3$-fold at $24 \mathrm{~h}$, and only 4.1 -fold at $36 \mathrm{~h}$, indicating that increases in PODa occur that are dependent upon the substrate and that different peroxidase isoforms may be preferred during germination. Using peroxidase inhibitors, it was observed that, between 18 and $36 \mathrm{~h}, \mathrm{KCN}$ induced between $93 \%$ and $99 \%$ inhibition when catechin was the substrate and between $96 \%$ and $99 \%$ inhibition when guaiacol was the substrate. The addition of salicylhydroxamic acid (SHAM) during the same period induced between $20 \%$ and $30 \%$ inhibition when catechin was the substrate and between $67 \%$ and $84 \%$ inhibition when guaiacol was the substrate (Figure $4 \mathrm{~b}$ and $4 \mathrm{~d}$ ). These results confirm the activity of phenol peroxidase in the scutellum.

\section{Quantification of extruded reduction power}

Superoxide has been reported to reduce XTT (Liszkay et al. 2004) and was observed to diffuse from the surface of the scutellum (Figure $5 \mathrm{a}-\mathrm{c}$ ). The extruded component exhibited similar capacities for basal reduction after 18 , 24, and $36 \mathrm{~h}$ of imbibition (Figure $5 \mathrm{a}-\mathrm{c}$; first column). When $200 \mu \mathrm{M}$ NADH, $200 \mu \mathrm{M}$ NADPH, $50 \mu \mathrm{M}$ of $\mathrm{CuCl}_{2}, \mathrm{NADH}+\mathrm{CuCl}_{2}$, or $\mathrm{NADPH}+\mathrm{CuCl}_{2}$ were added, the reduction capacity that were detected in 18 and $36 \mathrm{~h}$ of imbibition were not statistically significant (Figure $5 \mathrm{a}$ and $5 \mathrm{c}$ ). However, in embryos after $24 \mathrm{~h}$ of imbibition, the reduction power following the addition of $200 \mu \mathrm{M}$ NADH or NADPH to the medium increased by $91 \%$ and $56 \%$, respectively. The addition of $50 \mu \mathrm{M} \mathrm{CuCl}_{2}$, which has been reported to be a scavenger of $\mathrm{O}_{2}^{-}$(Liszkay et al. 2004), did not lead to changes in the basal reduction for $\mathrm{XTT}$ in vivo. However, the addition of $\mathrm{CuC}_{2}$ in the
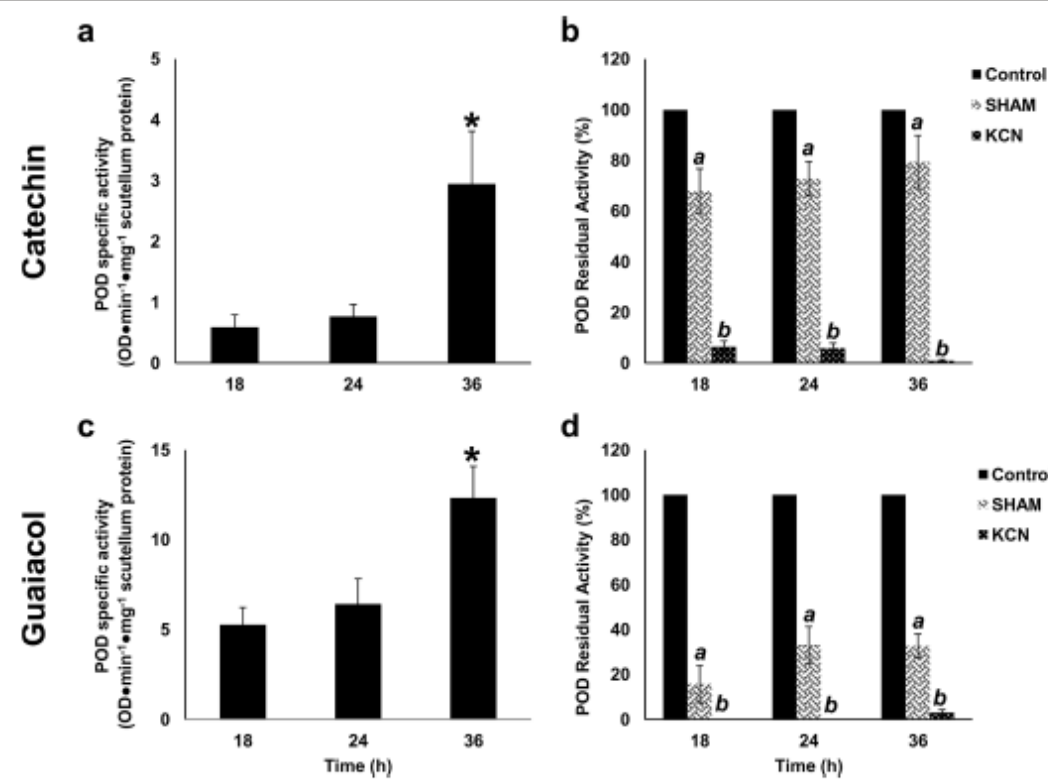

d

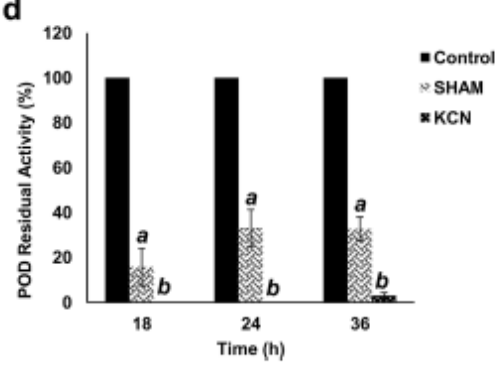

Figure 4 Peroxidase activity in maize scutella. a, activity detected with catechin $+\mathrm{H}_{2} \mathrm{O}_{2}$ b inhibiting effects of $\mathrm{KCN}$ and SHAM in presence of catechin $+\mathrm{H}_{2} \mathrm{O}_{2}$; , activity detected with guaiacol $+\mathrm{H}_{2} \mathrm{O}_{2}$, d, inhibiting effects of $\mathrm{KCN}$ and $\mathrm{SHAM}$ in presence of guaiacol $+\mathrm{H}_{2} \mathrm{O}_{2}$, Results are shown as means \pm standard deviations (SD), $n=6$. An ANOVA test and Tukey-Kramer Multiple-Comparison Test were performed with $p<0.05$. Symbols: data groups with different letters imply significant differences; *, statistically significant group; $a$, significant effect of SHAM with respect to control; $b$, significant effect of $\mathrm{KCN}$ with respect to control. 


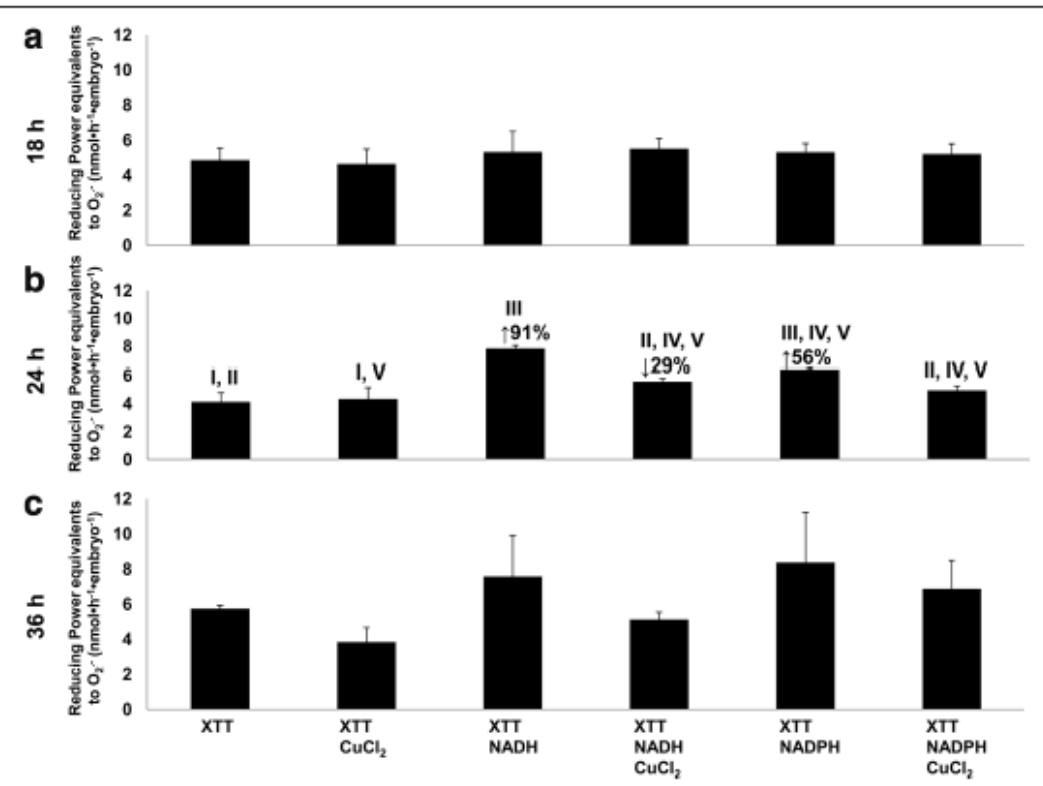

Figure 5 Superoxide equivalents extruded by scutellar epidermis. Reduction of XTT by substances produced from surface of scutellum in presence of one of the following conditions: $\mathrm{CuCl}_{2}, \mathrm{NADH}, \mathrm{NADPH}, \mathrm{NADH}+\mathrm{CuCl}_{2}$, or NADPH $+\mathrm{CuCl}_{2} ; \mathbf{a}$, after $18 \mathrm{~h} ; \mathbf{b}$, after $24 \mathrm{~h} ; \mathbf{c}$, after $36 \mathrm{~h}$ of imbibition. Results are shown as means $\pm S D$ of $n=3$. ANOVA and Tukey-Kramer Multiple-Comparison Tests were performed with $p<0.05$. Symbols: data groups with different numbers imply significant differences; $\uparrow \%$, represents percent increase in reduction capacity; $\downarrow \%$, represents percent decrease in reduction capacity.

presence of $\mathrm{NADH}$ resulted in a significantly decreased reduction capacity of $29 \%$, and a diminution of $24 \%$ was observed with NADPH (Figure 5b), indicating the presence of $\mathrm{O}_{2}^{-}$among the compounds that were extruded from the surface of the scutellum.

Because compounds with reducing capacities were extruded from the scutellum to the apoplast, other components were assayed in vitro to determine their interactions with XTT (Table 1). At concentrations within the $\mathrm{mM}$ range, the highest reduction capacity was observed with catechin, the lowest with gallic acid, and intermediate levels were detected with ascorbic acid. At concentrations in the $\mu \mathrm{M}$ range, $\mathrm{CuCl}_{2}$ showed the same reduction power as gallic acid. The capacity for NADH to reduce XTT was similar to that of $\mathrm{CuCl}_{2}$ at equimolar conditions while that of NADPH was slightly lower. These results indicate that the compounds that are extruded from the scutellum (Figure 5, first column) may potentially include other types of reducing factors. It has been reported that the scutellum surface adjacent to the endosperm can reduce ferricyanide (Szcziparev 2006), which had been previously reported for the in situ localization of phenols (Price and Butler 1977). For this reason, the $\mathrm{FeCl}_{3}-\mathrm{K}_{3} \mathrm{Fe}(\mathrm{CN})_{6}$ reduction power was measured in the scutellum extrudates following 18, 24, and $36 \mathrm{~h}$ of imbibition, in which the amount of extruded phenols did not significantly change between measurements, although there was a slight increase after $24 \mathrm{~h}$ of imbibition of $17 \%$ or $47 \%$ when compared with the measurements that were obtained after 18 or $36 \mathrm{~h}$ of imbibition (Figure 6). These results indicate that reduced phenols in the apoplast can be found within a timeframe that is strictly regulated and coincides with the maintenance of basal values of XTT reduction (Figure 5, first column).

\section{Table 1 Compounds effects in reduction of XTT in vitro}

\begin{tabular}{lc}
\hline Substance & XTT reduction equivalents $(\mathbf{n m o l})^{\mathrm{a}}$ \\
\hline $\mathrm{CuCl}_{2}(50 \mathrm{uM})^{\mathrm{b}}$ & $1.71 \pm 0.28$ \\
Gallic acid $(7.8 \mathrm{mM})^{\mathrm{c}}$ & $1.72 \pm 0.87$ \\
$\mathrm{NADPH}(200 \mathrm{uM})^{\mathrm{d}}$ & $4.36 \pm 1.26$ \\
$\mathrm{NADH}(200 \mathrm{uM})^{\mathrm{d}}$ & $6.79 \pm 0.39$ \\
Ascorbic acid $(50 \mathrm{mM})^{\mathrm{c}}$ & $26.45 \pm 0.22$ \\
Catechin $(5 \mathrm{mM})^{\mathrm{e}}$ & $48.04 \pm 5.75$
\end{tabular}

athe equivalent reducers were determined using the molar extinction coefficient of XTT: EXTT $=2.16 \times 10^{4} \mathrm{~mol}^{-1} \mathrm{~cm}^{-1}$ (Sutherland and Learmonth 1997):

'concentration reported as $\mathrm{O}_{2}$-scavenger (Liszlay et al. 2004); ' concentrations of phenols per embryo, the phenols are detached from the scutellar surface in maize embryos with 24 hours of imbibition; ${ }^{d}$ concentrations reported by Frahry and Schopfer (2001); "concentration calculated from constant rates of

ROS scavenging. 


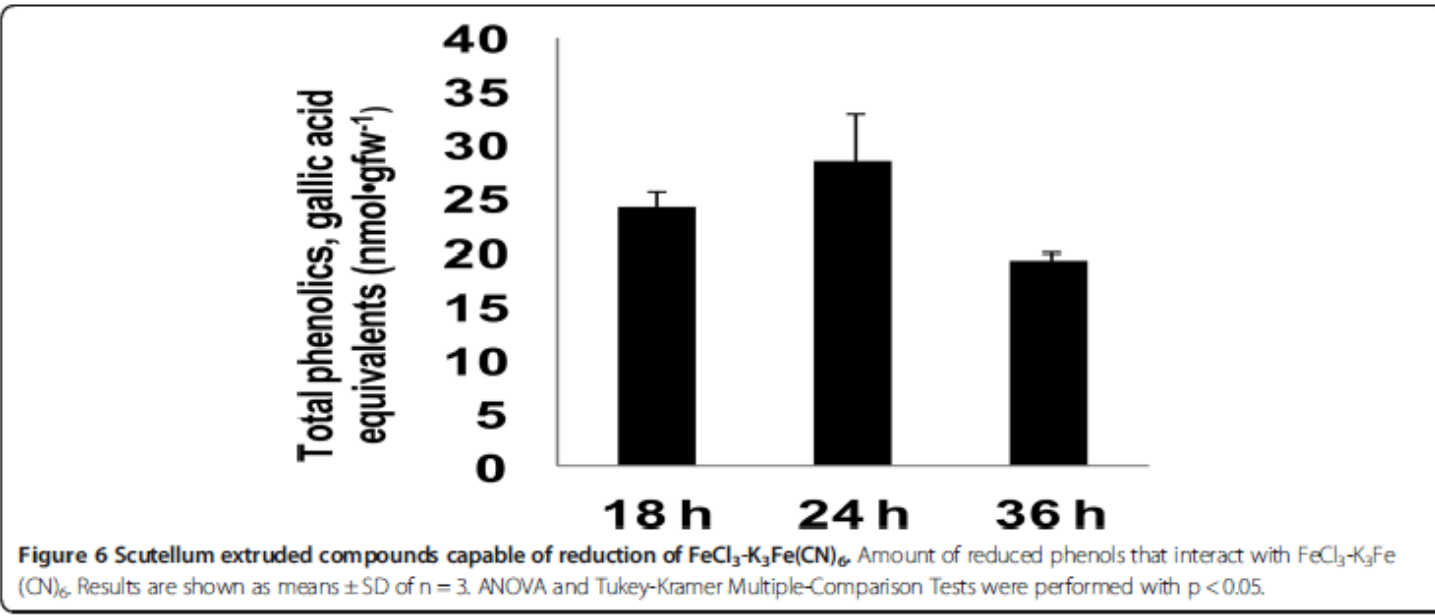

Effects of storage on peroxidase activity, vigor and autofluorescence of endogenous compounds

In the scutellum after $24 \mathrm{~h}$ of imbibition, the PODa levels fluctuated around a constant value for samples that had been stored between 0 to 6 months at $40 \%$ and $88 \% \mathrm{RH}$ and $7{ }^{\circ} \mathrm{C}$ with high germination rates. For samples that had been stored at $88 \% \mathrm{RH}$ and $25^{\circ} \mathrm{C}$, after $24 \mathrm{~h}$ of imbibition, the PODa levels and germination rates decreased and reached zero in the third month (Figure $7 \mathrm{a}, 7 \mathrm{~b}$, and $7 \mathrm{c}$ ).

In the SG between 8 and 12 months at $40 \% \mathrm{RH}$ and $7^{\circ} \mathrm{C}$, the scutellum after $24 \mathrm{~h}$ of imbibition showed significantly increased PODa levels compared with the initial values, with maximum activity levels being detected between 8 and 9 months with catechin (Figure 7a) and at 8 months with guaiacol (Figure $7 \mathrm{~b}$ ). These activity levels remained elevated until 12 months. Unlike the SG at $88 \% \mathrm{RH}$ and $7^{\circ} \mathrm{C}$, the PODa with catechin showed similar fluctuations as those which were observed between 3 to 6 months (Figure 7a). The PODa increased at 8 months with guaiacol and then declined at 12 to 13 months to similar levels as those that were detected at the beginning of the experiment (Figure $7 \mathrm{~b}$ ). The $\mathrm{SG}$ at $40 \% \mathrm{RH}$ and $7{ }^{\circ} \mathrm{C}$ maintained its germination rates at a mean value of $90 \%$ until 12 months, while the embryos that had been extracted from storage at $88 \% \mathrm{RH}$ and $7{ }^{\circ} \mathrm{C}$ maintained $78.8 \%$ germination rates during the first 3 months and fluctuated downward until 12 months, when they reached a significantly lower germination rate of $42 \%$ (Figure 7c).

After 12 months of storage at $40 \% \mathrm{RH}$ and $7^{\circ} \mathrm{C}$, the PODa in the scutella after $24 \mathrm{~h}$ of imbibition decreased, reaching its baseline value at 17 months with catechin or guaiacol. This activity is significant with respect to the maximum values that were obtained but is similar to the PODa that was observed at baseline (Figure 7a and $7 \mathrm{~b})$. For the same frame time, in SG at $88 \% \mathrm{RH}$ and $7{ }^{\circ} \mathrm{C}$, the PODa decreased below initial levels and reached a minimum value between 17 to 19 months (Figure 7a and $7 \mathrm{~b}$ ). During this time frame, the germination rate for SG at $40 \% \mathrm{RH}$ and $7{ }^{\circ} \mathrm{C}$ was similar to that which was found at the start of the study. The germination rate of samples that had been stored at $88 \% \mathrm{RH}$ and $7^{\circ} \mathrm{C}$ decreased below $30 \%$ with a minimum value of $3.3 \%$, which was observed at 18 months (Figure 7c).

When storage was extended to 22 months, the SG at $40 \% \mathrm{RH}$ and $7^{\circ} \mathrm{C}$ showed high (Figure 7jc) to medium vigor (Figure 7ja,b), whereas that at $88 \%$ RH and 7 or $25^{\circ} \mathrm{C}$ showed low vigor (Figure 7ka; 7la) and in some cases, grains were ungerminable (Figure $7 \mathrm{~kb}$, $7 \mathrm{kc}, 7 \mathrm{lb}, 7 \mathrm{lc})$.

The storage conditions at $88 \% \mathrm{RH}$ and $25^{\circ} \mathrm{C}$ or $7^{\circ} \mathrm{C}$ caused a fast or slow deterioration, respectively. Accordingly, the loss of grain viability with a concomitant diminution in PODa below the baseline, which was recorded at the beginning of the assay in embryos following $24 \mathrm{~h}$ of imbibition, was detected. Moreover, in SG at $40 \% \mathrm{RH}$ and $7^{\circ} \mathrm{C}$, a high vigor and germination rate was found in accordance with the baseline value or higher levels of $\mathrm{PODa}$ at $24 \mathrm{~h}$ of imbibition (Figure $7 \mathrm{~d}-\mathrm{i}$ ).

Because PODa levels increased at 9 months of storage in comparison with levels that were observed at the beginning of the assay and germination rates remained high, a comparative anatomical study was performed between embryos (at $24 \mathrm{~h}$ of imbibition) from the SG after 1 and 9 months. The results showed that the anatomy of the scutellum epidermis corresponded with monostratified and uninucleate cell layer, which were independent of storage conditions (Figure 3a-e and Figure 8). The scutellum and FL of the embryos of the dry grain (Additional file 2) showed autofluorescence in three parts of the spectrum: red $\left(\mathrm{F}_{626-635} \mathrm{~nm}\right)>$ green $\left(\mathrm{F}_{512} \mathrm{~nm}\right)>$ blue $\left(\mathrm{F}_{460 \mathrm{~nm}}\right)$. After $24 \mathrm{~h}$ of imbibition, the scutella from the 


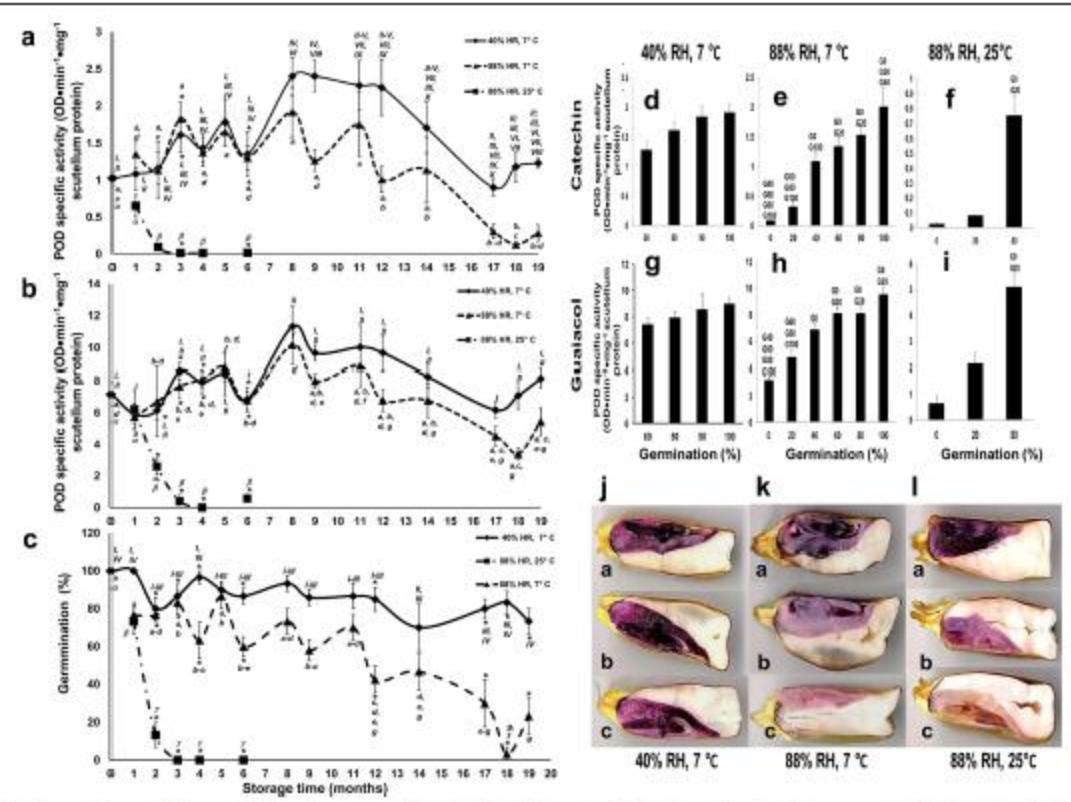

Figure 7 Quantification of peroxidase activity in scutella of grains kept under controlled storage; germination and vigor assay. PODa is shown, with: $\mathbf{a}$, catechin $+\mathrm{H}_{2} \mathrm{O}_{2}$ and $\mathbf{b}$, guaiacol $+\mathrm{H}_{2} \mathrm{O}_{2}$ in extracts of scutella from maize grains that were stored up to 19 months. Activities were quantified after $24 \mathrm{~h}$ of imbibition; c, germination after $24 \mathrm{~h}$ of imbibition; correlation between germination and PODa, $\mathrm{d}-\mathrm{f}$ quantified with catechin $+\mathrm{H}_{2} \mathrm{O}_{2}$ g-i quantified with guaiacol; $\mathrm{j}-$, vigor assays with MTT, which was applied to grains at end of storage time. Results are shown as means \pm SD with up to 12 independent assays. ANOVA followed by a Tukey-Kramer Multiple-Comparison Tests were performed with $p<0.05$. Symbols: data groups with different letters or numbers from the same storage conditions imply significant differences; and *, statistically significant differences comparing different treatments with same storage time.

SG at $40 \% \mathrm{RH}$ and $7^{\circ} \mathrm{C}$ for 1 and 9 months had lower proportion of green vs blue emissions compared with those that were unimbibed (Additional file 2). The FL was observed to fluoresce blue, varying in appearance between a fibrous (Figure 8a) and loose consistency (Figure $8 \mathrm{~g}$ ), and in some specific areas, autofluorescence disappeared (Figure $8 \mathrm{~b}$ ), although the scutellum remained structured (Figure $8 \mathrm{~h}$ ). In the scutellar epidermis and the FL from the SG after 1 month at $88 \% \mathrm{RH}$ and $7^{\circ} \mathrm{C}$ from $24 \mathrm{~h}$ of imbibition, green fluorescence predominated, and blue fluorescence was observed in the remainder of the scutellum (Figure $8 \mathrm{c}$ ). In the basal area of the

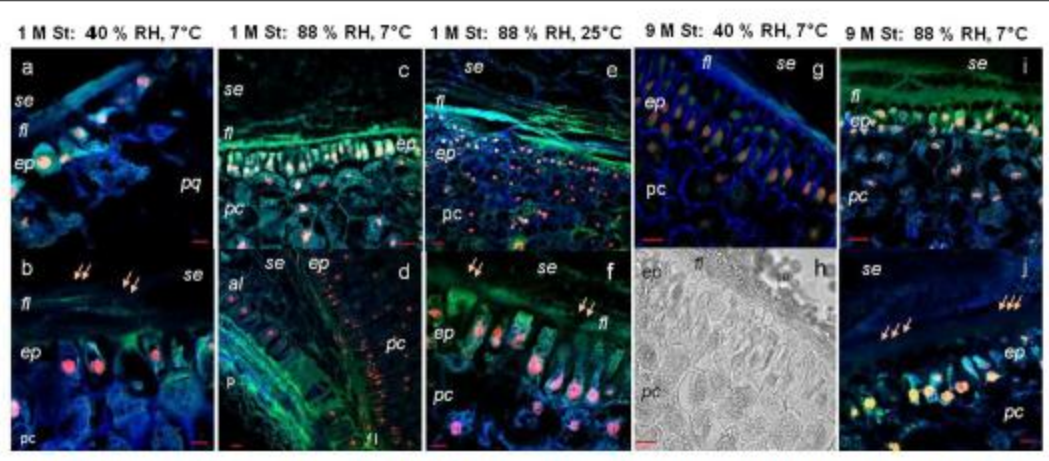

Figure 8 Autofluorescence of scutella after $24 \mathrm{~h}$ of imbibition from grains stored under controlled conditions. a-f, 1 month of storage; g-j, 9 months of storage; where $\mathbf{a}, \mathbf{b}, \mathbf{g}$, and $\mathbf{h}$ at $40 \% \mathrm{RH}$ and $7^{\circ} \mathrm{C}, \mathbf{c}, \mathbf{d}, \mathbf{i}$ and $\mathbf{j}$ at $88 \% \mathrm{RH}$ and $7^{\circ} \mathrm{C}$; e and $\mathbf{f}$ at $88 \% \mathrm{RH}$ and $25^{\circ} \mathrm{C}$. Abbreviations al, aleurone layer; ep, epidermis; fi, fibrous layer, p, pericarp, pc, parenchyma cells; se, central starchy endosperm. Symbols: $\rightarrow$, modification of emission by the FL Bars: $\mathbf{a}, \mathbf{b}$, and $\mathbf{f}: 10 \mu \mathrm{m} ; \mathbf{c}$-e and $\mathbf{g - j}: 20 \mu \mathrm{m}$. 
scutellum, where the epidermis, SE, and aleurone layer meet (Figure 8d), the FL maintained its green fluorescence. After 9 months, the parenchyma of the scutellum maintained its emission patterns, whereas the FL, which had a loose structure, and the epidermis showed predominately green (Figure $8 \mathrm{i}$ ) or blue (Figure $8 \mathrm{j}$ ) fluorescence. After 1 month, the scutella of the SG at $88 \% \mathrm{RH}$ and $25^{\circ} \mathrm{C}$ had an epidermis that displayed blue autofluorescence (Figure 8e). Additionally, the apical section of the epidermis emitted green autofluorescence, and in the basal portion of the cell, blue fluorescence predominated (Figure 8f). The FL primarily fluoresced green, either continuously or in small sections, and the subjacent parenchymal cells fluoresced blue (Figure $8 \mathrm{e}$ and $8 \mathrm{f}$ ).

\section{Discussion}

The presence of an FL limiting the SE, which has been reported by Enríquez-Arredondo et al. (2005), has been confirmed in the present study using maize grains of Chalco. It was observed that the FL forms a continuous layer that envelopes the embryo from the basal to the apical region. In maize, the FL consists of compacted cellular walls that originate from the peripheral strata of the SE, which is in contact with the scutellum (Bourdu and Bousser 1991) and is homologous to the structure that is found in other cereals, such as rice (Bechtel and Pomeranz 1977; Okamoto et al. 1982), wheat (Swift and O'brien 1972), and barley (MacGregor and Matsuo 1982; MacGregor and Dushnicky 1989).

This study adds to existing reports describing the chemical composition of the FL, which includes collapsed walls that contain lipids, phenols, and a $\beta$-glucan of the callose type. The presence of phenols is in accordance with the distribution of compounds that surround the scutellum, which was previously described but not defined by Sen et al. (1994) and Bergvinson and García-Lara (2004). The callose in the cell walls is known to contribute to the hermetic sealing of the tissues where it is deposited (Parre and Geitmann 2005; Tiwari 1982) and to provide a matrix for the association of other components of the cell wall (Eschrich 1975), including phenols, which participate in the assembly of polysaccharides with structural proteins (Fry et al. 2000; Saulnier and Thibault 1999). Some of them may form suberin or cutin by chemical bonds that are formed with lipids (Kolattukudy 1981), which occurs in the embryonic sac or in the cuticle-like layer that is found in the soybean (Chamberlin et al. 1993), thus contributing to the generation of semi-permeable structures, such as the envelope of the perisperm-endosperm that is found in muskmelon and cucumber seeds (Amritphale et al. 2010; Ramakrishna and Amritphale 2005; Yim and Bradford 1998). Crushed cell walls in the FL with deposits of $\beta$-glucan of the callose type may form a mesh with pores in which lipids and phenols could be inserted, contributing to the function of the FL as a diffusion barrier (Figure 1 and 2). This barrier generates two separate compartments, and in this way, the embryo remains isolated in the dry grain.

The independence that is maintained by the two compartments when the $\mathrm{FL}$ is intact may benefit the embryo because it enables the compartmentalization of signals and metabolic processes that are produced during germination. This compartmentalization prevents the diffusion of signals and other components to the rest of the grain and maintains the optimum concentrations of the metabolites that are necessary during this stage. During early postgermination, an increase in the nutrient demand by the growing embryo axis leads to a decrease in the reserves of the scutellum. Therefore, it is indispensable for the embryo to transform the FL, enabling the diffusion of amylolytic enzymes from the scutellum to the endosperm and of signals from the embryo to the aleurone, inducing amylase and protease synthesis (among other enzymes), allowing for the absorption of hydrolyzed reserves from the SE by the scutellar epithelium (Okamoto et al. 1982; Szcziparev 2006).

The transformation of the FL is performed in small areas at $24 \mathrm{~h}$ of imbibition, correlating with structural and functional modifications of the epidermal cells. The isolation between the embryo and endosperm compartments is eliminated, enabling the diffusion of substances between the SE and epidermal cells from the scutellum. For this process, some alterations occur, in which the epidermal cells become elongated, and the basal pole is expanded, acquiring finger-like extensions and then some perforate the cell walls (Figure 3j). This is accompanied by the extrusion of components to the apoplast, which have the capacity to reduce XTT, indicating that the scutellum generates $\mathrm{O}_{2}^{-}$(Figure $5 \mathrm{~b}$ ) and release phenols (Figure 6) and likely other compounds (Table 1). In addition to $\mathrm{O}_{2}^{-}$ and phenols, PODa was detected in the apoplast (Figure 3), which uses phenols, such as guaiacol (García-Lara et al. 2007 ) and catechin, as substrates and can be inhibited by specific inhibitors (Figure 4; Liszkay et al. 2004). This in turn contributes to the modification of the FL (Figure 3j). After $36 \mathrm{~h}$ of imbibition, these cells are associated with the absorption of nutrients that originate in the endosperm, corresponding with the role of the functional epithelium as described by Szcziparev (2006).

PODa may possess dual functions because it acts as an antioxidant during stress conditions but can also act as a pro-oxidant under other conditions. In the apoplastic microenvironments of the scutellum, an oxidative burst occurred at $24 \mathrm{~h}$ of imbibition (Figure $5 \mathrm{~b}$ ). During this time, $\mathrm{O}_{2}^{-}$were generated via an oxidative cycle of the enzyme (Liszkay et al. 2003). It has often been suggested that in addition to $\mathrm{NAD}(\mathrm{P}) \mathrm{H}$ oxidases, peroxidases may also serve as sources for apoplastic $\mathrm{O}_{2}^{-}$production 
in vivo (Bolwell et al. 2002; Minibayeva et al. 2009). $\mathrm{NAD}(\mathrm{P}) \mathrm{H}$ oxidase or a portion of its activity can be attributed to the RBOH-type flavoenzyme, which is the plant equivalent of the gp $91^{\text {phox }}$ subunit of NADPH oxidase of mammalian phagocytes (Sagi and Fluhr 2006). Peroxidases exhibit $\mathrm{O}_{2}^{-}$-producing activities only if they are exogenously supplied with an electron donor, such as $\operatorname{NAD}(\mathrm{P}) \mathrm{H}$, at high concentrations (Chen and Schopfer 1999). However, all attempts to identify a genuine electron donor for the peroxidases in vivo were unsuccessful (Heyno et al. 2011). Subsequently, the activation of the hydroxylic cycle of PODa may lead to the consumption of the $\mathrm{O}_{2}^{-}$or $\mathrm{H}_{2} \mathrm{O}_{2}$ generating ${ }^{\circ} \mathrm{OH}$ (Liszkay et al. 2003), in which case apoplastic hydroxyl radical generation depends mainly upon peroxidases that are localized in the cell walls or even membranes (Heyno et al. 2011; Mika and Lüthje 2003). This radical may modify components of the cell wall. The interaction between the ROS that are generated by PODa and the components of the FL in maize would alter this structure, similarly to the previously proposed model of the root elongation by Schopfer (2001), that suggesting when the structure of the FL is modified, its resistance to diffusion is eliminated.

In support of the previous discussion, it has been reported that in vitro and at alkaline $\mathrm{pH}$ levels, some flavonoids, such as catechin, can initiate an autooxidative cycle that could produce $\mathrm{O}_{2}^{-}$and $\mathrm{H}_{2} \mathrm{O}_{2}$ (Mochizuki et al. 2002). Moreover, it has been reported that polyphenols, which normally act as antioxidants, can be converted to pro-oxidants by hydrolysis. The pro-oxidant activities of phenols depends of their chelating behaviors, metal reducing properties, and $\mathrm{O}_{2}^{-}$reducing capacities, which are related to the redox potentials of the oxidized species and the lifetimes of the phenoxyl radicals (Sakihama et al. 2002).

However, in a broader context, PODa might function as an antioxidant when the grain is exposed to stress conditions. During seed storage, a loss of vigor and germination abilities occurs. The degree of seed degeneration depends upon specific protection mechanisms, including the activities of antioxidant enzymes, such as superoxide dismutase, catalase, and peroxidase (BaleševićTubić et al. 2005, 2010; Chauhan et al. 2011; Goel and Sheoran, 2003). PODa acts as an antioxidant because it displays a peroxidative cycle, during which $\mathrm{H}_{2} \mathrm{O}_{2}$ is consumed by the oxidation of various substrates, such as phenols (Liszkay et al. 2003). It has been demonstrated that flavonoids and hydroxinamic acids are capable of scavenging $\mathrm{H}_{2} \mathrm{O}_{2}$ by acting as electron donors for guaiacol peroxidases (Sakihama et al. 2000). When phenols act as antioxidants, they are univalently oxidized to their respective fenoxil radicals, either by direct radical scavenging mechanisms or by an enzymatic pathway (Kagan and Tyurina 1998). Particularly, polyphenols, as opposed to monophenols, act as antioxidants (Sakihama et al. 2002). For this reason, the antioxidant/pro-oxidant capacities of phenols depend upon microenvironmental factors, such as $\mathrm{pH}$, solubility, chelating behaviors, and metal-reducing potentials (Decker 1997).

The decreased PODa levels that have been observed in various seeds is associated with losses of viability and germination capacities during storage (Balešević-Tubić et al. 2005, 2011; Bao et al. 2011; Chauhan et al. 2011; Goel and Sheoran 2003; Scialabba et al. 2002). In stored maize, increased temperatures in conditions of high humidity $\left(88 \% \mathrm{RH}\right.$ at $\left.25^{\circ} \mathrm{C}\right)$ lead to rapid deterioration after 3 months with decreased germination rates and abrupt decreases in scutellum PODa levels (Figure 7c). This deterioration is in accordance with previous reports of maize grains that were stored at $75 \% \mathrm{RH}$ and $35^{\circ} \mathrm{C}$ (Bernal-Lugo and Leopold 1992). In the first 6 months of storage at $88 \% \mathrm{RH}$ and $7^{\circ} \mathrm{C}, \mathrm{POD}$ and germination rates fluctuated over baseline values, with considerable losses of germination and PODa being observed after 12 months. The FL and scutellar epidermis from these SG exhibited autofluorescence with increased green compared with blue emissions (Figure $8 \mathrm{c}-\mathrm{f}, 8 \mathrm{i}$, and $8 \mathrm{j}$ ), which are qualitatively similar to those from the scutella of dry grains (Additional file 2), indicating that those embryos did not experience or complete their alterations of the components of the scutellum epidermis and the associated FL at $24 \mathrm{~h}$ of imbibition, revealing that the grains presented with low vigor to ungerminability at 22 months. Storage at high humidity levels ( $88 \% \mathrm{RH})$ provokes a cumulative oxidative stress that exceeds the acceptable window (Bailly et al. 2008), resulting in the deterioration and concomitant loss of vigor of the seed. This process is fast at high temperatures $\left(25^{\circ} \mathrm{C}\right)$ and slower at low temperatures $\left(7^{\circ} \mathrm{C}\right)$, leading to a lack of capacity for maintaining basal antioxidant levels, such as those of PODa in the scutellum, during germination. The relationship between the decreased PODa in the scutellum and loss of viability that was observed in the maize grain has also been observed in sunflower seeds and soybean (Balešević-Tubić et al. 2005, 2011).

The SG at $40 \% \mathrm{RH}$ and $7^{\circ} \mathrm{C}$ maintained a high germination capacity, while the PODa in the scutellum after $24 \mathrm{~h}$ of imbibition increased from 6 to 12 months of storage. These results imply that the embryos, starting at 6 months of storage, are subjected to stress levels that are likely lower than those that are found in the SG at $88 \% \mathrm{RH}$ and $7^{\circ} \mathrm{C}$, given that the deterioration is less severe and vigor is maintained at high-medium levels for a longer time period. Maintaining high-medium vigor is sufficient to induce increases in protective mechanisms during imbibition, thus keeping the ROS concentrations within an acceptable range. PODa protects the scutellum by counteracting the stress that is provoked during storage 
and germination, helping to maintain oxidant conditions within an acceptable window (Bailly et al. 2008), which enables the embryonic root to grow vigorously and establish the seedling. High vigor and germination in association with activity levels exceeding the baseline allows for the proportion of green emission to decrease in the scutellum after $24 \mathrm{~h}$ of imbibition, permitting the observation of blue fluorescence in the epidermis and $\mathrm{FL}$ or the disappearance of autofluorescence in some areas. (Figure 3, Figure $8 \mathrm{a}, 8 \mathrm{~b}$, $8 \mathrm{~g}, 8 \mathrm{~h})$. The differences in the proportions of blue and green fluorescence under the conditions that were studied indicate that there may be alterations in certain emission properties (for example, by effect of $\mathrm{pH}$ or ionic strength) or the proportions of components of integral elements of the FL and epidermis. These include phenols, such as cinnamic acids and catechin, which fluoresce blue, or anthocyanins, quercitrine, quercitin, and kaempferol, which fluoresce mainly green with a basal shoulder which emits in the blue region (Harborne 1973; Lang et al. 1991), correlating with alterations in microenvironmental conditions and changes in the anatomies of the scutellum and FL. These results imply that a low temperature and low relative humidity level enables the conservation of grain vigor and viability for longer time periods when compared with storage at higher temperatures and humidity levels, confirming the observations that were reported by Eskandari (2012). The maintenance of high vigor enables the increase in scutellum PODa levels as a protective mechanism against the stress that occurs during storage and germination.

\section{Conclusion}

These findings suggest that, based on its histochemical composition, the FL represents a physical barrier that prevents free flow between the scutellum and endosperm. The FL keeps the isolation and independence of the two compartments in the dry grain, this compartmentalization is beneficial to the embryo because it prevents resource diffusion to the endosperm. Therefore, the concentrations of metabolites are maintained at optimum levels. Nutritional requirements increase when the embryonic root begins to elongate. Accordingly, the epidermis of the scutellum is modified and peroxidase activity is heightened in the apoplast along with the emergence of higher levels of superoxide and maybe other radicals. These elements react with compounds of cell wall, enabling the transformation of the FL, thus allowing for free flow between the chambers. The PODa, due to its dual function, may participate in the process of FL modification in small areas or microenvironments by generating ROS, which is a process that must be tightly regulated. Outside of these microenvironments, the PODa of the scutellum acts broadly as an antioxidant enzyme for the fine control of ROS levels to avoid damage, counteracting the oxidative stress that occurs during storage and germination and conserving the integrity and functionality of the scutellum. This contributes to the high vigor of the embryo and its capacity to establish the seedling. Therefore, the PODa in the scutellum and proportion of $\mathrm{F}_{\text {green }}$ is $\mathrm{F}_{\text {blue }}$ emission after $24 \mathrm{~h}$ of imbibition may be used as indicators of the degree of deterioration of the SG.

\section{Materials and methods Biological materials}

The source of grains was creole maize cultivated in Valle de Chalco, Mexico. For the experiment, up to 12 replicas by assay with ten grains were used, as follow: 1) whole grains were used to determine the diffusion capacity through the FL; 2) whole grains were imbibed for $12 \mathrm{~h}$ for viability tests with tetrazolium. 3) embryos were manually dissected from the ripe grains to determine the FL compositions, and 4) embryos were dissected, superficially disinfected with $3 \% \mathrm{NaClO}$ for $5 \mathrm{~min}$, and washed 3 times with sterile distilled water. They were then incubated in moist germinators in the dark at $25^{\circ} \mathrm{C}$ for the following time periods: a) 18,24 , or $36 \mathrm{~h}$ time points were used to quantify PODa in the scutellum, the compounds that were extruded into the apoplast near the scutellum with the capacities to reduce 2,3-bis (2-methoxy-4-nitro-5-sulfophenyl)-2H-tetrazolium-5-carboxanilide inner salt (XTT), and the liberation of phenols using the Prussian Blue technique; b) 24 or $36 \mathrm{~h}$ time points were used for the in situ localization of PODa and its anatomical correlations; and c) a $24 \mathrm{~h}$ time point was used for grains at various stages that originated from controlled storage to determine the germination capacity and PODa content of the scutellum and to detect the autofluorescence of endogenous compounds that are associated with its anatomy.

\section{Histochemical detection of components of fibrous layer} Fixation, infiltration, and cutting

Embryos from dry grains were fixed in $4 \%$ paraformaldehyde ( $\mathrm{pH}$ 6.9), infiltrated in $300 \mathrm{mM}$ saccharose, and processed as described by Enríquez-Arredondo et al. (2005).

\section{Detection of lipids}

Histological sections were hydrated for $10 \mathrm{~min}$ and treated using 1 of 2 methods: a) for the detection of neutral lipids and esters, sections were immersed in $60 \%$ ethanol for $10 \mathrm{~min}$ and stained with a $0.5 \%$ Oil Red O solution in propanol:water $(6: 4, \mathrm{v:v})$ for $15 \mathrm{~min}$, and the excess stain was washed with distilled water (Krishnamurty 1988; Pearse 1968); and b) for the detection of lipid components, the sections were stained for 15 min with a $0.09 \%$ Sudan IV solution in glycerol:ethanol (1:1, v:v), and the excess stain was washed off with distilled water (Ruzin 1999). The preparations were mounted in an aqueous medium and 
observed with Nomarski differential interference contrast microscopy using an Axoskop Zeiss microscope.

\section{Detection of phenolic compounds}

For the in situ detection of phenols, histological sections were treated for $10 \mathrm{~min}$ with ethyl acetate and then incubated for the same length of time in $0.5 \%$ diphenylborinic acid that was dissolved in ethyl acetate (Reich et al. 2006). Excess reactivity was eliminated by absorption, and the detection of phenolic compounds was performed with an epifluorescence Axoskop Zeiss microscope, using an excitation wavelength of $365 \mathrm{~nm}$ and an emission filter for fluorescein.

\section{Detection of 1,3- $\beta$-glucan (callose)}

Aniline blue interacts with glucose residuals containing $\beta-1,3$ bonds to form fluorescent compounds and is used to detect polysaccharides, such as callose (Smith and McCully 1978). The sections were hydrated for $10 \mathrm{~min}$ and treated with $0.01 \%$ aniline blue that was dissolved in $0.1 \mathrm{M}$ phosphate buffer ( $\mathrm{pH}$ 9) for $15 \mathrm{~min}$. Excess stain was eliminated by absorption. A $365 \mathrm{~nm}$ wavelength was used for the excitation of the aniline- $\beta-1,3$ polysaccharide complex, and its emissions were observed in the blue region (Ruzin 1999) using an epifluorescence Axoskop Zeiss microscope.

\section{In situ localization of peroxidase activity}

For the determination of the in situ localization of PODa in the scutellum, embryos that had been imbibed for 24 or $36 \mathrm{~h}$ were incubated for $30 \mathrm{~min}$ at $25^{\circ} \mathrm{C}$ in $50 \mathrm{mM}$ sodium acetate buffer $(\mathrm{pH} 4.5)$ with $0.22 \% \mathrm{H}_{2} \mathrm{O}_{2}$ and $0.05 \%$ 3-amino-9-ethylcarbazole (AEC) that was dissolved in N,N-dimethylformamide (Graham et al. 1965), followed by fixation, infiltration, and cutting as previously described. Embryos that had been incubated in the same solution without $\mathrm{H}_{2} \mathrm{O}_{2}$ were used as controls. The histological sections were observed with Nomarski differential interference contrast microscopy using an Axoskop Zeiss microscope.

\section{Diffusion and permeability assays}

Grain perforation and capacity for dye diffusion through fibrous layer

Dry grains were perforated either on the embryo or endosperm side 3 times using a dissecting needle. To evaluate the diffusion between the two compartments, an $\mathrm{I}_{2}-\mathrm{KI}$ aqueous solution, which was prepared according to (Landry and Smyth 1988), was used to stain the starch in the endosperm and scutellum, and a $0.5 \%$ Brilliant Green solution (Merck 1310) that was dissolved in 95\% ethanol was used to stain the cytoplasm and cell walls green. The perforated grains were incubated at $4^{\circ} \mathrm{C}$ for $24 \mathrm{~h}$ in the aqueous solution or $48 \mathrm{~h}$ in the ethanol solution. The excess stain was removed by washing exhaustively with distilled water to prevent the contamination of the cutting knife when the grains were cut longitudinally, and stained areas were observed to establish the diffusion between the two compartments. Stain diffusion in unperforated or perforated grains from the embryo to the endosperm were also evaluated.

\section{Extraction of components from fibrous layer and effects on} permeability

Grains that had been perforated through the embryo or endosperm were incubated for 4 days in acetone, chloroform, or acetone:chloroform (1:1, v:v) at room temperature. After 11 days of solvent evaporation, the diffusion was established as previously described.

\section{Quantification of peroxidase activity in scutellum}

In embryos that had been imbibed for 18,24 , or $36 \mathrm{~h}$, the scutella were dissected from the embryonic axes on an ice bed and weighed. The embryonic axes were discarded to eliminate the high PODa levels that were present in the areas of embryonic root growth (Liszkay et al. 2004). The scutella were homogenized in $3 \mathrm{ml}$ of $100 \mathrm{mM}$ phosphate buffer ( $\mathrm{pH} 6.8$ ) and centrifuged at $10,000 \mathrm{xg}$ for $30 \mathrm{~min}$ at $4^{\circ} \mathrm{C}$. The supernatants, which were used as raw extracts, were maintained at $4^{\circ} \mathrm{C}$ until analyzed (García-Lara et al. 2007). The protein concentrations were determined using the method described by Lowry et al. (1951) with bovine serum albumin as the standard. PODa was determined using the following 2 methods: a) to begin the reaction, $4 \mu \mathrm{l}$ of $3 \% \mathrm{H}_{2} \mathrm{O}_{2}$ were added to the reaction mix, consisting of $440 \mu \mathrm{l}$ of $50 \mathrm{mM}$ phosphate buffer ( $\mathrm{pH} 6.8$ ), $20 \mu \mathrm{l}$ of enzyme extract, and $440 \mu \mathrm{l}$ of $20 \mathrm{mM}(+)$-catechin, and the absorbance at $475 \mathrm{~nm}$ wavelength was recorded every minute for $5 \mathrm{~min}$; and b) $870 \mu \mathrm{l}$ of $50 \mathrm{mM}$ phosphate buffer (pH 6.8), $10 \mu \mathrm{l}$ of enzyme extract, $10 \mu \mathrm{l}$ of $1 \mathrm{M}$ guaiacol, and $9 \mu \mathrm{l}$ of $3 \% \mathrm{H}_{2} \mathrm{O}_{2}$ were added to begin the reaction, and the absorbance at $475 \mathrm{~nm}$ was recorded every $20 \mathrm{~s}$ for $2 \mathrm{~min}$. PODa inhibitors, which included either $10 \mu \mathrm{l}$ of $0.3 \mathrm{M}$ salicylhydroxamic acid (SHAM) or $10 \mu \mathrm{l}$ of $0.1 \mathrm{M} \mathrm{KCN}$ (Liszkay et al. 2004), were added to the solutions that are described above, and the quantification of activity levels was performed as described. For the spectrophotometric assessments, a Perkin Elmer UV/VIS Spectrometer Lambda 2 was used.

\section{Reducing capacity of contents extruded from scutellum Quantification of extruded reducing power: XTT reduction by $\mathrm{O}_{2}^{-}$equivalents}

The reducing capacities for XTT were determined in embryos that had been imbibed for 18,24 , or $36 \mathrm{~h}$. Briefly, embryos with different imbibition times were placed into a Costar 6-well culture plate with the sides of the scutella that were exposed to the SE facing the bottoms of the wells. The embryos were incubated in 
$1 \mathrm{ml}$ of a $500 \mu \mathrm{M}$ XTT solution (Liszkay et al. 2004) in a $10 \mathrm{mM}$ potassium citrate buffer ( $\mathrm{pH} 7.4$; Sagi and Fluhr 2001) for $1 \mathrm{~h}$ in the dark. The absorbances at $470 \mathrm{~nm}$ were then quantified. The blank consisted of $1 \mathrm{ml}$ of the same solution that had not been in contact with the embryos.

To determine the effects of NADPH, NADH, and $\mathrm{CuCl}_{2}$, embryos were treated as described above and placed into one of the following solutions: $200 \mu \mathrm{M}$ $\mathrm{NADH}, 200 \mu \mathrm{M}$ NADPH, $50 \mu \mathrm{M} \mathrm{CuCl}_{2}, 200 \mu \mathrm{M} \mathrm{NADH}$ with $50 \mu \mathrm{M} \mathrm{CuCl}_{2}$ or $200 \mu \mathrm{M}$ NADPH with $50 \mu \mathrm{M}$ $\mathrm{CuCl}_{2}$ in $10 \mathrm{mM}$ potassium citrate buffer ( $\mathrm{pH} \mathrm{7.4)}$ with $500 \mu \mathrm{M}$ XTT (Liszkay et al. 2004). The absorbances of the solutions at $470 \mathrm{~nm}$ were then quantified. The blank consisted of $1 \mathrm{ml}$ of the same solution that had not been in contact with the embryos.

\section{Solutes with capacities to reduce XTT}

To determine the contributions of other compounds towards the reduction of XTT, the following substances were added to $1 \mathrm{ml}$ of $10 \mathrm{mM}$ potassium citrate buffer ( $\mathrm{pH} 7.4)$ containing $500 \mu \mathrm{M}$ XTT: $200 \mu \mathrm{M} \mathrm{NADH}$, or $200 \mu \mathrm{M}$ $\mathrm{NADPH}$, or $50 \mathrm{mM}$ ascorbic acid, or $5 \mathrm{mM}$ catechin, or $50 \mu \mathrm{M} \mathrm{CuCl}_{2}$ or $7.8 \mathrm{mM}$ gallic acid. The mixtures were incubated at $25^{\circ} \mathrm{C}$ in the dark, and the absorbances at $470 \mathrm{~nm}$ were measured at 5 and $60 \mathrm{~min}$ after the reaction began, using the corresponding reduction factor. The equivalent reduction factors were determined by subtracting the final absorbances from the initial absorbances and using the coefficient of molar extinction of XTT $\left(\varepsilon_{\mathrm{XTT}}=2.16 \times 10^{4} \mathrm{M}^{-1} \mathrm{~s}^{-1}\right)$ as reported by Sutherland and Learmonth (1997).

\section{Phenol release measured by ferricyanide reduction}

Embryos were obtained after 18,24 , or $36 \mathrm{~h}$ of imbibition. They were deposited into a Costar 6-well culture plate and incubated in $1 \mathrm{ml}$ of distilled water for $10 \mathrm{~min}$, and thus prevented the radicle from coming into contact with the water. Aliquots of $100 \mu \mathrm{l}$ were retrieved and mixed with $60 \mu \mathrm{l}$ of $0.1 \mathrm{M} \mathrm{FeCl}_{3}$ in $0.1 \mathrm{~N} \mathrm{HCl}$. After shaking, $60 \mu \mathrm{l}$ of $0.008 \mathrm{M} \mathrm{K}_{3} \mathrm{Fe}(\mathrm{CN})_{6}$ in $0.1 \mathrm{~N} \mathrm{HCl}$ were added, bringing the volume to $1.12 \mathrm{ml}$ in water. The mix was incubated at room temperature for $10 \mathrm{~min}$, absorbances at $720 \mathrm{~nm}$ were recorded, and the data were interpolated into a gallic acid standard curve (Price and Butler 1977).

\section{Effects of storage on peroxidase activity, vigor and emission of endogenous compounds Conditions of controlled storage and quantification of peroxidase activity}

Maize grains were stored (SG) in an airtight container under the following controlled conditions: a) $40 \%$ relative humidity $(\mathrm{RH})$ at $7^{\circ} \mathrm{C}$ in a refrigerator with a system for humidity control; b) $7^{\circ} \mathrm{C}$ in a chamber with a $\mathrm{RH}$ of $88 \%$, which was generated using a solution of $10 \%$ sodium benzoate (Rockland 1960); and c) $25^{\circ} \mathrm{C}$ in a chamber with a $\mathrm{RH}$ of $88 \%$, which was similar to that described in b. Every 30 days, a sample of grains from each treatment was collected and manually dissected to separate the embryos. The embryos were then disinfected and imbibed. Percent germination was recorded, and a raw enzymatic extract was obtained from the scutella to quantify PODa.

\section{Autofluorescence of endogenous compounds}

Samples from grains that had been stored in controlled conditions were collected at 1 and 9 months. The embryos were dissected after $24 \mathrm{~h}$ of imbibition, fixed in $70 \%$ ethanol at room temperature, dehydrated, and infiltrated in paraplast. Sections that were $8 \mu \mathrm{m}$ thick were mounted onto microscope slides using a gelatin cover. Paraplast was removed, and the sections were hydrated and incubated with propidium iodide to detect the nuclei (Ruzin 1999). They were mounted in aqueous media, and their anatomies were assessed using a Confocal Spectral Carl Zeiss Microscopy System Model LSM 780 NLO. Independent tracks were used, including two for autofluorescence and a third to locate the nuclei with the following parameters: a) excitation: $405 \mathrm{~nm}$, emission: 410 to $516 \mathrm{~nm}$; b) excitation: $488 \mathrm{~nm}$, emission: 490 to $560 \mathrm{~nm}$; and c) excitation: $561 \mathrm{~nm}$, emission: 566 to $685 \mathrm{~nm}$.

\section{Vigor assays}

To determine the vigor of the SG under controlled conditions, they were collected after 20 to 22 months and imbibed for $12 \mathrm{~h}$. The vigor was determined using the technique that was described by DeVries and Goggi (2006) with slight modifications. The imbibed grains were longitudinally dissected, and one of each of the halves was soaked in water for $10 \mathrm{~min}$. Then, the water was replaced with a $0.1 \%$ thiazolyl blue tetrazolium bromide solution (MTT) to stain the grains for $70 \mathrm{~min}$ at room temperature. After staining, the MTT solution was drained, and the grains were well rinsed with water. Finally, the stained grains were scanned.

\section{Statistical analyses}

Quantitative results were expressed as the mean and standard deviation from 3 to 12 independent assays. A one-way ANOVA was performed followed by a TukeyKramer Multiple-Comparison Test with a significance level of $\mathrm{p}<0.05$. Analyses were performed with the NCSS and PASS 2000 software.

\section{Additional files}

Additional file 1: In situ localization of PODa in the scutellum. Embryos that had been imbibed for $24 \mathrm{~h}$ were incubated for $30 \mathrm{~min}$ at $25^{\circ} \mathrm{C}$ in a $50 \mathrm{mM}$ sodium acetate buffer $(\mathrm{pH} 4.5)$ with $0.22 \% \mathrm{H}_{2} \mathrm{O}_{2}$ and $0.05 \%$ 3-amino9. 
ethylcarbazole (AEO) dissolved in NN-dimethylformamide (Graham et al. 1965). Enzymes that were extruded during imbibition of the embryo were detected by reacting the germinator with $0.22 \% \mathrm{H}_{2} \mathrm{O}_{2}$ and $0.05 \%$ 3-amino9 -ethylcarbazole (AEC) that was dissolved in N,N-dimethylformamide in $50 \mathrm{mM}$ sodium acetate buffer $(\mathrm{pH} 45)$ for $30 \mathrm{~min}$ at $25^{\circ} \mathrm{C}$ or incubated in a solution with $0.22 \%$ of $\mathrm{H}_{2} \mathrm{O}_{2}$ and $10 \mathrm{mM}$ of gualacol in $50 \mathrm{mM}$ phosphate buffer $(\mathrm{pH} 6.8)$ for 15 minutes at $25^{\circ} \mathrm{C}$. Both of these reactions were carried out in the dark. For the histochemical sections, the embryos were incubated with $\mathrm{AEC}$ and $\mathrm{H}_{2} \mathrm{O}_{2}$, followed by fixation, infiltration, and cutting, and were observed with Nomarsk differential interference contrast microscopy using an Axoskop Zeiss microscope. Pesults. There are high PODa levels at the scutellum surface that is in contact with the SE in addition to the embryonic root region (Additional file 1a). During imbibition, PODa is extruded from the embryo (Additional file 1 b), confirming its activity in the apoplast via histological sectioning. A recapitulation of epidermal cell morphology after 24 hours of imbibition and papillate cell after $36 \mathrm{~h}$ of imbibition are shown in the Additional file 1c. Peroxidase activity at scutellar surface and extrusion to germinator. a, in situ PODa in embryo; b, PODa extruded from embryo to germinator after $24 \mathrm{~h}$ of imbibition; c, recapitulation of epidermal cell

morphology after $24 \mathrm{~h}$ of imbibition and papillate cell after $36 \mathrm{~h}$ of imbibition.

Additional file 2: Emission spectrum of the scutellum at $\mathbf{O h}$ of imbibition. Embryos of dry grains were fixed in $70 \%$ ethanol at room temperature for one day, and then dehydrated, infiltrated, and embedded in paraplast. Sections of 8 - $\mu \mathrm{m}$ thickness were obtained and mounted on a microscope slide cover with a gelatin film. The support media were extracted from specimens and mounted in an aqueous medium at $\mathrm{pH} 7.0$, and the emissions of the visible spectrum were recorded following excitation at $405,458,488,514,561$, or $633 \mathrm{~nm}$ with a laser from the Carl Zeiss Spectral Confocal Microscopy System Model LSM 780 NLO. Pesult. The emission spectrum of the scutellum at $0 \mathrm{~h}$ of imbibition showed 3 emission peaks: blue at $460 \mathrm{~nm}$; green at $512 \mathrm{~nm}$; and red between $626-635 \mathrm{~nm}$. Slight emissions at 617 and $643 \mathrm{~nm}$ were also observed. Each box contains the emission wavelength and color corresponding to the visible spectrum. Bar: $20 \mu \mathrm{m}$.

\section{Abbreviations}

(AEC): Aminoethylcarbazole; (PODa): Peroxidase activity; (SE): Central starchy endosperm; (ROS): Reactive oxygen species; (FL): Fibrous layer; (RH): Pelative humidity; (MTT): Thiazolyl blue tetrazolium bromide; (SG): Stored grain; (SHAM): Salicylhydroxamic acid; (XTT): 2,3-bis(2-methoxy-4 nitro-5sulfophenyl)-2H-tetrazolium-5-carboxanilide inner salt.

\section{Competing interests}

The authors declare that they have no competing interests.

\section{Authors' contributions}

IICC, MFP and GCN carried out the experiments and participated in data analysis. JICC and DMDP drafted the manuscript, designed and coordinated the study, evaluated the data, and wrote the final version of the manuscript. All authors read and approved the final version of the manuscript.

\section{Acknowledgments}

We thank Drs. Rocio Crz-Ortega and Marina Gavilanes-Ruiz for their contributions and observations. We thank the Laboratory of Confocal Microscopy of Universidad Autónoma Metropolitana I ¿tapalapa for providing facilities. lsaac Corona thanks Conacyt for scholarship 55063, which was awarded to complete PhD. studies in Experimental Biology.

\section{Author details}

'Department of Health Sciences, Division of Biological and Health Sciences, Laboratory for Tissue Biochemistry, Universidad Autónoma Metropolitana-Lztapalapa, Mexico City, Mexico. ${ }^{2}$ Posgrado en Biología Experimental, Division of Biological and Health Sciences, Universidad Autónoma Metropolitana-lztapalapa, Mexico City, Mexico.

Received: 11 July 2014 Accepted: 29 July 2014 Published: 2 August 2014

\section{References}

Amritphale D, Ramakishna P, Singh B, Sharma SK (2010) Solute permeation xcross the apoplastic barrier in the perisperm-endosperm envelope in acumber seeds. Planta dol:10.1007/s00425-010-1146-5

Apel K, Hirt H (2004) Reactive oxygen species: Metabolism, oxidative stress, and signal transduction. Annu Rev Plant Biol do:10.1146/annurev. arplant 55.031903 .141701

Bailly C, E-Maarouf-Bouteau $\mathrm{H}$, Corbineau F (2008) From intracellular signaling networks to cell death: the dual role of reactive oxygen species in seed physiology. C R Biol dot:10.1016/.orvi 2008.07.022

Baleševic-Tubic S, Malenđ̈ $\oplus$, Tatic M, Miladinovic J (2005) Influence of aging process on biochemical changes in sunflower seed. Helia 28(42):107-1 14, doi:10.2298/hel0542107b

Baleševic-Tubic' S, Tatic M, Đorđevic V, Nikolic Z, Đukic V (2010) Seed viability of oll crops depending on storage conditions. Helia 33(52):153-159, dol:10.2298/HEL 1052153B

Baleševic-Tubic S, Tatic M, Dorđevic V, Nikolic Z, Subic 1 , Dukic V (2011) Changes in soybean seeds as affected by accelerated and natural aging. Rom Biotechnol Lett 16(6):6740-6747

Bao J, Sha S, Zhang S (2011) Changes in germinability, lipid peroxidation, and antioxidant enzyme activities in pear stodk (Pyrus betulaefollaBge) seeds during room- and low-temperature storage. Acta Physiol Plant 33(5)2035-2040

Bechtel DB, Pomeranz Y (1977) Ultrastructure of the mature ungerminated Rice (Oryza sativa) caryopsis. The caryopsis coat and the aleurone cells. Am J Bot 64:966-973

Berger F (1999) Endosperm development. Curr Opin Plant Biol 2:28-32

Bergvinson D, Garda-Lara S (2004) Genetic approaches to reducing losses of stored grain to insects and diseases. Curr Opin Plant Biol 7(4):480-485

Bernal-Lugo l, Leopold AC (1992) Changes in soluble carbohydrates during seed storage. Plant Physiol dot:10.1104/pp. 98.3.1207

Bernards MA, Lewis NG (1998) The macromolecular aromatic domain in suberized tissue: A changing paradigm. Phytochemistry do: 10.1016/50031. 9422(98)80052-6

Bewley JD, Black M (1994) Seeds: Physiology of development and germination Plenum Press, NewYork

Bolwell GP, Bindschedler LV, Blee KA, Butt VS, Davies DR, Gardner SL, Gerrish C, Minibayeva F (2002) The apoplastic oxidative burst in response to biotic stress in plants: a three-component system. J Exp Bot dot:10.1093/Jexbot/ 53.372 .1367

Bourdu R, Bousser A (1991) Structures et infrastructures du mais au cours de la germination. In: Picard D (ed) Physiologie et Production du Mais. INRA, Paris

Chamberlin MA. Homer HT, Palmer PG (1993) Nutrition of ovule, embryo sac, and young embryo in soybean: an anatomical and autoradiographic study. Can J Bot do: 10.1 139/b93-136

Chauhan DS, Deswal DP, Dahilya OS Punia RC (2011) Change in storage enzymes xtivities in natural and accelerated aged seed of wheat (Triticum aestivum). Indian J Agr Sci 81(11):1037-1040

Chen S, Schopfer P (1999) Hydroxyl-radical production in physiological reactions. Eur J Biochem dot:10.1046//.1432-1327.1999.00199x

Consonni G, Gavazzi G, Dolfini S (2005) Genetic analysis as a tool to investigate the molecular mechanisms underlying seed development in maize. Ann Bot doi:10.1093/aob/mci187

Daniel 10 (2007) Longevity of malze (Zea mays L) seeds during low input storage under ambient conditions of southwestern Nigeria.J Trop Agric 45 $(1-2): 42-48$

Decker A (1997) Phenolics: Procxidants or Antioxidants? Nutr Rev dot:10.1111/ j.1753-4887.1997.tb01580x

DeVires M, Goggi AS (2006) Determining the extent of frost damage in make seed using the tetrazolium test Crop Manage do:10.1094/CM-2006-0414-01-RS

Dolfini S, Consonni G, Viotti C, Prà MD, Saltini G, Giulini A, Pilu R, Mal gioglio A, Gavazz G (2007) A mutational approach to the study of seed development in maize.J Exp Bot do: $10.1093 / \mathrm{jbb} / \mathrm{er} 290$

Enriquez-Arredondo C Sánchez-Nieto S, Rendón-Huerta E, González-Halphen D, Gavilanes Ruiz M, Dlaz-Pontones D (2005) The plasma membrane H + -ATPase of maize embryos local lzes in regions that are critical during the onset of gemination. Plant So 169:11-19

Eschrich W (1975) Sealing systems in phloem. In: Zimmermann MH, Milburn JA (eds) Encyclopedia of Plant Physiology. Springer-Verlag, Berlin, pp 39-56

Eskandari $H$ (2012) Seed quality variation of crop plants during seed development and maturation. Int J Agron Plant Prod 3(11):557-560 
Frahry G, Schopfer P (2001) NADH-stimulated, cyanide-resistant superoxide production in maize coleoptiles analyzed with a tetrazolium-based assay. Planta 21 2(2):175-183, doi:10.1007/s004250000376

Fry SC (2004) Oxidative coupling of tyrosine and ferulic add residues: Intra- and extra-protoplasmic ocourrence, predominance of trimers and larger products, and possible role in inter-polymeric cross-linking. Phytochem Rev dol:10.1023/BPHYT.0000047808.74647.43

Fry SC, Willis SC, Paterson AEJ (200) Intraprotoplasmic and wall-localised formation of arabinoxylan-bound diferulates and larger ferulate coupling-products in maize cell-suspension cultures. Planta dol:10.1007/s004250000330

Garcla-Lara S, Arnason JT, Dlaz-Pontones D, Gorzalez E, Bergvinson DJ (2007) Soluble peroxidase activity in make endosperm assoclated with maize veevil resistance. Crop Sci dol:10.2135/cropso 2006.10.0687

Goel A, Sheoran 15 (2003) Lipid peroxidation and peroxide-scavenging enzymes in cotton seeds under natural ageing. Biol Plant dot:10.1023/A:1 QQ 4398724076

Graham RCI, Lundholm U, Karnousky MU (1965) Cytochemical demonstration of peroxidase activity with 3-amina.gethyicarbazole.J Histochem Cytochem dot:10.1177/132.150

Harborne JB (1973) Phenolic Compounds. In: Phytochemical Methods. A guide to modern techniques of plant analysis. Chapman and Hall, London, pp 33-80

Heyno E, Mary V, Schopfer P, Krieger-Liszkay A (2011) Oxygen activation at the plasma membrane: relation between superoxide and hydroxyl radical production by isolated membranes. Planta dot:10.1007/s00425-01 1-1379-y

Hiraga S, Sasaki K, Ito H, Ohashi Y, Matsui H (2001) A large family of dass III plant peroxidases Plant Cell Physiol 42(5):462-468

Hollmann F, Arends IWCE (2012) Enzyme initiated radical polymerizations Polymers 4:759-793

Kagan VE, Tyurina YY (1998) Recycling and redox cycling of phenolic antioxidants, Ann N Y Acad Sci do: 10.1111/.1.1749-6632.1998.tb09921x

Kiessel bach TA, Walker ER (1952) Structure of Certain Specialized Tissue in the Kernel of Corn. Am J Bot 39(8):561-569

Kolattukudy PE (1981) Structure, biosynthesis, and biodegradation of cutin and suberin. Annu Rev Plant Physiol dot:10.1 146/annurevpp. 32060181.00254

Krishnamurty KV (1988) Methods in plant histochemistry. S. Viswenathan, Chennai

Lagrimini LM (1991) Wound-Induced deposition of polyphends in transgenic plants overexpressing peroxidase. Plant Physiol dot:10.1104/pp. 96.2577

Landry LG, Smyth DA (1988) Characterization of starch produced by suspension cell cultures of Indica rice (Oryza sativa L). Plant Cell Tissue Organ Cult dol: $10.1007 / B F 00039886$

Lang M, Stober F, Lichtenthaler HK (1991) Fuorescence emission spectra of plant leaves and plant constituents. Radiat Environ Biophys dot:10.1007/BF01210517

Liszkay A, Kenk B, Schoofer P (2003) Evidence for the involvement of cell wal peroxidase in the generation of hydroxyl radicals mediating extension growth. Planta dot:10.1007/s00425-003-1028-1

Liszkay A, van der Zalm E, Schopfer P (2004) Production of reactive oxygen ntermediates $\left(\mathrm{O}_{2}\right.$-, $\mathrm{H}_{2} \mathrm{O} 2$, and $\left.\mathrm{OH}\right)$ by maize roots and their role in wall loosening and elongation growth. Plant Physid dot:10.1104/pp. 104.044784

Lowry OH, Rosebrough NJ, Farr AL, Randall RJ (1951) Protein measurement with the folin phenol reagent. J Bid Chem 193:265-275

MacGregor AW, Dushnicky L (1989) Starch degradation in endosperms of developing barley kernels. J Inst Brew do: 10.1002/.2050-0416.1 989.tb04638x

MacGregor AW, Matsuo RR (1982) Starch degradation in endosperms of barley and wheat Kernels during initial stages of gemination. Cereal Chem 59-210-216

Mila A. Lūthje S (2003) Properties of Gualacol Peroxidase Activities isolated from Corn Root Plasma Membranes. Plant Physiol dol:10.1104/pp. 103.020396

Minibayeva F, Kolesnikov O, Chasov A, Beckett RP, Lüthje S, Wylegzhanina N, Buck E, Böttger M (2009) Wound-induced apoplastic peroxidase activities: their roles in the production and detoxification of reactive oxygen species. Plant Cell Environ dol:1 0.1111//.1365-3040.2009.01944x

Mochizuk M, Yamazaki S Kano K, lkeda T (2002) Kinetic analysis and mechanistic aspects of autoxidation of catechins Biochim Biophys Acta dot:10.1016/50B04 4165(01)00230-6

Maller IM, Jensen PE, Hansson A (2007) Oxidative modifications to cellular components in plants Annu Rev Plant Biol do: 10.1146/annurevarplant58032806.103946

Okamoto K, Mural T, Eguchi G Okamoto M, Akazawe T (1982) Enzymic mechanism of starch breakdown in germinating rice seeds II. Ultrastructural changes in soutellar epithelium. Plant Physiol do: 10.1104/pp. 703.905

Parre E, Geitmann A (2005) More than a leak sealant. The mechanical properties of callose in pollen tubes. Plant Physiol dot:10.1104/po. 104.050773

Passardi F, Cosio C, Penel C, Dunand C (2005) Peroxidases have more functions than a Swiss army knife. Plant Cell Rep 24(5):255-265
Pearse AGE (1968) Histochemistry, Theroretical and applied, Churchill, London Pourcel L, Routaboul IJ, CheynierV, Lepinic L, Debeaujon I (2007) Favonoid oxidation in plants from biochemical properties to physiological functions. Trends Plant So do:10.1016/Jtplants 2006.11.006

Price ML, Butler LG (1977) Rapid visual estimation and spectrophotomatric determination of tannin content of sorghum grain.J Agric Food Chem dot:10.1021//\$502143034

Ramakishna P, Amritphale D (2005) The perispermendosperm envelope in Cuamis; structure, proton diffusion and cell wall hydrolysing activity Ann Bot 96(5):769-778

Reich E, Schibli A, Widmer V, Jorns R. Wolfram E, DeBatt A (2006) HPTLC methods for identification of green tea and green tea extract. J Liq Chromatogr Relat Technol 29(14):2141-2151

Rockland LB (1960) Saturated salt solutions for static control of relative humidity between $5^{\circ}$ and $40^{\circ} \mathrm{C}$. Anal Chem 32(10):1375-1376

Ruzin ES (1999) Plant microtechnique and microscopy. Oxford University Press, USA

Sabelli PA, Larkins BA (2009) The development of endosperm in grasses. Plant Physiol do: 10.1104/pp. 108.129437

Sagi M, Fluhr R (2001) Superoxide production by plant homologues of the gp91 phox NADPH Oxidase. Modulation of activity by caldum and by tobacco mosaic virus infection. Plant Physiol dot:10.1 104/pp. 126.3.1281

Sagi M. Fluhr R (2006) Production of reactive oxygen species by plant NADPH Oxidases. Plant Physiol dot:10.1104/pp. 106.078089

Sakihama Y, Mano J, Sano S, Asada K, Yamasaki H (2000) Reduction of phenoxyl radicals mediated by Monodehydroascorbate Reductase. Biochem Biophys Pes Commun dol:10.1006/bbrc 2000.4053

Sakihama Y, Cohen MF, Grace SC, Yamasaki H (2002) Plant phenolic anticxidant and prooxidant activities: phenolics-induced oxidative damage mediated by metals in plants. Toxicology do: $10.1016 / 50300-483 \times(02) 001968$

Saulnier L, Thibault J (1999) Ferulic acid and diferulic adds as components of sugar-beet pectins and maize bran heteroxylans. J Sci Food Agric doi:1 0.1002/(SIC) 1 1097-0010(19990301)79:3<396-AID-ISFA.262>3.0.CO;2-B

scanlon M, Takocs BM (2009) Kernel Biology, Handbook of Maze: Its Biology. In: Hake SC (ed) Benndzen JLSpringer, New York, pp 121-143

Schopfer P (2001) Hydroxyl radical-induced cell-wall loosening in vitro and in vivo: implications for the control of elongation growth. Plant $J$ doi:10.1046/.1365-313x.2001.01187x

Sclalabba A, Bellani LM, Dell'Aquila A (2002) Effects of ageing on peroxidase activity and localization in adish (Raphanus sativus $L$ ) seeds Eur J Histochem 46(4):351-358

Sen A, Bergvinson D, Miller SS, Atkinson J, Fulcher GR, Arnason JT (1994) Distribution and microchemical detection of phenolic adds flavonoids, and phenolic acid amides in maize kernels. J Agric Food Chem 42(9):1879-1883

Smith MM, McCully ME (1978) A critical evaluation of the spedfidty of aniline blue induced fluorescence. Protoplasma dol:10.1007/BF01294453

Sutherland MW, Learmonth BA (1997) The tetrazolium dyes MTS and XTT provide new quantitative assays for superoxide and superoxide dismutase. Free Radic Res 27 B) $283-289$

Swift JG, Obrien TP (1972) The fine structure of the wheat scutellum durng germination. Aust J Biol So 25(3):469-486, dot:10.1071/B19720469

Szcziparev SM (2006) Scutellum and its role in germination. In: Batygina TB (ed) Embriology of flowering plants. Terminology and concepts, Vol 2 Seed Science Publishers USA, pp 443-446

Tan S, Morrison W (1979) Lipids in the germ, endosperm and pericarp of the developing maize kernel. J Am Oil Chem Soc dol:10.1007/BF0266305.

Tiwari SC (1982) Callose in the walls of mature embryo sac of Torenia fournieri Protoplasma dot:10.1007/BF01314674

Tnani H, López l, Vicient CM (2011) Control of the scutellar epithellal cell elongation during germination in maze (Zea mays L). Seed Sci Technol 39:253-258

Winkd-Shrley B (2002) Biosynthesis of flavonoids and effects of stress Curr Opin Plant Biol dox:10.1016/51369-5266(02)00256-X

Yim KO, Bradford KJ (1998) Callose deposition is responsible for apoplastic semipermeability of the endosperm envelope of muskmebon seeds 1. Plant Physibl 118(1)83-90

\section{doi: 10.1186/2193-1801-3-399}

Gite this article as: Corona-Carrillo ef al:- Peroxidase activity in scutella of maize in association with anatomical changes during germination and grain storage. SpringerPlus 2014 3:399. 